\title{
Supramolecular Biofunctional Materials
}

\author{
Jie Zhou, Jie Li, Xuewen Du, and Bing $\mathrm{Xu}^{*}$
}

\begin{abstract}
:
This review discusses supramolecular biofunctional materials, a novel class of biomaterials formed by small molecules that are held together via noncovalent interactions. The complexity of biology and relevant biomedical problems not only inspire, but also demand effective molecular design for functional materials. Supramolecular biofunctional materials offer (almost) unlimited possibilities and opportunities to address challenging biomedical problems. Rational molecular design of supramolecular biofunctional materials exploit powerful and versatile noncovalent interactions, which offer many advantages, such as responsiveness, reversibility, tunability, biomimicry, modularity, predictability, and, most importantly, adaptiveness. In this review, besides elaborating on the merits of supramolecular biofunctional materials (mainly in the form of hydrogels and/or nanoscale assemblies) resulting from noncovalent interactions, we also discuss the advantages of small peptides as a prevalent molecular platform to generate a wide range of supramolecular biofunctional materials for the applications in drug delivery, tissue engineering, immunology, cancer therapy, fluorescent imaging, and stem cell regulation. This review aims to provide a brief synopsis of recent achievements at the intersection of supramolecular chemistry and biomedical science in hope of contributing to the multidisciplinary research on supramolecular biofunctional materials for a wide range of applications. We envision that supramolecular biofunctional materials will contribute to the development of new therapies that will ultimately lead to a paradigm shift for developing next generation biomaterials for medicine.
\end{abstract}

Keywords: supramolecular, hydrogels, noncovalent interaction, biofunctional, materials, applications 


\section{Introduction}

In this review, supramolecular biofunctional materials refer to the biomaterials that are held together mainly by noncovalent intermolecular interactions among small molecules. Being formed via molecular self-assembly (usually in water) and possessing ordered superstructures, supramolecular biofunctional materials have found increased numbers of biomedical applications.[1] Moreover, when molecular selfassembly integrates with cellular events (e.g., enzymatic reactions, ligand-receptor binding, or electron transfer), it provides a bioinspired, yet fundamentally new path to generate molecular processes in cell milieu for simultaneously interacting with multiple protein targets,[2] cells, and even organs. Because of their potentials, over the last two decades, supramolecular biofunctional materials and related molecular processes have received intensive research attentions. For example, Stupp et al. used the $\mathrm{pH}$-controlled self-assembly of peptide amphiphiles (PAs) to develop a group of supramolecular fibrous scaffolds with promising biological applications, like directing formation of hydroxyapatite in vitro to mimic biomineralization[3] or inducing rapid differentiation of progenitor cells into neurons while discouraging the development of astrocytes in cell assays.[4] Using supramolecular hydrogels as a platform for incorporating different artificial receptors, Hamachi and coworkers developed a class of semi-wet sensor chips, which recognized a variety of chemicals such as cations, saccharides, anionic fluorescent dyes, phosphate derivatives, polyamines, and polyols.[5-10] They also reported a smart multicomponent system consisting of self-sorted supramolecular nanofibers.[11] Van Esch et al. demonstrated that the selfassembly of molecular building blocks driven by a chemical fuel led to the transient formation of an active material, in which reaction kinetics and fuel levels determined the properties such as lifetime, stiffness, and self-regeneration capability of the material.[12] Ulijn et al. expanded the development of supramolecular materials based on Fmoc-capped small molecules and used computational tools to screen the self-assembling propensity of more than 8,000 possible tripeptides in water.[13] Taking advantages of the chemical structures and the self-assembling ability of peptides, Cui et al. developed a novel class of drug amphiphiles (one-component nanomedicine) by covalently linking one or more anticancer drugs to a rationally chosen/designed peptide backbone through a biodegradable linker to achieve precise control of 
drug loading and physicochemical properties of nanomedicines.[14-17] Yang et al. developed a promising vaccine adjuvant made of self-assembling peptide hydrogels. Compared with the clinically used alum adjuvant, the L- and D-peptide hydrogels increased the IgG production against the proteins (e.g., ovalbumin (OVA)),[18] and such D-peptide hydrogels are being explored as an adjuvant for HIV vaccine based on DNA.[19] Parallel to these studies, a new and versatile progress, firstly reported in 2004, is to integrate enzymatic reactions and self-assembly (i.e., enzyme-instructed self-assembly (EISA)) to build up supramolecular biofunctional materials for the applications in biomedicine such as cancer therapy, $[2$, 20-24] infectious diseases,[25] and drug delivery[26, 27]. Moreover, besides the exploration of the selfassembling drug molecules, $[28,29]$ the development of D-peptides, which usually resist endogenous proteases and act as novel biofunctional materials, has generated fruitful results and opened a new direction for the development of biomaterials.[21, 30-33] All these research activities have generated considerable exciting and promising results, which warrant a brief review of supramolecular biofunctional materials.

We arrange this review in the following way: we first compare the supramolecular hydrogels with traditional polymeric hydrogels to highlight the merits of supramolecular interactions (i.e., noncovalent interactions) and orders of molecular arrangement in the context of hydrogels or nanostructures. After introducing the basic building blocks of supramolecular hydrogels (amino acids, nucleic acid architectures, and saccharides) by discussing their unique properties, we focus on the potential biological and medical applications of these supramolecular biomaterials and relevant molecular processes, followed by the perspectives and outlooks of this field. In this review, we intend to provide a snapshot of recent achievements at the intersection of supramolecular chemistry and biomedical science in hope of contributing to the multidisciplinary research on the development of supramolecular biofunctional materials for a wide range of applications. Due to the fast development of the field, the choice of examples for this review inevitably is arbitrary and incomplete. For more comprehensive discussions, interested readers can refer to other authoritative review and research articles.[34-45] 


\section{Supramolecular Hydrogels as Biofunctional Materials.}

\subsection{Polymeric Hydrogels and Supramolecular Hydrogels}

Sharing certain characteristics with traditional polymeric biomaterials, the most explored and prominent type of supramolecular biofunctional materials are supramolecular hydrogels.[41] Thus, it is appropriate to understand supramolecular biofunctional materials by comparing conventional polymeric hydrogels[46] to supramolecular hydrogels.[1] As illustrated in Figure 1A, conventional polymeric hydrogels, composed of 3D elastic networks formed by macromolecules (either synthetic or biological polymers), are able to hold or immobilize substantial amount of water through surface tension and capillary forces. Depending on the nature of crosslinking, polymeric hydrogels can be further classified to type I (covalent crosslinking) and type II (noncovalent crosslinking).[47] Composed of polymer chains interconnected to each other by covalent bond, type I polymeric hydrogels are generally permanent and irreversible, but may still have certain dynamic freedom. Being crosslinked by covalent bonds, this type of hydrogels is brittle and unable to re-build (i.e., self-healing) after the network is broken. Since the formation of type I polymeric hydrogels usually involves chemical reactions that require metal catalysts, initiators, or UV, the processes for generating the hydrogels are hardly biocompatible. Having limited dynamic freedom, type I hydrogels usually are insensitive to external stimuli. All these disadvantages largely limit the applications of type I polymeric hydrogels in biomedicine. In contrast, type II polymeric hydrogels, in which the crosslinking relies on transient noncovalent interactions between the polymer chains (referred as "gellants"), usually are weaker and susceptible to external disturbs/stimuli. Nevertheless, this dynamically transient nature can be an advantage as it makes the formation of the polymeric hydrogels reversible (or "self-healing").[48] Compared to type I polymeric hydrogels, type II polymeric hydrogels find applications more readily in biological research due their two desirable characteristics - "self-healing" and responsiveness derived from the transient nature of noncovalent interactions. Since 1955 when Czech chemists Drahoslav Lím and Otto Wichterle developed the first polymeric hydrogel (poly-2-hydroxyethyl methacrylate) for potential biomedical applications,[49] 
polymeric hydrogels have independently defined a remarkable research area and constituted a large group of biomaterials. Having been used in a variety of biological disciplines (e.g., superabsorbent materials,[50] drug storage and delivery in biomedicine,[51] scaffolds to reconstitute artificial extra-cellular matrix,[52, 53] contact lenses, [49] and tissue engineering,[34, 54, 55]), these polymeric hydrogels are still expanding the scope of their applications.

In the past two decades, the successful development of polymeric hydrogels and low-molecularweight organogelators have stimulated the emergence and thriving of small molecular hydrogelators (being named to correspond to gellants in polymeric hydrogels). The self-assembly of hydrogelators in water results in supramolecular "chains", nanofibers, or other nanoscale assemblies as the 3D networks of the hydrogels to immobilize water. The resulting hydrogels thus are named as supramolecular hydrogels or molecular hydrogels.[1, 41] Resulted from self-assembly of small building molecules (e.g., peptide derivatives) via noncovalent interactions, the supramolecular "chain", nanofibers, or other nanoscale assemblies usually possess orders that, however, are transient and reversible. Unlike the crosslinks in polymeric hydrogels, the crosslinks among nanofibers of supramolecular hydrogels are noncovalent (Figure 1B). Thus, the supramolecular hydrogels are often thermally reversible or easily respond to certain stimuli. However, the major limitation of supramolecular hydrogels is their mechanical strength. We compare type I and type II polymeric hydrogels with supramolecular hydrogels on several important characteristics that are important for biological and biomedical applications in Table 1.

Table 1. Comparison between two different types of hydrogels - polymeric hydrogels and supramolecular hydrogels.

\begin{tabular}{|c|c|c|c|}
\hline & \multicolumn{2}{|c|}{ polymeric hydrogels } & \multirow{2}{*}{$\begin{array}{l}\text { supramolecular } \\
\text { hydrogels }\end{array}$} \\
\hline & $\begin{array}{l}\text { type I (covalent } \\
\text { crosslink) }\end{array}$ & $\begin{array}{l}\text { type II (noncovalent } \\
\text { crosslink) }\end{array}$ & \\
\hline $\begin{array}{c}\text { mechanical strength } \\
\text { tunability }\end{array}$ & $\begin{array}{l}\text { extremely strong } \\
\text { poor }\end{array}$ & $\begin{array}{l}\text { relatively strong } \\
\text { good }\end{array}$ & $\begin{array}{c}\text { weak } \\
\text { excellent }\end{array}$ \\
\hline $\begin{array}{c}\text { responsiveness to biological } \\
\text { stimuli }\end{array}$ & poor & medium to excellent & excellent \\
\hline $\begin{array}{c}\text { biocompatibility } \\
\text { mimicry of extracellular matrices }\end{array}$ & not good & medium to excellent & excellent \\
\hline $\begin{array}{c}\text { (e.g., signal presentation, network } \\
\text { topology) }\end{array}$ & poor & excellent & good to excellent \\
\hline reversibility & brittle and irreversible & less reversible & reversible \\
\hline
\end{tabular}


A

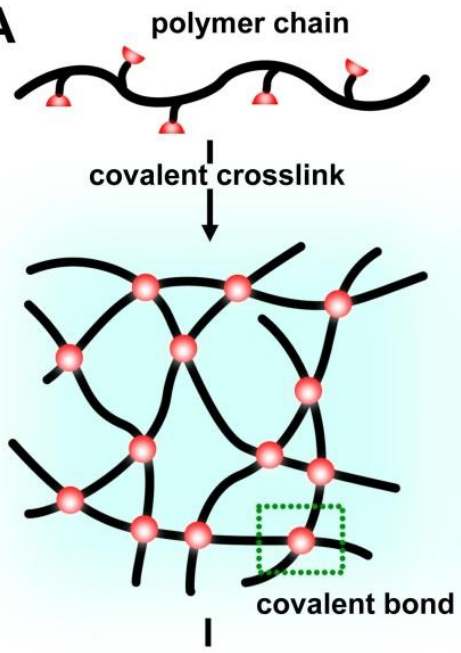

polymeric hydrogel medium to excellent

excellent

excellent incorporation of multiple biological functionalities

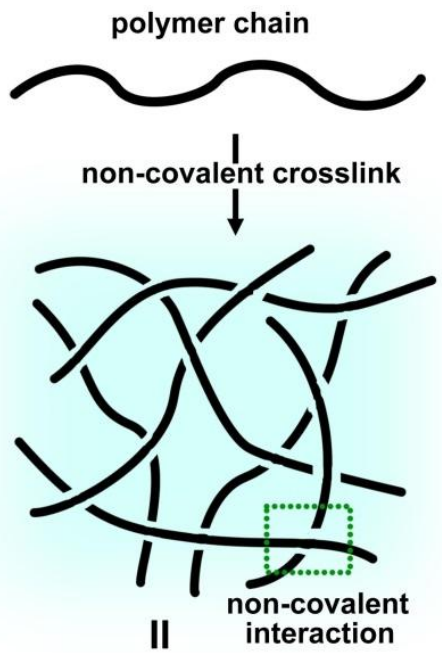

II interaction

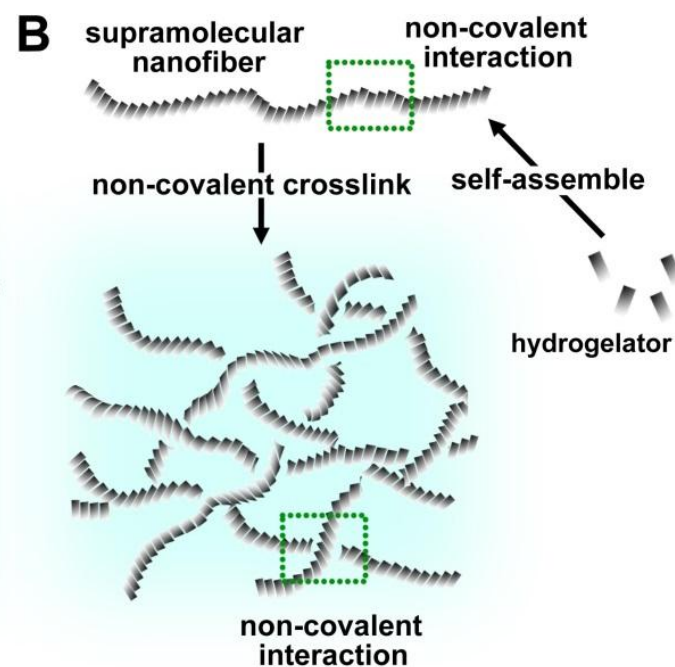

supramolecular hydrogel

Figure 1. Schematic illustration of (A) covalent crosslinking of functional polymer chains/precursors to form covalent polymeric hydrogels (type I) and noncovalent crosslinking of functional polymer chains/precursors to form polymeric hydrogels (type II) and (B) small molecules to form supramolecular nanofibers via noncovalent interactions and self-assembly, which further entangle with each other to form the network of supramolecular hydrogels.

\subsection{Merits of Supramolecular Biofunctional Materials}

Due to their noncovalent nature, supramolecular hydrogels, as a valuable addition to polymeric hydrogels, contribute a large portion of functional biomaterials, and are being extensively explored today. Molecular self-assembly is a process in which molecules adopt a defined arrangement spontaneously and is ubiquitous in nature. As a key concept in supramolecular chemistry, self-assembly is primarily based on noncovalent interactions (e.g., van der Waals force, hydrogen bonding, electrostatic interaction, and hydrophobic interactions) between molecules. Among these noncovalent interactions, hydrophobic interactions, as the result of a nonpolar group in water and acting over long range, are uniquely important for the self-assembly of hydrogelators in water. The self-assembly of hydrogelators to form nanofibers as 
networks/matrix of supramolecular hydrogels, which shares many characteristics of certain biological processes in nature (e.g., the dynamics of cytoskeletons such as actin and tubulin), is a fundamental molecular process, typically noncovalent, three-dimensional, structural, dynamic, adaptive, responsive, and organized. This kind of molecular process can easily interact with, interfere, or even mimic the cellular events in various biological systems, thus promising various fundamentally new biological and biomedical applications (e.g., mimicking the function of glycoproteins[56, 57]). The extensive noncovalent nature of molecular self-assembly renders supramolecular biofunctional materials with several unique merits as highlighted below.

\subsubsection{Responsiveness}

Due to the dynamic nature of noncovalent interactions, the biofunctional materials based on supramolecular hydrogels exhibit stimuli responsiveness to various physical, chemical, or biological stimuli, like temperature,[58] ultrasound,[59, 60] light,[61] magnetic field,[62] pH,[63-65] ionic strength,[66, 67] redox agent,[68] ligand-receptor interactions, [69-72], enzymes (Figure 2A),[25, 73-80] and many other reaction agents and catalysts.[81-83] Utilizing this property, one is able to not only control the self-assembly/disassembly process as in situ response to external stimuli for desired biomedical applications, but also to generate chemical, physical, and biological sensors for the detection of various external stimuli.
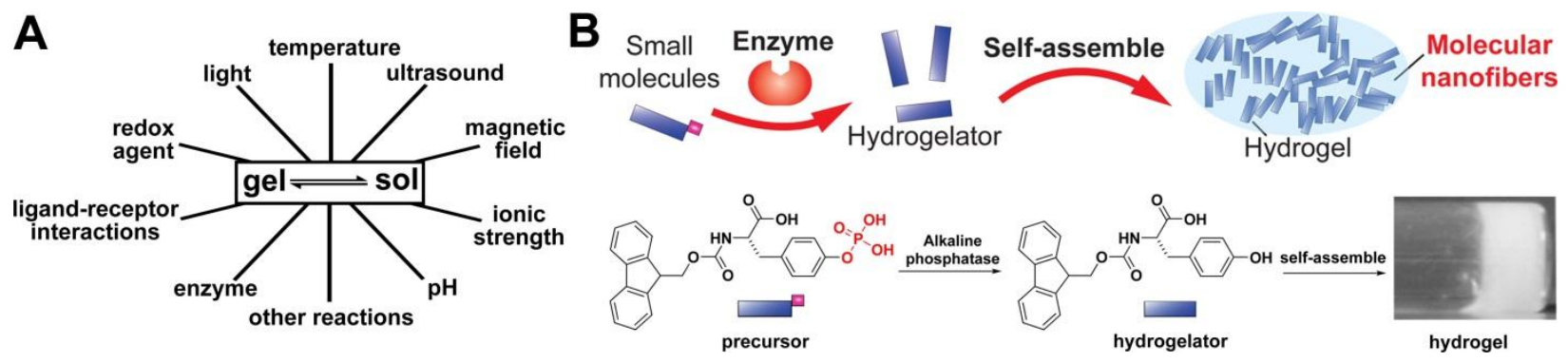

Figure 2. (A) Gel-sol or sol-gel transformation is responsive to different physical, chemical, biological stimuli. (B) Illustration of the enzyme-instructed self-assembly (EISA) of small molecules to form a supramolecular hydrogel. (Adapted from (c) 2004 Wiley-VCH Verlag GmbH \& Co. KGaA, Weinheim with permission.[84]) 
One of the most common ways to control the reversible self-assembly is temperature, and a large amount of supramolecular hydrogels undergo a sol-gel or gel-sol transition upon the change of temperature. With the change of temperature (usually increasing and then decreasing), the noncovalent interactions between molecules likely undergo rearrangement to favor more ordered molecular assemblies that are thermodynamically more stable. Ultrasound, an efficient approach to promote dissolution or dispersion of molecules (usually) in a solvent, is also widely used for preparing supramolecular hydrogels by disrupting, redistributing, and rebuilding the stacking of small molecules, making the hydrogels more homogenous.[59, 60] Light-controlled self-assembly requires the presence of light sensitive motifs, such as tetrazole,[61, 85] merocyanine,[86] $\alpha$-carboxy-2-nitrobenzyl (CNB),[87] and azobenzene.[88] Although light is a physical stimulus, chemical reactions and structural changes, in most cases, also occur to initiate the light-triggered sol-gel or gel-sol transition, and the resulting conformation of the molecules typically favor more compact stacking when a hydrogel forms. An interesting but much less used physical trigger is magnetic field,[62, 89, 90] which is contactless, homogeneously effective over the whole sample and can produce structured materials with different sizes. However, this technique heavily relies on the (dia)magnetic susceptibility of the sample and the strength of the applied magnetic field.[62] The adjustment of $\mathrm{pH}$ serves as the most common and convenient chemical process for preparing supramolecular hydrogels. The protonation or deprotonation mediated by changing $\mathrm{pH}$ directly influences not only the intensity and strength of hydrogen bonding between hydrogelators, but also the conformations of the hydrogelators to promote the rearrangement of the molecular stacking.[63-65] Adjusting ionic strength is another effective way to induce hydrogelation and to modulate hydrogel properties, including mechanical, structural, and transport properties of hydrogels.[91-93] Many kinds of chemical reactions (e.g., redox reactions, [68, 94, 95] click chemistry,[81, 85] Michael addition,[82] and ligations[83]) have recently found increasing applications to generate supramolecular hydrogels. Generally, the non-self-assembling reactants turn into hydrogelators to self-assemble. Another important and increasingly explored hydrogelation pathway is ligand-receptor interactions.[66, 67] However, the ligand-receptor pairs between small molecules in nature are rather rare.[69, 70] One important kind of 
ligand-receptor interactions is metal-ligand interactions, as a form of noncovalent interaction or alternative weak driving force commonly leading to gelation.[71, 72] Recently, many studies have exploited enzyme-responsive motifs and enzymatic reactions to control molecular self-assembly since enzymatic reactions govern most of the molecular assembly or signal event in biology.[76-78, 96] In general, enzymes initiate the self-assembly by simply converting a non-self-assembling precursor into a self-assembling molecule via bond cleavage or formation. Such a self-assembly of small molecules usually results in the formation of supramolecular nanoscale assemblies (e.g., nanofibers or nanoparticles) in water, and above a threshold concentration, hydrogelation (Figure 2B).[84] This seemingly simple approach, in fact, holds great promises for the development of supramolecular biofunctional materials.

Since many physical, chemical, and biological stimuli are able to trigger molecular self-assembly, self-assembly/aggregation/hydrogelation, as an observable phenomenon, can reciprocally report the presence of these external triggers for developing chemo- or biosensors as economical, rapid, and highthroughput diagnostics. For example, a simple approach is to develop the assays based on the hydrogelation of small molecules for quick detecting the presence of enzymes (e.g., phosphatase), as well as enzyme inhibitors.[97] As the substrate of phosphatase, a precursor transforms into a hydrogelator upon enzyme catalysis, which induces the formation of a hydrogel. When inhibitors bind with the active site of the enzyme and block the conversion of the precursor, no hydrogel forms. Such an easily observable change can serve as an inexpensive and facile visual assay where the colorimetry or fluorescence approach fails. In a work using the similar concept demonstrated by Hamachi et al.,[98] Yang and coworkers developed a phosphorylated short peptide with adamantane-capping group, which self-assembled to form nanospheres after the treatment of phosphatase. Upon the formation of nanospheres, ${ }^{19} \mathrm{~F}-\mathrm{NMR}$ signal of the fluoride containing backbone faded away, but would reappear after the treatment of tyrosinase, which led to the disassembly of the nanospheres into unassembled small molecules. Apparently, the dephosphorylated molecules are less soluble, thus self-assemble. After being oxidized, the molecules change structure to disfavor self-assembly. ${ }^{19}$ F-NMR signal broadens and attenuates upon the formation of large aggregates because ${ }^{19} \mathrm{~F}$ has a large chemical shift anisotropy while 
the transverse relaxation of ${ }^{19} \mathrm{~F}$-NMR signal is sensitive to the apparent molecular weight due to the CSA relaxation mechanism.[99] Jong and Kim designed and prepared a novel stimuli-responsive supramolecular hydrogel based on the host-guest interaction between gamma-cyclodextrin and an azo dye. Because the azo dye, containing an 8-hydroxyquinolinem, also is a ligand for metal ions, different metal ions lead to different binding patterns, which are responsible for different morphological transitions of the supramolecular assembly in the hydrogels.[100]

\subsubsection{Reversibility}

Due to the transient nature of noncovalent interactions, supramolecular networks are capable of restoring their mechanical properties after deformations and destructions. In other words, the transient character confers reversibility to supramolecular biofunctional materials, which is essential not only for the spatiotemporal control of functions, but also for extending the lifetime and improving the safety and performance of materials, particularly, for biomedical applications. For example, MAX1 and MAX8, two peptides developed by Schneider et al., were highly responsive to mechanical shear-when exposed to a shear stress, the hydrogel formed by either MAX1 or MAX8 shear-thinned and flowed with very low viscosity, while the hydrogel immediately restored its original rigidity upon the removal of the stress (Figure 3).[101] In this regard, this inherent property of supramolecular hydrogels allows the hydrogel (incorporated with drugs) to be delivered via syringe with precision to target sites. Homogenous cellular distribution and cell viability are unaffected by the shear thinning process and the hydrogel reconstructs and stays fixed at the point of introduction, suggesting that these kind of hydrogels may be useful for the delivery of cells to targeted disease sites for tissue regeneration. For example, Banerjee and coworkers developed a cell-compatible synthetic tripeptide-based hydrogel with similar mechanical properties for entrapment and sustained release of an antibiotic vancomycin and vitamin B12 at physiological pH.[102] Moreover, due to their transient nature, the formed supramolecular hydrogels ultimately dissociate after certain period, which minimizes long-term toxicity. 


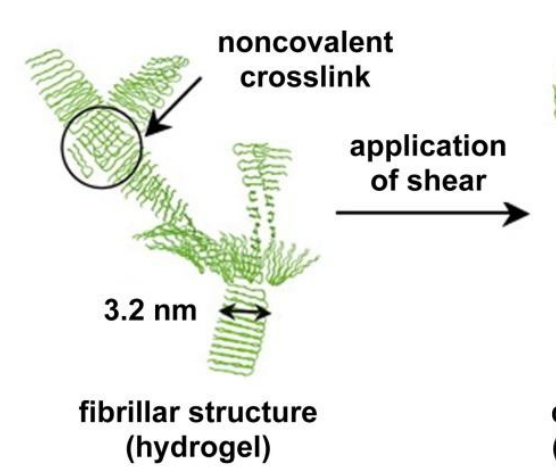

(hydrogel)
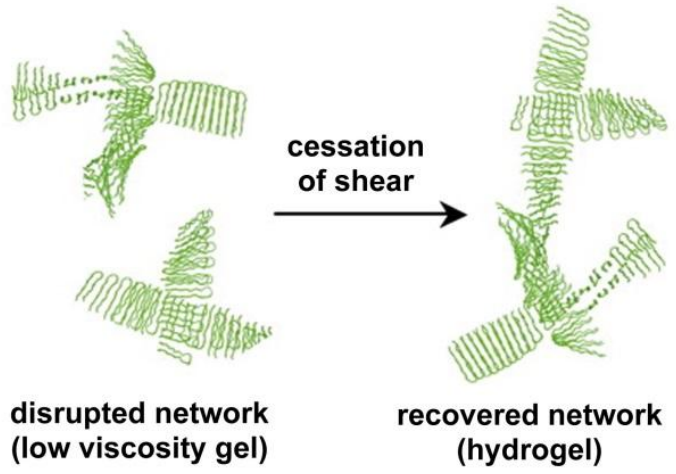

recovered network (hydrogel)

B

\section{MAX1: VKVKVKVKVDPLPTKVKVKVKV-NH} MAX8: VKVKVKVKVDPLPTKVEVKVKV-NH ${ }_{2}$

Figure 3. (A) Self-assembly, shear-thinning, and self-healing mechanism allowing rapid formation of hydrogels that can be delivered by syringe. (B) Peptide sequences of MAX8 and MAX1. (Adapted from (C) 2007 National Academy of Sciences with permission.[101])

\subsubsection{Tunability}

In order to tune the mechanical properties of covalent polymeric hydrogels, material scientists typically modulate the density or distance between crosslinking points according to traditional network theory of polymeric gels.[103] This approach has inspired the modulation of the mechanical properties of supramolecular hydrogels by simply varying the concentrations of self-assembling units or the density of molecular recognition motifs. Since hydrophobic interaction, one of the most critical interactions within supramolecular hydrogels, is much weaker than electrostatic interactions, the combination of aromaticaromatic and electrostatic interactions, becomes an effective approach to tailor the elasticity of supramolecular hydrogels.[104] For example, simply using calcium ions to increase interfiber crosslinking was able to enhance the elasticity of the hydrogels based on aromatic-aromatic interactions over several orders of magnitude, even by a subtle increase of calcium concentration.[91] In addition, molecular recognition is also able to enhance the elasticity of the supramolecular hydrogels. For instance, the addition of the ligands (i.e., vancomycin) into mechanically weak hydrogels of a derivative of receptors (pyrene-D-Ala-D-Ala) leads to up to a $10^{6}$-fold increase of storage modulus (Figure 4A).[105] 

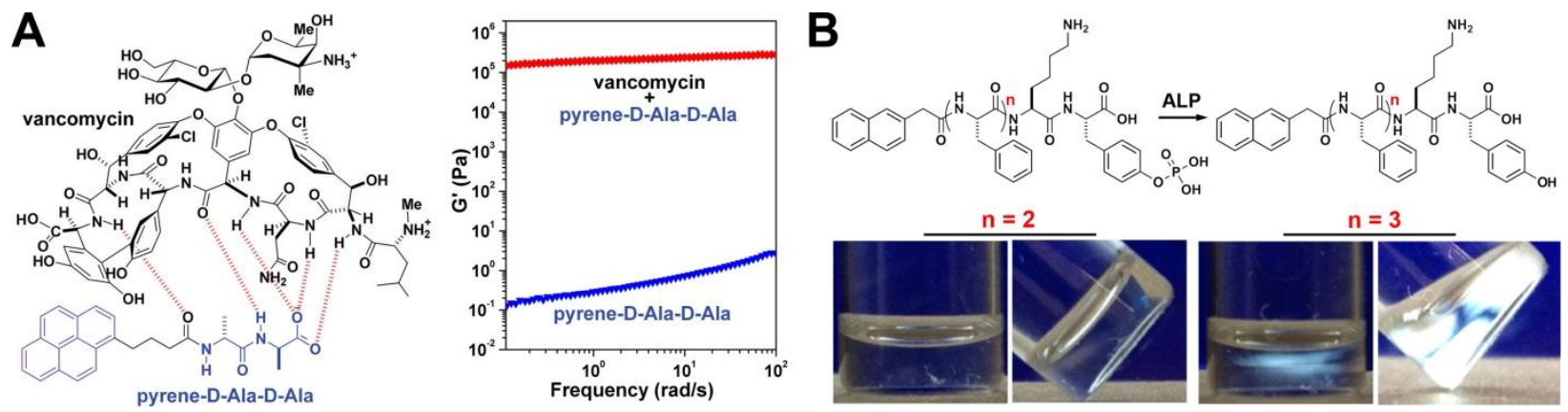

Figure 4. (A) Addition of vancomycin to the supramolecular hydrogel of self-assembled pyrene-D-AlaD-Ala increases the storage modulus of the hydrogel of pyrene-D-Ala-D-Ala by about $10^{6}$-fold. (B) The precursor with three phenylalanines formed a birefringent hydrogel upon enzymatic transformation while the precursor with only two phenylalanines formed a non-birefringent hydrogel. (Adapted from (C) 2004, 2014 American Chemical Society with permission.[105, 106])

Altering the molecular structure of the building blocks for supramolecular materials directly leads to changes in macroscopic properties, such as optical properties, cell compatibility, and biostability. For example, the increase of the intermolecular aromatic-aromatic interaction of hydrogelators during enzymatic hydrogelation resulted in spontaneous formation of an anisotropic hydrogel (Figure 4B).[106] The design and preparation of two pairs of precursors/hydrogelators that differed only in the number of phenylalanine residues has demonstrated that the precursor with three phenylalanines formed a birefringent hydrogel upon enzymatic transformation while the precursor with only two phenylalanines formed a non-birefringent hydrogel. Also, it is possible to build systems that exhibit different levels of cell compatibility to achieve selective targeting, $[20,21]$ or enhanced biostability by utilizing non-natural amino acids, such as D-amino acids.[21, 27, 30-33] For example, based on that placental alkaline phosphatase represents a generic difference between cancer and normal cell, a small D-peptide containing a tyrosine phosphate as an enzymatic trigger selectively inhibited cancer cells while sparing normal cells.[107]

\subsubsection{Biocompatibility and Biomimicry}


Biological systems are extremely complicated, and there remains a great demand to develop synthetic materials that are capable of mimicking the structural and functional complexity of biological materials in nature. Since the networks of supramolecular hydrogels largely rely on noncovalent interactions among small molecules (M.W. $<2,000 \mathrm{~g} / \mathrm{mol}$ ), this kind of hydrogels are typically biocompatible, and in most cases biodegradable. This feature makes supramolecular hydrogel an excellent platform for cell culture and tissue engineering, for example, mimicking extracellular matrix that supports cell survival, assisting cell adhesion and division, or even promoting cell proliferation and differentiation. Ulijn and coworkers reported the 2D and 3D cell culture using hydrogels formed by Fmocdipeptides/tripeptides, Fmoc-FF (Figure 5A) and Fmoc-RGD.[108, 109] The fibrous structures of the networks of the hydrogels were stable under cell-culture conditions and had similar dimensions to the fibrous components of the extracellular matrix, thus capable of supporting cell culture of chondrocytes in two and three dimensions. Several other groups also showed that it was feasible to use supramolecular hydrogels as cell compatible biofunctional materials.[110-112] A notable example is the hydrogelator containing D-glucosamine, which resulted in a hydrogel possessing the potential to mimic glycoproteins and was able to promote the wound healing and even to reduce the formation of scars.[56]
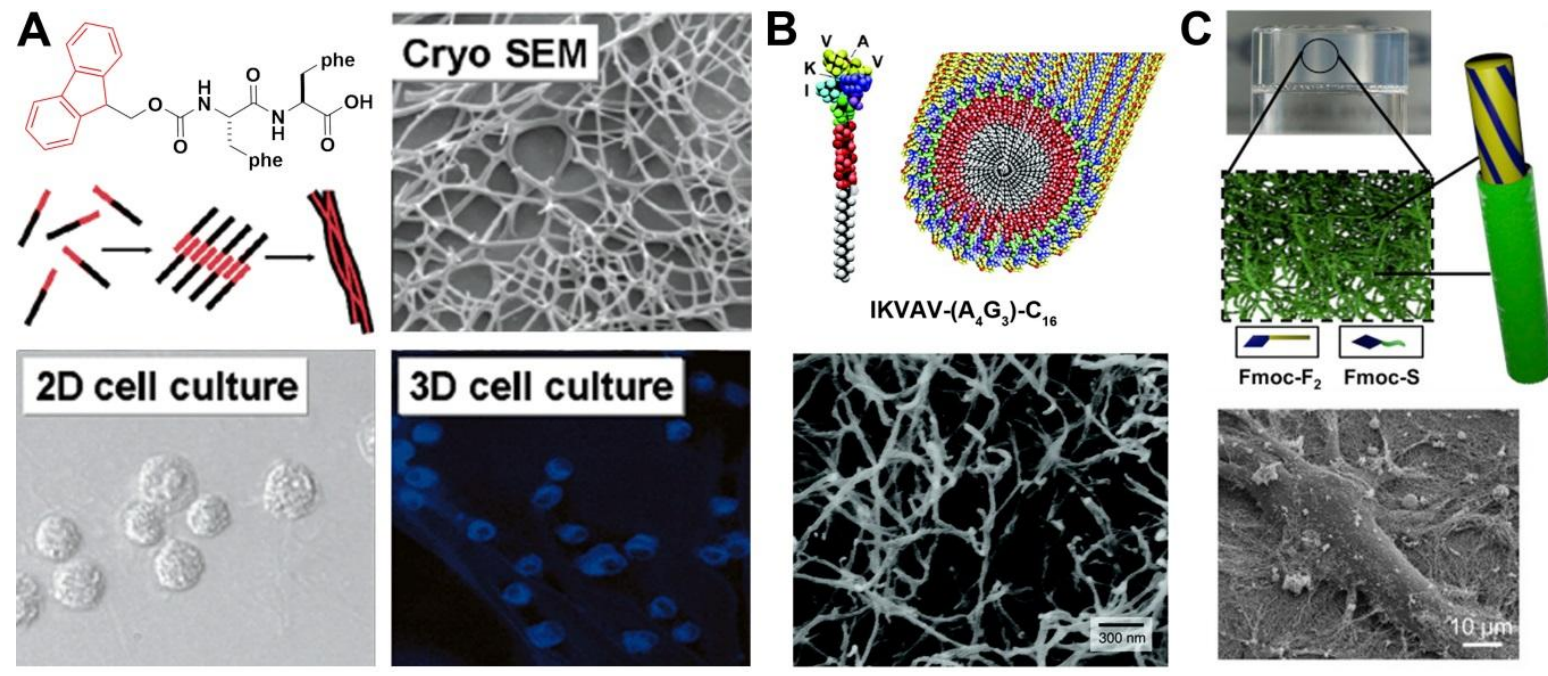

Figure 5. (A) The short peptide of diphenylalanine linked to fluorenylmethoxycarbonyl (Fmoc) spontaneously form fibrous hydrogels under physiological conditions, for 3D cell culture. (B) Molecular graphics illustration of an IKVAV-containing peptide amphiphile molecule and its self- 
assembly into nanofibers, as shown in SEM image. (C) Schematic presentation of proposed core-shell nanostructures in a hydrogel formed by the co-assembly of Fmoc-diphenylalanine and Fmoc-serine and the hydrogel is able to control the differentiations of stem cells cultured in it. (Adapted from (C) 2006 Wiley-VCH Verlag GmbH \& Co. KGaA, Weinheim, ${ }^{98} 2004$ American Association for the Advancement of Science,[4] 2016 Elsevier Inc. with permission.[113])

By controlling the display of bioactive epitopes (e.g., RGD and IKVAV) on supramolecular biomaterials, scientists are able to tailor the functional biomimicry of biological signal in nature. For example, molecular hydrogels that can mimic the structure or function of collagen in nature (the most abundant component of extracellular matrix) could be useful in the preparation of artificial cell scaffolds or in replicating the role of collagen in biomineralization.[3, 114-118] Stupp et al. showed that selfassembly of peptide amphiphiles (PA) with the neurite-promoting laminin epitope IKVAV encapsulated neural progenitor cells to induce rapid differentiation of the cells into neurons (Figure 5B).[4] Ulijn and co-workers recently tried to control the stem cell differentiations in supramolecular hydrogels by modulating the stiffness of these hydrogels. They cultured perivascular stem cells on supramolecular peptide hydrogels of three different stiffness and observed neuronal, chondrogenic, and osteogenic differentiation, respectively (Figure 5C).[113] One novel approach is to use the molecular self-assembly of the conjugate of nucleobase, amino acids, and saccharide to mimic complex glycans for promoting the proliferation of murine embryonic stem cells and the development of mouse zygotes into blastocysts.[57] This approach is noteworthy because it greatly expands the diversity of self-assembling building blocks for developing supramolecular biofunctional materials.

\subsubsection{Modularity and Multiple Functions}

Supramolecular hydrogelators have flexible molecular scaffolds that are able to incorporate a large variety of functional entities (e.g., drugs) to make multifaceted or multifunctional biomaterials. Particularly, these hydrogelators can conjugate with many clinically used drugs for producing hydrogels as "self-delivery" drugs, thus eliminating the step of drug encapsulation and sometimes offering enhanced performance.[28, 29] 


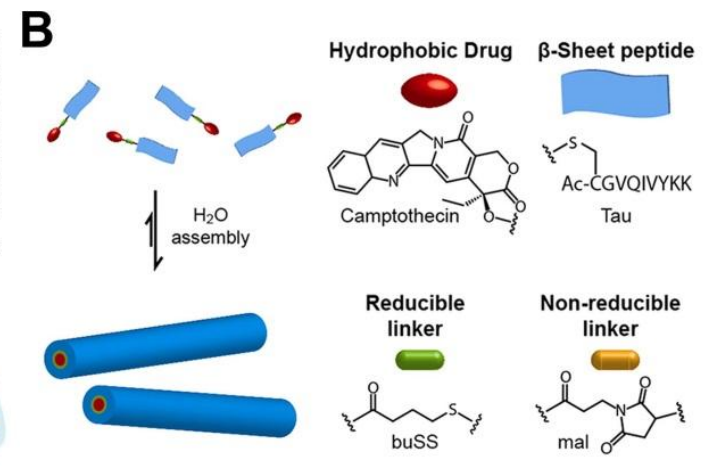

Figure 6. (A) Upon the action of an enzyme, the phosphorylated precursor turns into a hydrogelator, which self-assembles to form nanofibers and affords a supramolecular hydrogel of the taxol derivative for controllable release of drugs. (B) Schematic illustration of the designed and synthesized drug amphiphiles (DAs). (Adapted from @ 2009,2012 American Chemical Society with permission.[14, 31])

In most cases, the modification of self-assembling molecules with drugs, hardly disrupts their selfassembly properties. For example, with rational molecular design, the integration of enzymatic reaction of self-assembly and drug molecules (e.g., taxol) provided a powerful method to create molecular hydrogels of clinically used therapeutics without compromising bioactivities of the drugs. Specifically, the conjugation of taxol (which binds to $\beta$-tubulin subunit of microtubules to result in cell apoptosis) to a selfassembling precursor with tyrosine phosphate as an enzymatic trigger resulted in a new molecule that was able to form a hydrogel through EISA. This hydrogel was capable of slowly releasing anticancer drugs and at the same time prevented the quick clearance of this drugs, thus achieving enhanced retention time[26] and high efficacy in animal model (Figure 6A).[31] Realizing that the noncovalently encapsulated drugs may still diffuse away quickly, Cui et al. directly incorporated the hydrophobic anticancer drug, camptothecin (CPT), into hydrophilic peptide backbones by a biodegradable linker for a high and quantitative drug loading. The loading amount of CPT determined the morphologies of the resulting nanostructures, which could be either nanofibers or nanotubes. The formation of nanostructures provided protection for the CPT drug from the external environment, thus achieving controlled release of CPT. These drug nanostructures could release the bioactive form of CPT and showed enhanced in vitro efficacy against a number of cancer cell lines (Figure 6B).[14] Such strategies promise to generate 
nanostructures made of other types of anticancer drugs, thus presenting new opportunities for the development of self-delivering drugs[28] as cancer therapeutics. In addition to the incorporation of drugs, the incorporation of a fluorophore (NBD) to generate a fluorescent hydrogelator has allowed the first demonstration of self-assembly of small molecules inside cells. The imaging contrast conferred by the nanofibers of the hydrogelators allowed the evaluation of intracellular self-assembly, the dynamics, and the localization of the nanofibers formed by the hydrogelators in live cells.[119]

\subsubsection{Predictability and Ordered Molecular Arrangement}

Being ubiquitous in nature, noncovalent interactions drive protein folding, protein-protein/nucleic acid/ligand interactions, cytoskeleton dynamics, DNA-double-helix formations, RNA structure formation, antibody-antigen, receptor/ligand/hormone, drug-target interactions, and enzyme-substrate interactions. Most cases mentioned above are complicated, so simplified models are always helpful. Supramolecular hydrogelation of small molecules is such a model, though still far away from actual biological counterparts, offering a useful system to study the self-assembly of biomacromolecules in biological systems since these smaller molecules are easy to synthesize/engineer and more suitable for highresolution structural techniques such as X-ray, NMR, EM, and fluorescent imaging. For example, Lynn et al. used the self-assembly of small peptides to build up a couple of nucleated conformational conversion models of amyloid assembly in hope to elucidate the role of $A \beta$ in Alzheimer's disease (Figure 7A).[120122]

Sophisticated biological systems are an unlimited source of inspiration to scientists.[123] For example, that most proteins exist in dimeric forms has led to the generation of a pair of new nucleopeptides, with the nucleobases conjugating to the short peptide sequences selected from the interface of a heterodimer of proteins (Figure 7B). Driven by hydrogen bonds, this pair of nucleopeptides self-assembled to form nanofibers upon mixing in water, and the resulting hydrogel exhibited excellent proteolytic resistance against proteinase K.[124] 


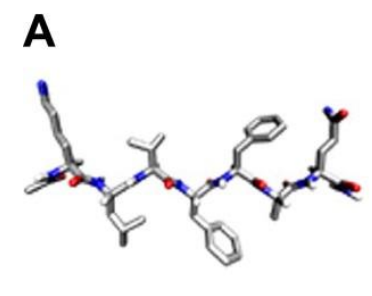

KLVFFAQ

B

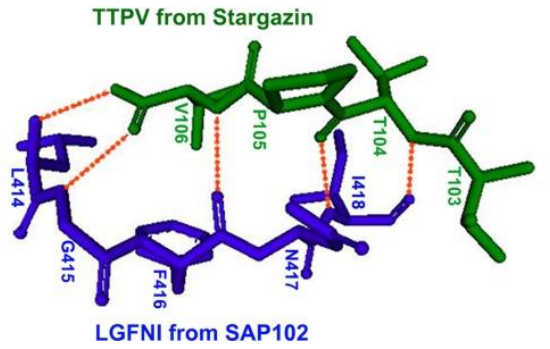

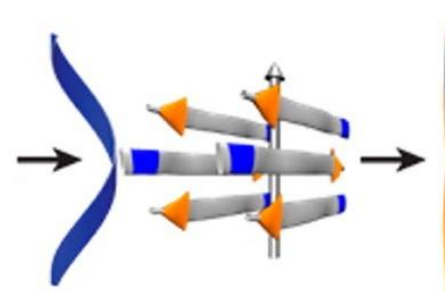

Anti-parallel

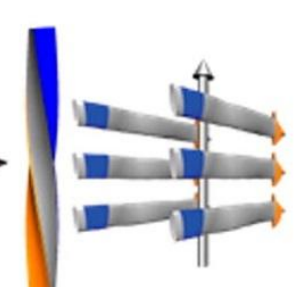

Parallel

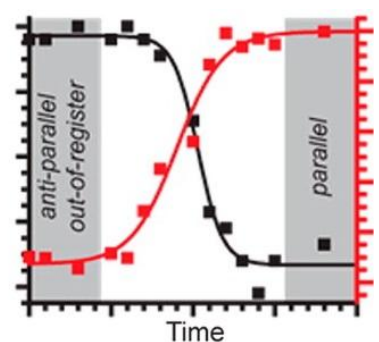

Supramolecular hydrogel

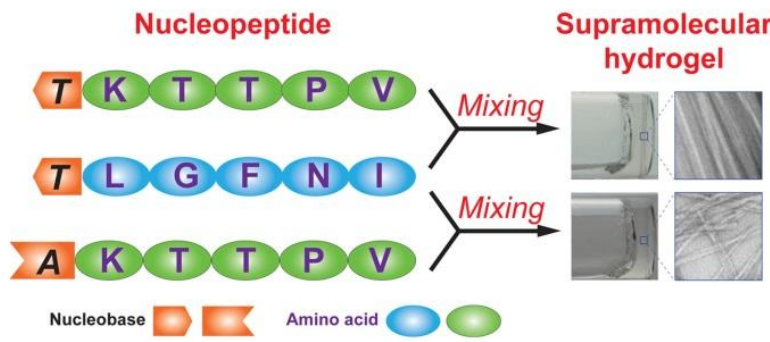

Figure 7. (A) Model for the progressive transitions observed for A $\beta$ (16-22). (B) Molecular structures of the nucleopeptides containing the epitopes from stargazin. Hydrogels form upon mixing. (Adapted from (C) 2014 American Chemical Society, 2015 Wiley-VCH Verlag GmbH \& Co. KGaA, Weinheim with permission.[120, 124])

Unlike polymeric hydrogels, supramolecular hydrogels have more ordered structures, which usually lead to well-defined configurations and conformations. Based on the increased amount of structural data, it becomes increasingly easy to design self-assembling molecules with controllable nanostructures for predictable biological functions and desired biomedical applications.

\section{Supramolecular Hydrogels Made of the Basic Biological Building Blocks}

\subsection{Amino Acids--the Most Prevalent Building Blocks for Supramolecular Biofunctional Materials}

In fact, life relies on noncovalent interactions that maintain the 3D-structures of biomacromolecules (e.g., protein, nucleic acids, and polysaccharides) and control specific binding/recognition events in biological systems. This fundamental fact offers material scientists blue prints for using basic biological building blocks, typically amino acids or peptides, to build up self-assembling molecules for generating supramolecular biofunctional materials. Compared with other small organic molecules, such as urea derivatives, used for the early development of supramolecular hydrogels,[41] the use of the unified 
building blocks of life[125] are more suitable and general for biomedical applications. Of course, the design of such kind of supramolecular biofunctional materials requires an understanding of the nature's underlying principles of noncovalent interactions resulted from these essential building blocks of life. The following section use the supramolecular hydrogels made of peptides or peptide derivatives to illustrate the advantages, versatility, and opportunity of the functional biomaterials derived from amino acids, the simple but essential building blocks of life.

\subsubsection{A Large Space for Molecular Design}

As the building blocks of proteins, amino acids are ideal for generating supramolecular biofunctional materials, including hydrogels. First, according to permutation and combination rules, the 22 natural amino acids, together with non-natural ones (40+, including D-version enantiomers), provide an enormous molecular space for generating self-assembling peptides, considering that even a dipeptide, for example, diphenylalanine, can self-assemble to form well-ordered, tubular, and elongated assemblies (Figure 8A).[126] Second, even a subtle difference may have a profound impact on the capabilities to self-assemble as well as the consequent physical and biological properties. For example, dipeptide Ile-Phe and Val-Phe, differing in only one methyl group, exhibited dramatically different self-assembling behaviors - the former one was able to form a hydrogel consisting of persistent nanofibers while the latter one didn't even self-assemble (Figure 8B).[127] Third, the carboxylic acid (-COOH), amine (-NH 2$)$, and thiol (-SH) on the peptide terminals and side chains allow facile incorporation of a variety of small molecular entities into the self-assembling backbones to generate even more diverse self-assembling molecules.[84, 94, 128-132]
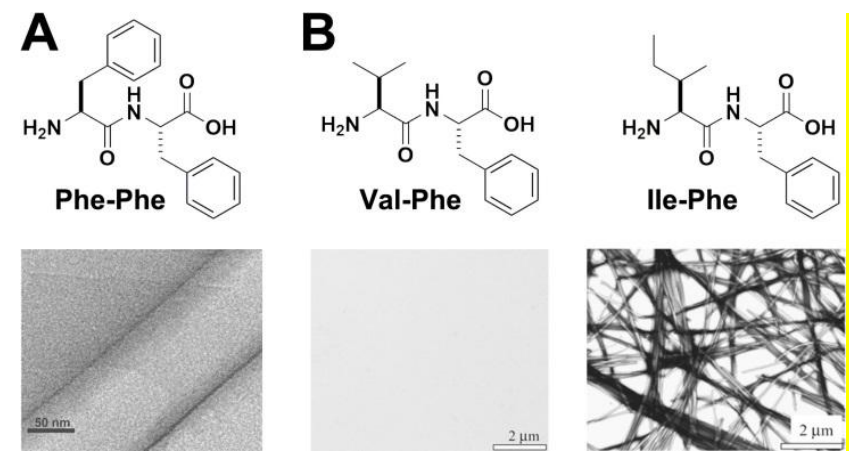
Figure 8. (A) Self-assembly of Phe-Phe dipeptide to form well-ordered and elongated peptide nanotubes (B) Ile-Phe forms a gel with nanofibers as the network whereas Val-Phe does not aggregate in solution. (Adapted from (C) 2003 American Association for the Advancement of Science,[126] 2007 Elsevier Inc. with permission.[127])

Based on their affinity to water and the hydrophobicity (or hydrophilicity) of their side chains, 22 amino acids roughly fall into two categories: hydrophobic amino acids (e.g., phenylalanine, tyrosine, valine, leucine, and methionine) and hydrophilic amino acids (e.g., aspartic acid, glutamic acid, arginine, and lysine). The side chains of hydrophobic amino acids usually contain aromatic or alkyl group and hydrophilic amino acids typically have $-\mathrm{COOH}$ or $-\mathrm{NH}_{2}$ on their side chains. Recently, Frederix and Ulijn aimed to generate designing rules for peptidic hydrogelators by computationally assessing the ability of more than 8,000 tripeptides to self-assemble in water. They have generated considerable results regarding the properties of specific amino acid and their combinations, and identified a limited number of hydrogelators from over 8000 candidates.[13] This research is a valuable effort towards a priori design of a hydrogelator consisting of amino acids.

\subsubsection{Easy Synthesis}

The development of solid phase peptide synthesis (SPPS) and the commercialization of peptide synthesizers, largely reduces the burden of peptide synthesis and allow large scale preparations of peptides to be quick and even automatic.[133] Although SPPS typically has an upper limit of approximately 50 amino acids,[134] it is feasible to synthesize a longer sequence by conjugating two oligopeptides using native chemical ligations.[135] Moreover, the reactive terminals $\left(-\mathrm{NH}_{2},-\mathrm{COOH}\right.$, and -SH) of peptides readily provide available sites for incorporating one or more functional motifs into the molecules, affording conjugates with further tailored functions. Meanwhile, the easiness for synthesizing peptide derivatives stimulates the development of synthetic biomacromolecules mimics, such as glycans, collagens, in the situation where it is difficult to study the structure, assembly, and biochemistry of natural biomacromolecules. For example, the synthetic challenges (e.g., branched structures, anomeric linkages, and selective bond formations) in glycobiology and glycochemistry hinder the development of 

to use the self-assembly of the conjugate of small glycoside and amino acids for mimicking the functions of glycoproteins/proteoglycans.[57, 136, 137]

\subsubsection{Chirality for Structural Diversity}

All natural amino acids, except glycine $(\mathrm{G})$, are chiral and exist exclusively in the form of Lconfiguration. L-Amino acids form L-peptides in nature, which, in most cases, are compatible to cells and thus promise a range of biomedical applications, like cell culture, tissue engineering, and drug delivery. D-peptides, consisting of D-amino acids, usually resist endogenous proteases and are presumably insensitive to most enzymes, readily finding applications in a variety of areas, including cancer therapy and immunomodulation. For example, the conjugation of a naphthyl group with D-Phe-D-Phe afforded a self-assembling molecule, which formed a hydrogel and resisted proteolytic hydrolysis to offer long-term biostability.[27] The nanofibers formed by this D-peptide derivative efficiently inhibited the glioblastoma cells but exhibited little toxicity toward a neuronal cell line.[138] Moreover, acting as de novo amyloid oligomers, the nanofibers also effectively inhibited the tumor progression both in vitro and in vivo (Figure 9A).[139] Mechanistic study revealed that the nanofibers selectively accumulated in cancer cells via macropinocytosis and induced apoptosis by impeding the dynamics of cytoskeletal filaments via promiscuous interactions with cytoskeletal proteins.[129] In a different but related study, after the in situ enzymatic dephosphorylation of a precursor of such kind of D-peptides, the product formed the pericellular nanofibers that selectively inhibited cancer cells.[107]

To increase the life time of the peptides, proteins, or antibodies for maintaining their bioactivities, Merrifield has pioneered the development of the analogues of the native peptide sequences using D-amino acids, namely retro-inverso peptides.[140] The retro-inverso peptides, consisting of D-amino acids in the reversed sequence, share a similar side-chain arrangement of the corresponding L-peptides, although their terminal carboxyl and amino groups point in opposing directions. If the binding of a small peptide to a target is independent to the secondary structure of the peptide, its retro-inverso peptide is likely to have a similar binding affinity with the target (Figure 9B).[141] 

replacing any one of the three L-amino acids in a hydrophobic tripeptidic precursor or its hydrogelator (Nap-Phe-Phe-p Tyr/Nap-Phe-Phe-pTyr) with a D-amino acid significantly increased its proteolytic resistance[32]. Moreover, doping L-peptides with D-amino acids (or vise versa) provides a platform to control the intramolecular folding and the subsequent self-assembly of the monomeric peptides. This approach thus allows the design of materials that are responsive to this intramolecular folding event. One representative classes of peptides that use a D-amino acid to control molecular folding is the $\beta$-hairpin peptides (e.g., MAX1 and MAX8), pioneered by Schneider and Pochan et al. [34, 87, 142-145] As a general design, a $\beta$-hairpin contained two prolines in the middle (one is L- and the other is D-version) of the peptide and was able to respond to a range of stimuli (e.g., $\mathrm{pH}$, temperature, ionic strength, or shear forces) to self-assemble in water and to afford hydrogels that were rich in $\beta$-sheet.

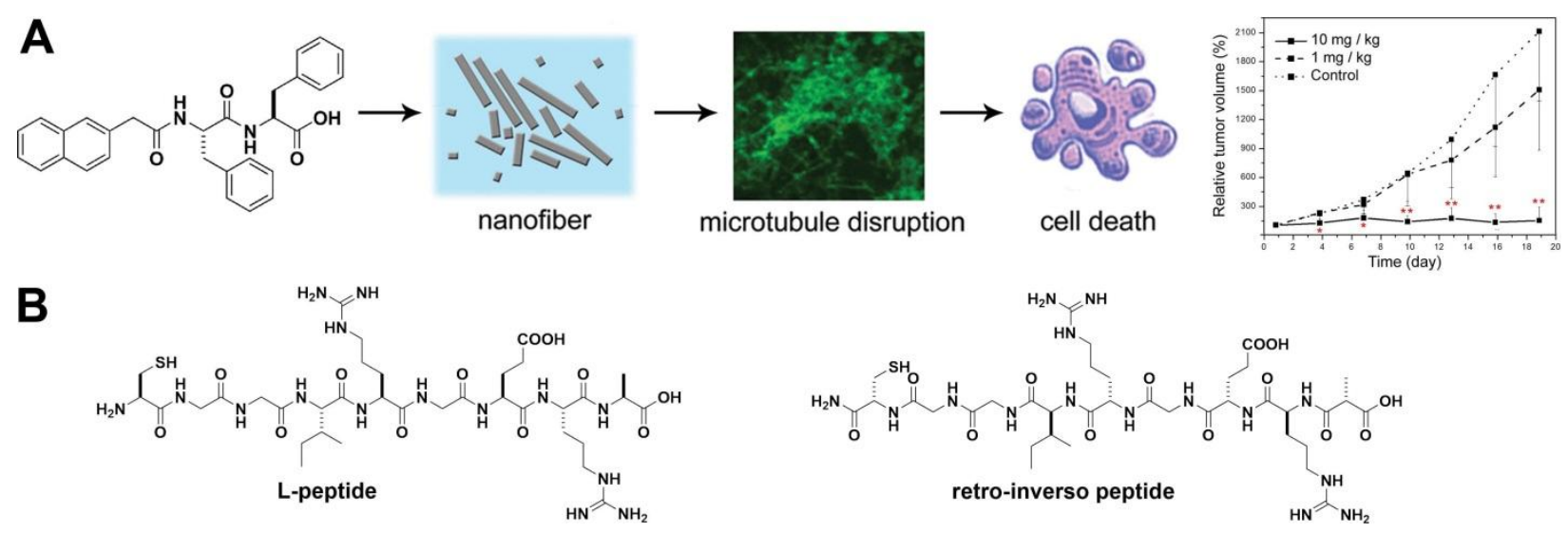

Figure 9. (A) Nap-Phe-Phe self-assembles in water to form nanofibers that inhibit tumor in vitro and in vivo by disrupting cytoskeletons. (B) An example of L-peptide and its retro-inverso isomer. (Adapted from (c) 2013, 2014 Wiley-VCH Verlag GmbH \& Co. KGaA, Weinheim, 1994 National Academy of Sciences with permission.[27, 139, 141])

\subsubsection{Peptides-Perfect Self-Assembling Backbones}

As a kind of biomaterials, supramolecular hydrogels are noncovalently crosslinked nanofiber networks with high water content. Their formation requires a balance between the forces driving the association of nanofibers and those mediating solvation of the network. Considering that proteins have 
evolved to fold and to function in aqueous environments and that many proteins self-assemble into larger structures, they would seem to be ideal candidates for developing hydrogelators or precursors. In fact, nature uses proteins to make hydrogels (e.g., collagens for cornea). Moreover, the segments of proteinpeptides - are suitable for self-assembly. The amide structures in the peptide backbone provide both hydrogen bonding donors and acceptors to facilitate molecular stacking, which is essential in the process of self-assembly and hydrogelation. A common conformation in the supramolecular nanofibers of small peptidic hydrogels is $\beta$-sheet. For example, Zhang et al., while investigating the sequence of Ac$(\text { AEAEAKAK })_{2}-\mathrm{NH}_{2}$ (EAK16) from yeast proteins, observed the gelation of a self-complementary peptide which consisted of opposite charged residues and hydrophobic residues. The pattern of alternating alanine (A) and glutamic acid (E) or lysine (K) residues promoted the formation of $\beta$-sheets in which the hydrophobic and charged side-chains were pointing towards opposite directions of the peptide backbone. Hydrogen bonding between peptides led to the formation of intermolecular $\beta$-sheets containing a hydrophobic alanine face and a charged Glu/Lys face.[146] They also designed several other peptides altering the sequences containing RAD motif, RADA16-I, (RADARADARADARADARADA), and RAD16-II, (RARADADARARADADADA). These peptides have motif RAD that is similar to the ubiquitous integrin receptor binding site RGD. These peptides, similar to EAK16, formed well-ordered nanofibers by adopting a $\beta$-sheet conformation.[147] Compared to $\beta$-sheets, $\alpha$-helical structures have played a less prominent role in the development of supramolecular hydrogels. There are few examples of the hydrogelation of $\alpha$-helical peptides, which require more sophisticated design.[148] For example, Woolfson reported the first example of rationally designed and fully characterized self-assembling peptide hydrogels containing more than $99 \%$ water, based on linear peptides with purely $\alpha$-helical structures. Two helices, formed by 28 mers, wrapped around one another to form a dimer, with complete 3.5 residues per turn mediated by multiple hydrogen bonds.[149] Recently, it was reported that certain bacterial amyloids are $\alpha$-helices,[150] implying that it should be feasible to use $\alpha$-helices for generating supramolecular hydrogels.

\subsubsection{Terminal or Side Chain Modifications to Expand Applications}


One of the attractive aspects of peptides is that their C- and N-terminals, as well as side chain with $\mathrm{NH}_{2}$, $-\mathrm{COOH}$, $-\mathrm{SH}$, or $-\mathrm{OH}$ groups, are readily available for further functionalization. Such a conjugation accommodates a broad range of non-peptidic structural moieties without compromising the excellent selfassembling abilities provided by the peptides. The modification mainly falls into two categories —one is to give rise to an additional directional driving force for self-assembly of the peptides, and the other is to functionalize the peptides without hampering its self-assembling abilities. The former one generates numerous excellent supramolecular hydrogelators or precursors, such as peptide amphiphiles bearing an alkyl chain[3, 151-153] or peptides modified with aromatic groups.[27, 154-156] The latter one readily finds applications in a wide range of biological and biomedical areas, which would be discussed in more details later (see section 4). For aromatic rings like benzene, there is a partial negative charge on both faces of the benzene ring while there is a partial positive charge around the aromatic ring. In this case, a face-to-face stacking of $\pi$ system is largely disfavored, and an edge-to-face stacking, where regions of positive charge directly interact with negative charged regions, dominates. Being similar to electrostatic interaction, such aromatic-aromatic interaction is strong and directional.[157]
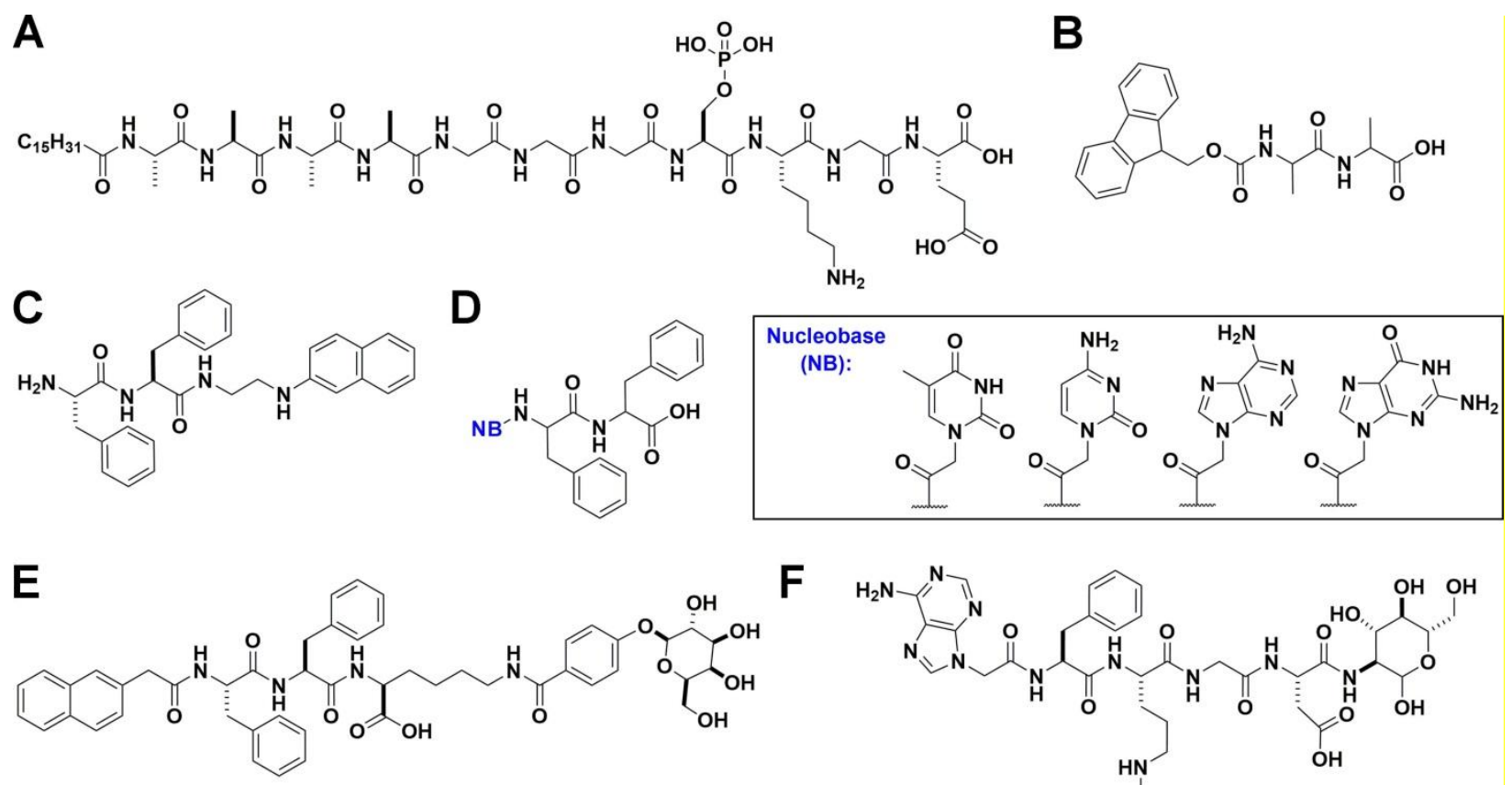

Figure 10. Chemical structures of some hydrogelators. 
Stupp and co-workers have pioneered the development of peptide amphiphiles (PA) that selfassemble to form hydrogels for biological applications. Most of the peptide amphiphiles[158-162] contain a polar head (typically hydrophilic peptides) and a hydrophobic tail (typically alkyl chain) and selfassemble to form nanostructures like fibers, micelles, ribbons, tubes, and even sheets in water, which also afford supramolecular hydrogels upon $\mathrm{pH}$ changes or the addition of salts (Figure 10A). [163, 164] To augment the self-assembly ability of peptidic hydrogelators, aromatic groups, as the hydrophobic segments, are another prevalent choice to decrease the solubility of the peptides in water.[165-171] Shortly after the report of pyrene conjugated vancomycin to form a hydrogel with the dramatically enhanced antibacterial activity, fluorenylmethyloxycarbonyl motif (i.e., Fmoc, the commonly used protecting group of amine in amino acids) is found to turn simple dipeptides (e.g., Gly-Gly or Ala-Ala) into self-assembling molecules to form nanofibers as networking matrix of hydrogels.[172, 173] Although the Fmoc-dipeptide was reported to form a gel in 1995,[174] the observation of the selfassembled nanofibers of Fmoc-dipeptides was not reported until 2003 (Figure 10B).[175] Shortly after that, Ulijn et al. reported the development of Fmoc-diphenylalanine, one of the extensive investigated small molecular hydrogelators, which formed hydrogel either by adjusting the $\mathrm{pH}$ of its aqueous solution, or mixing with other hydrogelators.[63, 176-178] Being considered to be more biocompatible than Fmoc, 2-(naphthalene-2-yl) (Nap-) has emerged as the aromatic group to conjugate with Phe-Phe at either C- or $\mathrm{N}$-terminals for generating hydrogelators (Figure 10C). The Nap- group on the terminal provided the hydrophobic force to enhance self-assembly of these two hydrogelators in the aqueous environment.[90, 179-182] The simplicity of this approach has result in the subsequent design and development of a large group of self-assembling, peptidic hydrogelators capped by Nap motif.[22, 106, 183-185]

The existence of naturally occurring nucleopeptides has stimulated the development of selfassembling molecules by connecting nucleobases to small peptides in order to achieve increased hydrogen bonding interactions.[186-191] For example, the conjugation of nucleobases (e.g., thymine, adenine, cytosine, and guanine) to simple dipeptides, such as Phe-Phe, created a group of hydrogelators or 
precursors. Upon proper initiation (e.g., $\mathrm{pH}$ or enzyme), these nucleopeptides self-assembled in water to afford a new type of supramolecular hydrogels that not only were biocompatible but also exhibited significant resistance to proteases (Figure 10D).[192-196] The incorporation of sugar into peptide backbones usually increases the solubility of the peptides, which consequently decreases the selfassembling tendency of the molecule. However, the supramolecular hydrogels formed by the resulting molecules likely are biocompatible because they resemble natural glycopeptides and should be susceptible to enzymatic degradation.[197-200] A man-made substrate of $\beta$-galactosidase was the first example of such simple glycopeptides (i.e., simpler than the conjugate of pyrene and vancomycin[201]), which became a hydrogelator to self-assemble to form ordered nanostructure upon enzymatic deglycosylation (Figure 10E).[197] Another notable hydrogelator was an L-rhamnose containing glycopeptide that self-assembled to form nanofibers. The corresponding hydrogel was able to suppress the antibody response to phycoerythrin in mice, contrasting to the reported immunostimulatory properties of monomeric L-rhamnose.[202]

Nature, which exploits saccharides, peptides, and nucleobases as fundamental building blocks for the creation of biomacromolecules, has inspired the creation of a new class molecular conjugates consisting of saccharides, amino acids, and nucleobases (Figure 10F). [57, 137, 193, 203-206] These conjugates, surprisingly, acting as hydrogelators, self-assembled in water to form ordered nanostructures and supramolecular hydrogels that possessed multiple functions.

\subsection{Other Building Blocks — Nucleic Acid Motifs and Saccharides}

The combination of nucleic acid motifs (e.g., nucleoside, nucleotides, and nucleobase) with supramolecular chemistry principles provides another powerful approach to create supramolecular hydrogels/assemblies that exhibit tailored physical, chemical, biological properties and functions. For example, the pH-sensitive guanosine hydrazide, as an excellent hydrogelator, forms a stable supramolecular hydrogel based on a guanine quartet induced by metal cations (Figure 11A).[207] Besides, 2'-deoxyadenosine, having an octyl-lipid tail connected by a urea linker, gels water under ultrasonic 
irradiation.[208] Barthélémy and coworkers have pioneered the research on glycosyl-nucleoside-lipid (GNL) amphiphiles.[209, 210] In 2005, Barthélémy reported a neutral amphiphile derived from uridine with two oleyl chain and one glucose on its sugar ring,[211] and demonstrated that such a glycol-nucleoamphiphile was able to bind efficiently to the nuclei acid double helix structure. Barthélémy et al. also reported the use of GNL as a small hydrogelator for the delivery of oligonucleotides into cells. The conjugation of an oleyl chain and a glucose to a nucleoside via double "click chemistry" yielded a hydrogelator, which efficiently formed a hydrogel to encapsulate nuclei acids (Figure 11B).[212] The resulting nucleic acid loaded GNL hydrogel significantly increased the cellular uptake of nucleic acids even in presence of serum, without showing obvious toxicity. Fluorination of the lipid chain of such GNL amphiphile afforded a new family of glycosyl-nucleoside-fluorinate (GNF) compounds, which were able to form hydrogels by varying the temperature (Figure 11C).[213] Most recently, self-assembling molecules based on nucleic acid motif are finding more applications in biology and biomedicine.[214-216]
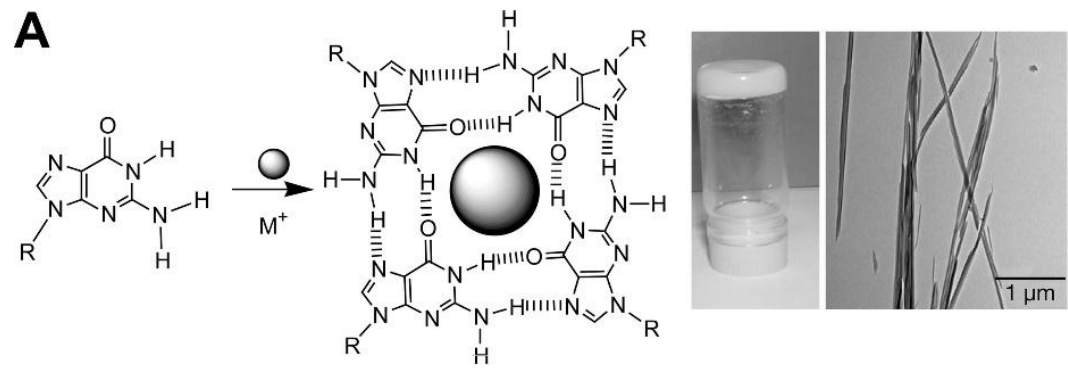

B
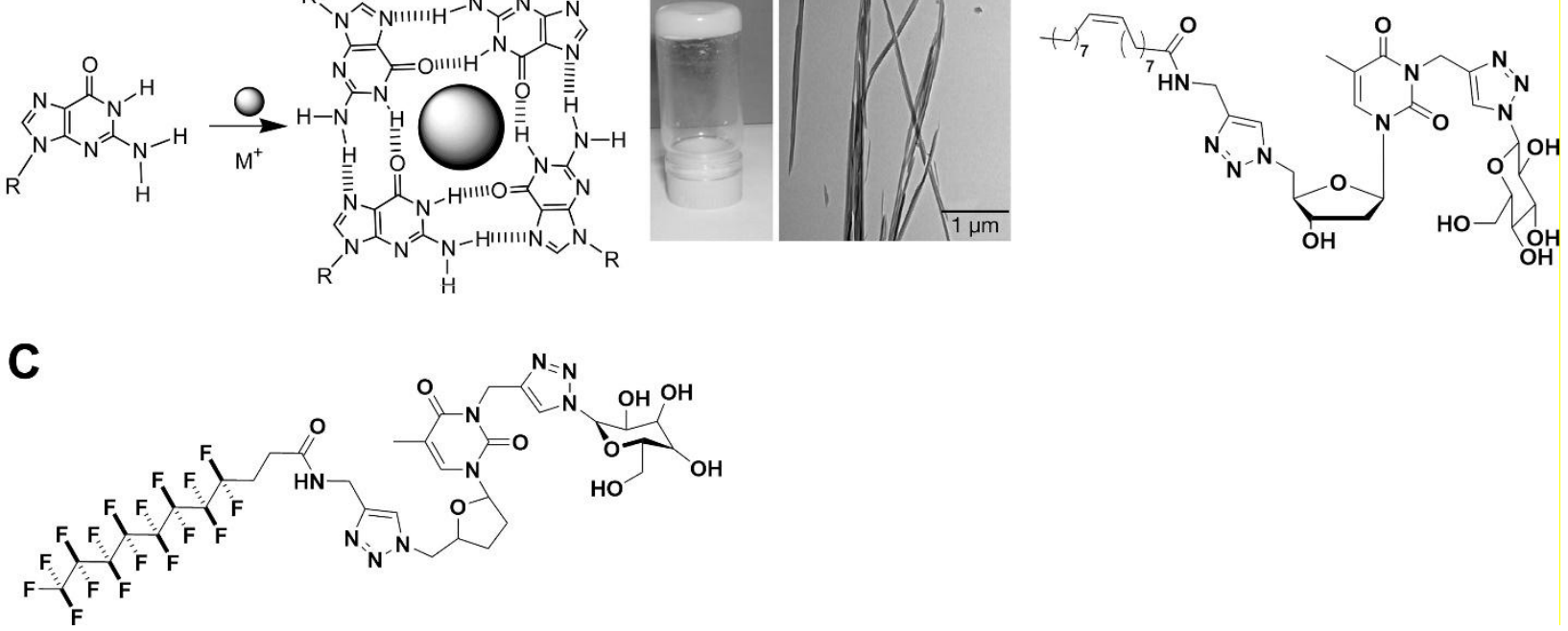

Figure 11. (A) Metal cations induce a guanine quartet to form a supramolecular hydrogel. (B) The conjugation of an oleyl chain and a glucose to a nucleoside via double "click chemistry" yields a hydrogelator. (C) Fluorination of the lipid chain of a GNL amphiphile affords a glycosyl-nucleosidefluorinate (GNF) compound, which forms hydrogels upon changing temperature. (Adapted from @ 2005 by the National Academy of Sciences of the USA with permission[207]) 
Polysaccharides, such as alginate, are a group of biomaterials that have found numerous biomedical applications. Most of them form hydrogels (i.e., noncovalent polymeric hydrogels) under mild conditions, which are particularly attractive in wound healing, drug delivery, and tissue engineering.[217] However, supramolecular hydrogels based on small saccharides remain less explored, and most of the saccharidederived hydrogels are based on lipid conjugates. For example, Thorton et al. synthesized and characterized three series of methyl $\alpha$-D-glucopyranoside derivatives (i.e., monosaccharide lipids (Figure 12A)). Most of them are excellent hydrogelators, which are able to form varies self-assembled structures, including birefringent fibers and tubules.[218] Wang and coworkers also reported hydrogelators based on 4,6-O-benzylidenea-D-methyl-glucopyranoside.[219] By clicking different saccharides as the polar heads onto a hydrophobic chain via copper(I)-catalyzed azide-alkyne $[3+2]$ cycloaddition, Oriol et al. developed several glycolipid hydrogelators (Figure 12B), which, at room temperature, self-assembled to form fibrillar supramolecular structures as the matrices of stable hydrogels. Hamachi et al. reported a classical example of supramolecular hydrogels formed by saccharide derivative (Figure 12C). At high concentration, the resulting hydrogel exhibited sufficient stability and mechanical strength for different applications, such as holding various shapes, acting as gel capsules, serving as cell culture platforms, and sensing and targeting prostate cancer cells.[220] Zhu et al. developed a chemo-responsive hydrogel made of a saccharide-based hydrogelator (methyl-4,6-O-(4'-aldehydephenylidene)- $\alpha$-D-glucopyranoside, Figure 12D). The hydrogel formed by this molecule not only showed thermal responsiveness, but also exhibited cysteine and $\mathrm{pH}$ responsiveness due to the presence of aldehyde and acetal groups.[221] Wang and coworkers conjugated different saccharides to a small peptide (Nap-Phe) as novel glycopeptide hydrogelators (Figure 12E). Such an approach integrated multiple types of building blocks into one single molecule, greatly expanding the candidate pool of supramolecular hydrogelators.[222] 
A
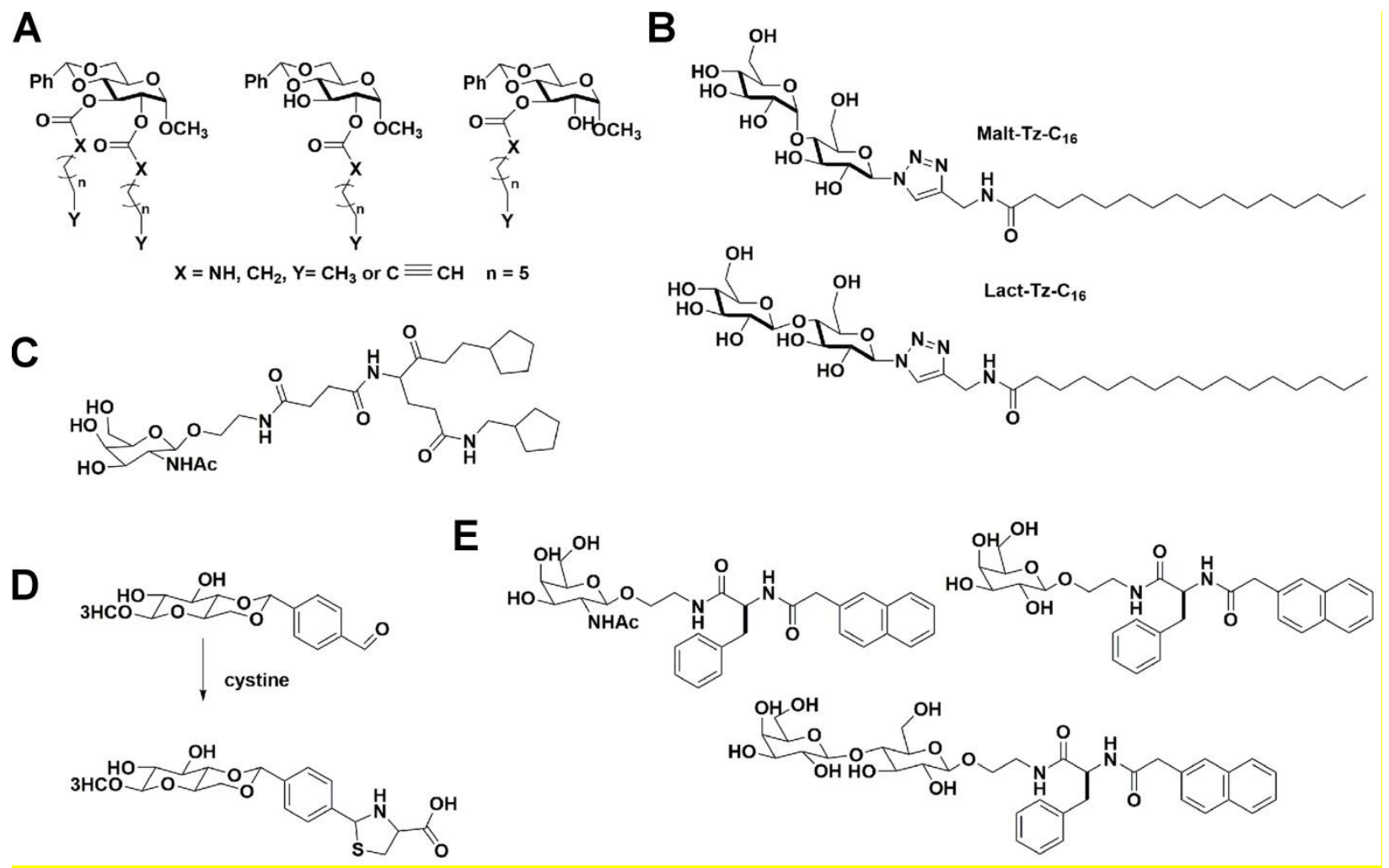

Figure 12. Chemical structures of some saccharide-derived hydrogelators.

\section{Applications of Supramolecular Biofunctional Materials}

In the past two decades, the field of supramolecular chemistry has developed from merely seeking self-assembling molecules to the design of advanced materials with well-controlled biological activities. Such an advance provides scientists, engineers, and physicians with new options to address problems in biomedicine and biology. Here, we briefly discuss the applications/functions of these biofunctional materials into the following five areas: i) cell culture and tissue engineering; ii) drug delivery; iii) cancer therapy; iv) imaging; and vi) immunology. By highlighting the most recent and representative examples in each area, we discuss the specific features and properties that make supramolecular biofunctional materials the promising candidates for these applications.

\subsection{Cell Culture and Tissue Engineering}

As a class of biofunctional materials, supramolecular hydrogels hold up large amount of water and typically contain biological building blocks derived from nature. Due to their resemblance to extracellular environment, one of the potential applications of supramolecular hydrogels is to mimic extracellular 

research of supramolecular hydrogels have been made for 3D cell cultures.[112, 223-228] Hamachi and the co-workers reported the design of a hydrogelator containing zwitter-ionic amino acid and $\mathrm{C}=\mathrm{C}$ double bond, which were both $\mathrm{pH}$ and UV sensitive. This hydrogelator was able to form a hydrogel as strong and multi-stimuli responsive as polymeric hydrogels, thus served as a unique molding template for fabricating various substrates, such as agarose containing proteins. They successfully mimicked a collagen gel by building up 2D/3D micro-channels and demonstrated its biocompatibility in the fabrication process.[229] Yang et al. developed a series of peptide derivatives with the sequences of Nap-GFFYX-ss-EERGD (X = E, K or S) so that glutathione (GHS) was able to break the disulfide bond to result in hydrogels.[230] Among the resulting hydrogels, only Egel $(\mathrm{X}=\mathrm{E})$ with storage modulus $\left(\mathrm{G}^{\prime}\right)$ of hundreds of pascals was suitable for 3D cell culture since the stiffness of the hydrogel had an influence on the cells adhesion, spreading, and proliferation. Besides stiffness, there was report that the change of chirality of nanofibrous structures greatly influenced cell adhesion and proliferation in the 3D extracellular matrix (Figure 13A)[231] — the nanofibers with left-handed helical structure promoted the cell adhesion and proliferation, whereas the nanofibers formed by its enantiomer showed the opposite effect. These results highlighted the crucial role of the stereochemistry of the nanofiber in cell adhesion and proliferation in 3D cell culture. Feng et al. reported the use of supramolecular self-assembly to create nanofibrous environments with the controllable wettability in both 2D and 3D environments.[232] They designed three 1,4-benyldicarbonxamide-phenylalanine derived supramolecular hydrogelators, which formed stable hydrogels with different surface wetting properties. They found that the least wettable nanofibers gave the fast cell adhesion and proliferation, indicating that properties other than stiffness and chirality dictated the cell behaviors. Luo and coworkers reported the application of self-assembled D-peptide in 3D cell cultures.[233] In spite that the D-peptide hydrogel exhibited similar biocompatibility as the hydrogels of the corresponding L-peptides, D-peptides, have advantages over L-peptides, such as that D-peptides, being proteolytically resistant, are more stable in vivo. 
A
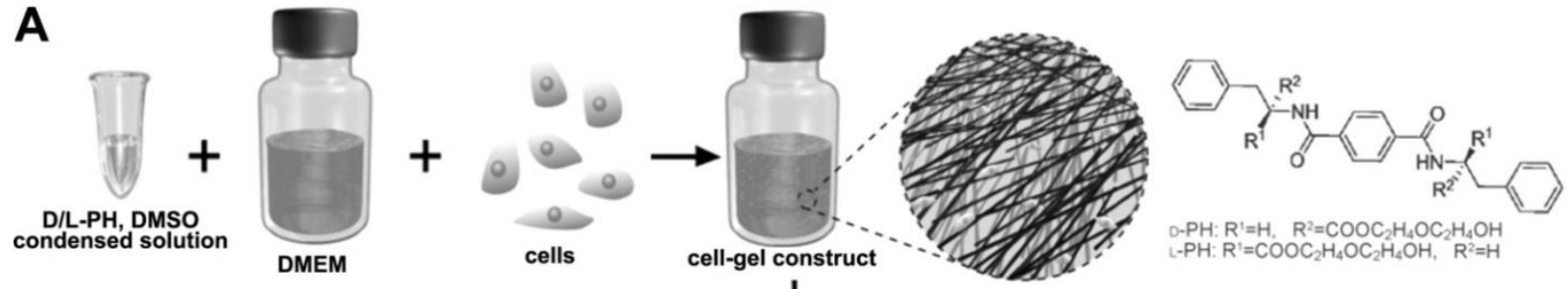

D-PH: $R^{\prime}=\mathrm{H}, \quad R^{2}=\mathrm{COOC}_{2} \mathrm{H}_{4} \mathrm{OC}_{2} \mathrm{H}_{4} \mathrm{OH}$
$-\mathrm{PH}: R^{1}=\mathrm{COOC}_{2} \mathrm{H}_{4} \mathrm{OC}_{2} \mathrm{H}_{4} \mathrm{OH}_{2}, \mathrm{R}^{2}=\mathrm{H}$
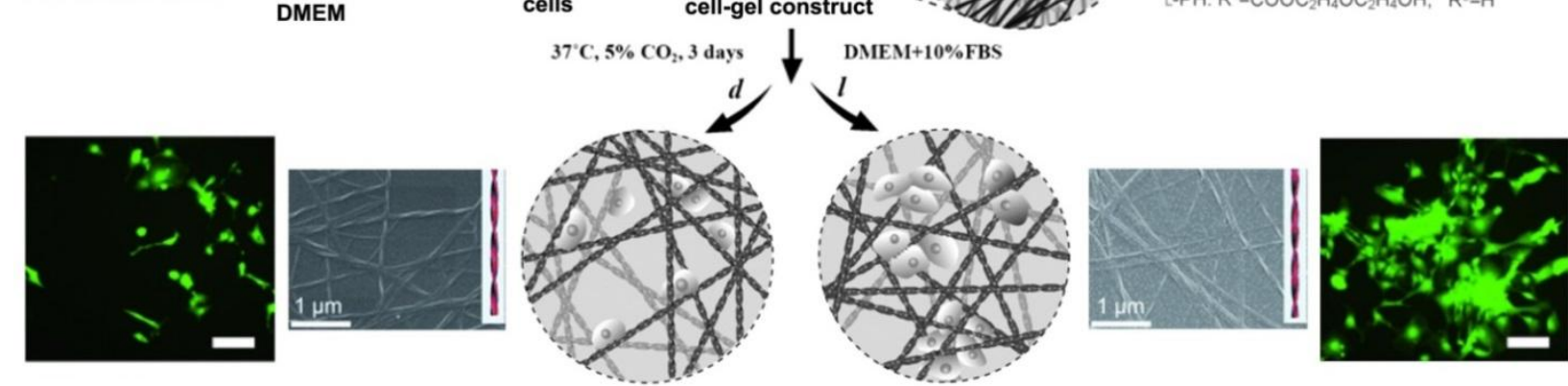

\section{B carbohydrate}
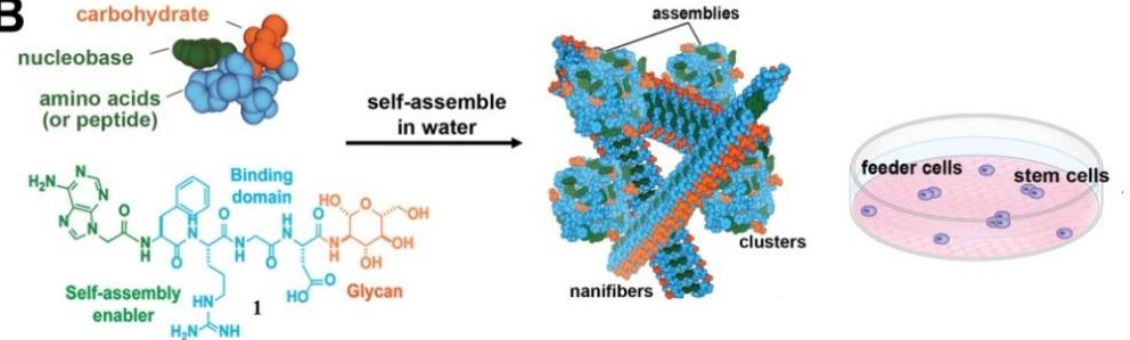

ES cells treated
by Ade-FRGD-glu

the assemblies of Ade-FRGD-Glu promots ES cell proliferation
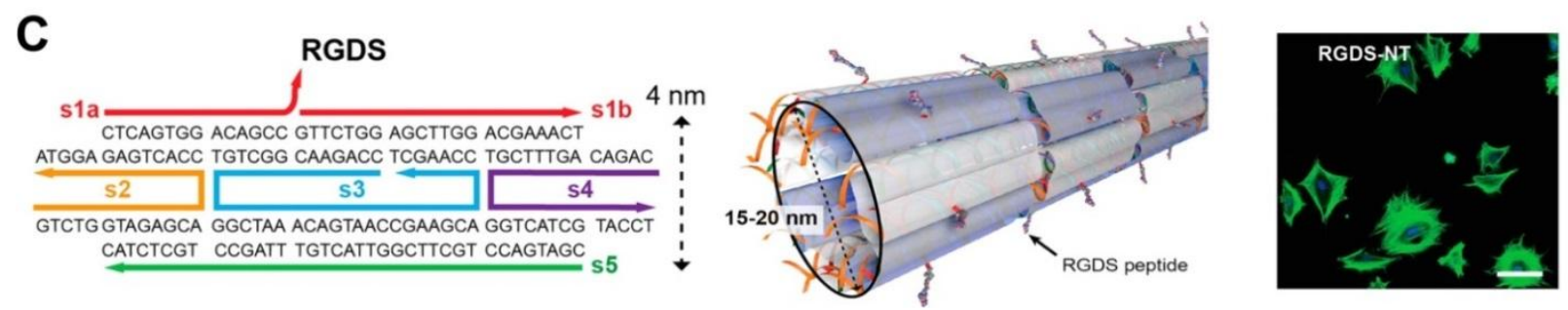

Figure 13. (A) The change of chirality of nanofibrous structures greatly influences cell adhesion and proliferation in the 3D extracellular matrix. (B) Supramolecular assemblies of a conjugate of nucleobase, amino acids and saccharide act as agonists for proliferation of embryonic stem cells. (C) The design of a DNA nanotube enhances the differentiation of neural stem cells into neurons. (Adapted from (C) 2014, 2015 American Chemical Society, 2014 Wiley-VCH Verlag GmbH \& Co. KGaA, Weinheim with permission. [57, 231, 234])

In the last decade, scientists have developed numerous cell compatible hydrogelators, some of which showed potential applications for inducing cell proliferation or differentiation.[235-237] While most of the hydrogelators consist of only amino acid, a unusual class of hydrogelators are the molecular 
conjugates of nucleobase, amino acids, and saccharide (e.g., Ade-FRGD-Glucosamine) (Figure 13B).[57] Unexpectedly, the assemblies of Ade-FRGD-Glucosamine promoted the proliferation of mouse embryonic stem cells (mES), indicating that the self-assembly of the conjugate of nucleobase, amino acids, and saccharide might mimic glycoconjugates to control the cell behaviors.[57] Stupp and coworkers reported the design of a DNA nanotube, which enhanced the differentiation of neural stem cells into neurons (Figure 13C).[234] The DNA nanotubes are self-assembled from five strands, one of which was functionalized by the RGDS sequence. They demonstrated that the co-assembled bioactive DNA/peptide-DNA supramolecular nanostructure promoted the cell adhesion and differentiation. Stupp et al. also reported the design of a peptide amphiphile (PA) that self-assembled into nanofibers, which could build up matrices and create self-supporting gels under cell culture conditions.[238] With phosphoserine residues in the peptide backbone, the peptide amphiphile promoted the hydroxyapatite formation in the culture medium. Experimental results suggested that human mesenchymal stem cell (hMSC) incorporated PA gels mineralized over time in the hMSC osteogenic medium supplemented with $\mathrm{CaCl}_{2}$, and the mineralized nanofibers promoted osteogenic differentiation of the hMSCs. 
increased collagen and vasculature
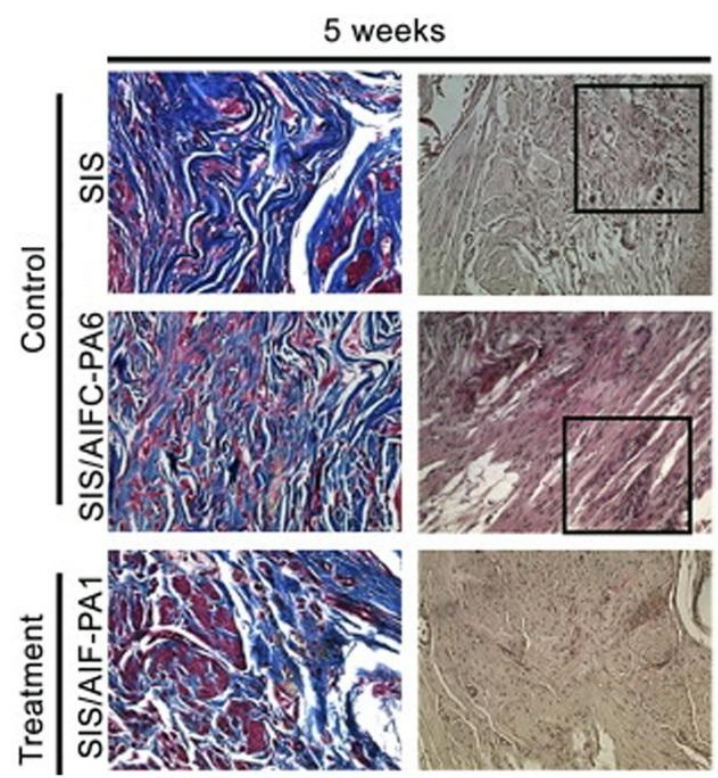

decreased inflammatory markers

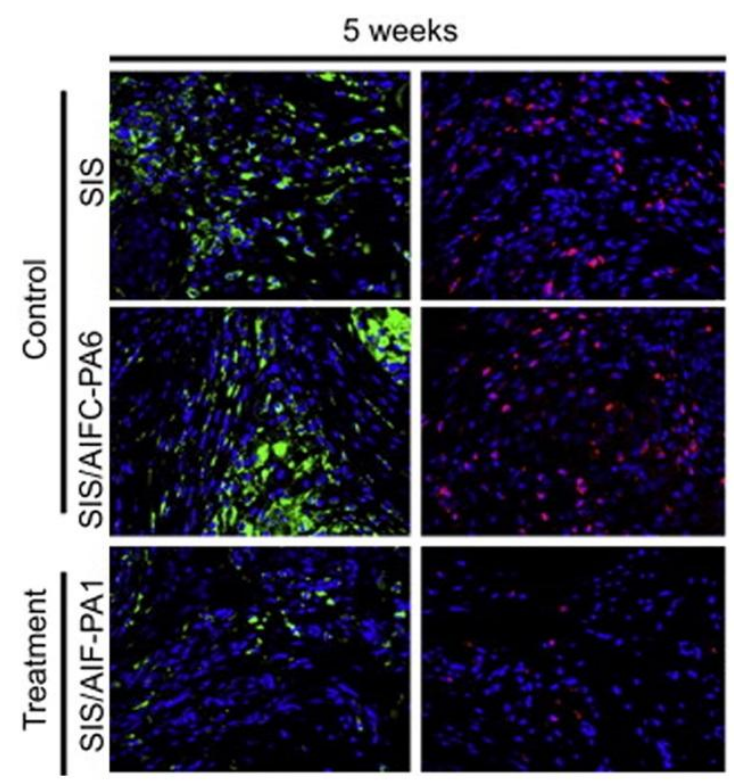

B
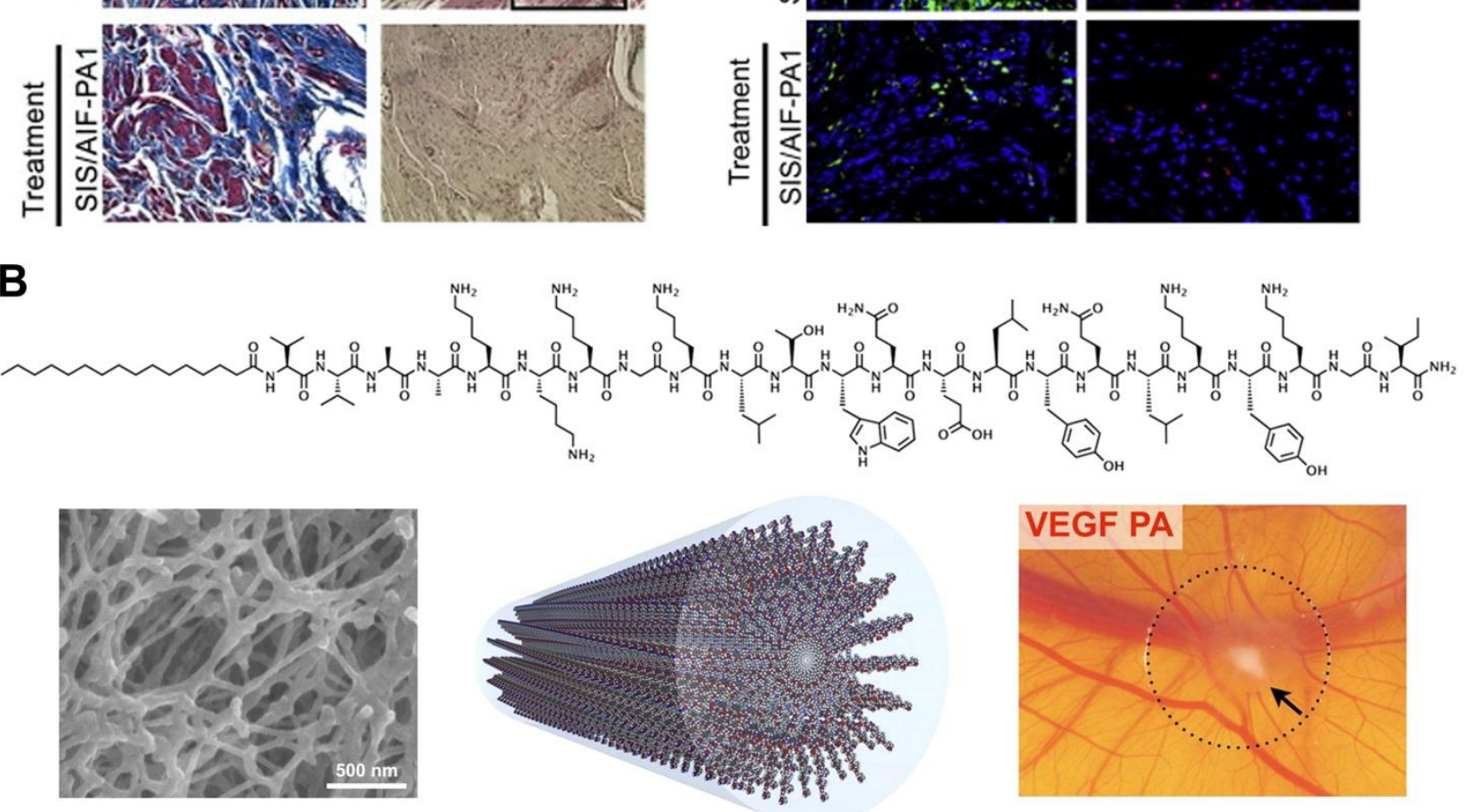

Figure 14. (A) An anti-inflammatory peptide amphiphile, AIF-PA1, has found applications for bladder regeneration. (B) A peptide amphiphile, that self-assembles to form cylindrical nanostructures, serves as a therapeutic strategy to regenerate microcirculation and ischemic tissue in cardiovascular diseases. (Adapted from @ 2014 Elsevier Ltd., 2010 National Academy of Sciences with permission.[239, 240])

In addition to cell culture, supramolecular biofunctional materials have also found increased applications in the field of tissue engineering. However, the development of tissue engineering using 
supramolecular materials is a slow progress due to the complexity and limited knowledge of the dynamics of biological processes. Meanwhile, due to their simple compositions and weak mechanical strength, supramolecular materials only played supplementary roles when being used in complicated endogenous processes. Although challenges remain, researchers have made significant progresses in exploring the utilizations of supramolecular biofunctional materials in tissue engineering.[111, 241-250] Stupp et al. reported the design of mono-domain gels of $\left(\mathrm{C}_{16}\right)-\mathrm{V}_{2} \mathrm{~A}_{2} \mathrm{E}_{2}-\left(\mathrm{NH}_{2}\right)$, which contained aligned peptide amphiphile (PA) nanofibers, for delivering sonic hedgehog $(\mathrm{SHH})$ protein to the cavernous nerve (CN).[251] This strategy imparted a unique advantage — directionality — for the delivery of proteins and the $\mathrm{SHH}$ to the $\mathrm{CN}$ via these aligned peptide amphiphile nanofibers. Indeed, this strategy promoted $\mathrm{CN}$ regeneration. The same group also reported a series of anti-inflammatory peptide amphiphiles (AIF-PAs) (e.g., AIF-PA1: $\mathrm{C}_{16}$-VVVAAAEEEMQMKKVLDS), for bladder regeneration (Figure 14A).[239] They observed significant regenerative advantages of the AIF-PAs such as potent angiogenic responses and limited tissue collagen accumulation. They demonstrated that AIF-PAs mitigated galvanic innate immune responses as well as providing a highly conducive regenerative environment. They also used heparinbinding peptide amphiphile (HBPA) and hyaluronic acid (HA) to form a self-assembled bioactive hierarchical membrane,[252] which had the potential capacity of binding and slowly releasing heparinbinding growth factors. Human mesenchymal stem cells (hMSCs) were able to attach to and remain viable on these membranes, which induced a significant and rapid enhancement of angiogenesis. By connecting $\mathrm{K}_{3} \mathrm{G}, \mathrm{V}_{2} \mathrm{~A}_{2}$, as well as $\mathrm{C}_{16}$ alkyl chain to the $\mathrm{N}$ terminus of the peptide sequence KLTWQELYQLKYKGI-NH ${ }_{2}$ that mimicked VEGF, one of the most potent angiogenic signaling proteins, Stupp et al. generated a series of peptide amphiphiles for self-assembling to form cylindrical nanostructures (Figure 14B).[240] The polyvalent self-assembling nanofibers were efficacious in a hindlimb ischemia model of cardiovascular disease - a promising result for developing synthetic therapeutic strategy to regenerate microcirculation and ischemic tissue in cardiovascular diseases. Using the supramolecular platform, Stupp et al. also have explored supramolecular nanofibers in bone regeneration and repair, [253] bioengineered peripheral nerve repair,[254] the design of optimal neuronal scaffold 
biomaterials,[255] improvement of the regenerative efficacy of cell-based strategies in ischemic tissue,[256] and many others applications.[257, 258] These works have stimulated others to explore the supramolecular biofunctional materials in the field of tissue regeneration. For example, Wang et al. reported the application of the self-assembly of peptide RADA $_{16}$-IKVAV in brain tissue engineering.[259] The hydrogel formed by RADA 16 -IKVAV enhanced survival of encapsulated neural stem cells, reduced the formation of glial astrocytes, and improved the regeneration and repair of injured brain. The same group also reported the design of two self-assembling peptides (RADA $16^{-}$GRGDS and RADA $16^{-}$YIGSR) $^{-}$ as well as their application in liver tissue regeneration.[260] These two peptides were able to selfassemble into $\beta$-sheet structures and have shown satisfactory gelation behavior and excellent hemostasis efficacy in a rat liver model. Galler et al. reported a cell adhesive, enzyme-cleavable hydrogel, capable of encapsulating dental pulp stem cells together with the growth factors via heparin binding.[261] In vivo results revealed that the resulting supramolecular biomaterial helped to form a vascularized soft connective tissue similar to dental pulp.

\subsection{Drug Delivery}

Recently, supramolecular hydrogels have emerged as an alternative to traditional polymeric hydrogels as promising carriers for therapeutic agents. The drugs or bioactive molecules can be either physically entrapped within the inert hydrogel matrix/scaffold or chemically conjugated to the self-assembling molecules. Thus, the applications of supramolecular hydrogels as drug delivery vehicles mainly fall into two categories: i) drugs encapsulated in hydrogels; [102, 262-277] ii) drugs conjugate covalently with the hydrogelators.[278-283]

Examples of the first category are the hydrogels carrying controllable amount of bioactive small molecules or drugs via noncovalent interaction to maximize access, retention, and therapy. Yang et al. have been actively involved in the design and development of a variety of multi-responsive supramolecular hydrogels for drug delivery. For example, they developed an innovative hydrogel based on charge attractions, in which the nanofibers were formed by the co-assembly of negative charged selfassembling peptides (Nap-GFFYGRGD) and positive charged responsive self-assembling components 
(Myristoyl choline or Ada-GFFYKKK-NH ${ }_{2}$ ). Myristoyl choline could respond to the enzyme acetyl choline esterase (ACE) and Ada motif could interact with methyl- $\beta-\mathrm{CD}$ (MCD) via ligand-receptor interaction. By controlling and modulating the enzymatic reactions or ligand-receptor interactions, they achieved sustainable release of drugs in biological systems.[284] Ulijn and co-workers reported a MMP-9 responsive peptide amphiphile, which self-assembled into micelles under physiological condition (Figure 15A).[285] In the presence of MMP-9, the self-assembled micelles transformed into nanofibers and released the encapsulated doxorubicin during the disassociation process. Thus, the micelles were able to serve as carriers for selectively delivering the anticancer drugs to tumor sites where MMP-9 was overexpressed. Pochan and Schneider demonstrated a curcumin delivery strategy for local delivery of curcumin to the targeting sites by encapsulating curcumin in a self-assembling peptide hydrogel.[286] The encapsulation of curcumin in the self-assembled hydrogel barely affected the biological activities of curcumin. Changing the concentration of the self-assembling peptide modulated the release rate and therapeutic efficacy of curcumin. Zhang and co-workers demonstrated the delivery of miRNA into live cells by a supramolecular hydrogel formed by Gly-Ala linked biphenyl-substituted tetrazole.[287] The hydrogel network delivered the encapsulated miRNA into the encapsulated cells, thus repressing the expression of target genes. Similarly, Kim et al. also used the molecular self-assembly derived from riboflavin to deliver VEGF-siRNA into human cells.[288] Liu et al. demonstrated the design of a metal ion triggered shrinkable supramolecular hydrogel, which showed excellent reversibility.[289] The unique shrinking features of the hydrogel were extremely useful in the controllable release of vitamin $\mathrm{B}_{1}$, as well as many other bioactive molecules. 


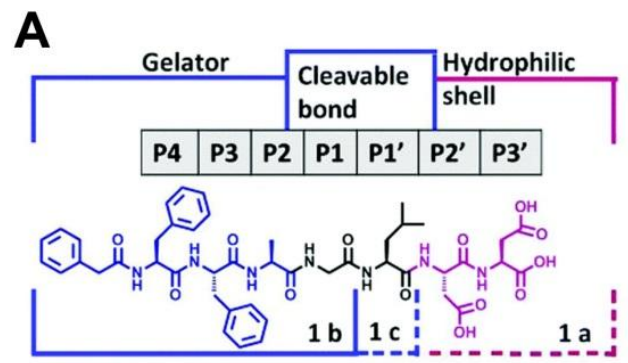

Fibre forming unit after enzyme cleavage

B

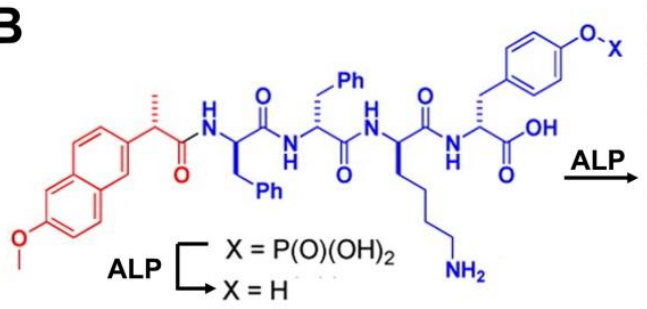

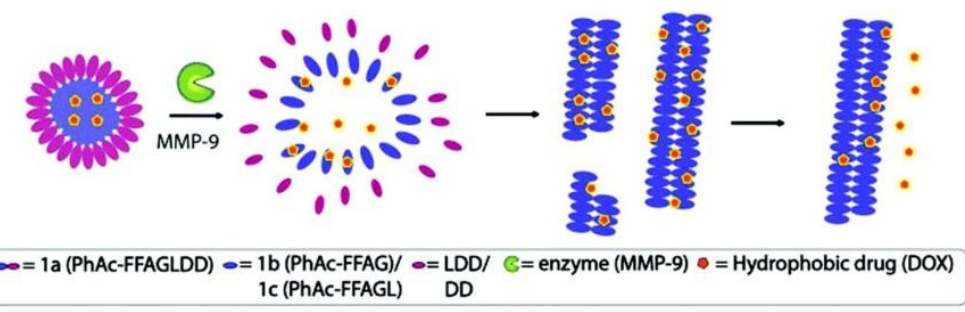
1c (PhAC-FFAGL) DD
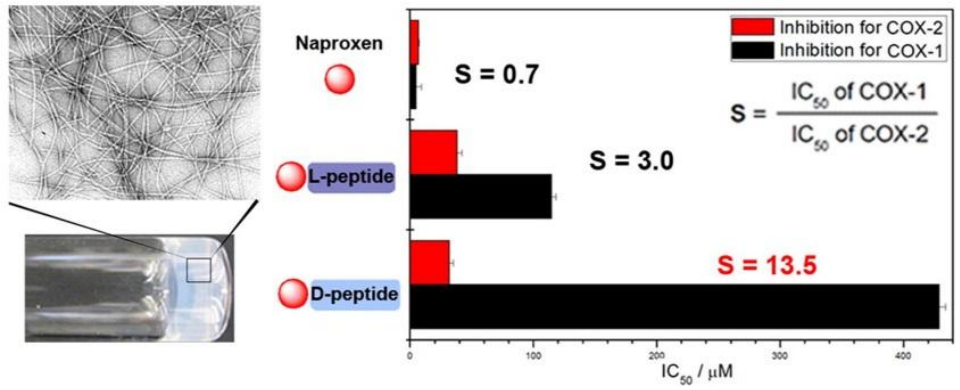

Figure 15. (A) MMP-9 triggered micelle-to-fiber transitions for slow release of doxorubicin. (B) Damino acids boost the selectivity and confer supramolecular hydrogels of NSAID (Adapted from @ 2015 Royal Society of Chemistry, 2012 American Chemical Society with permission.[31, 284, 285])

Besides physical encapsulation, covalently conjugating drugs with self-assembling peptide backbones, as a drug delivery strategy, has received considerable attentions. For example, connecting nonsteroidal anti-inflammatory drugs (NSAID) with D-peptides resulted in a group of multifunctional supramolecular hydrogelators (Figure 15 B).[31] Unexpectedly, the use of D-peptides significantly increased the selectivity of the drug toward COX-2, contributing to minimizing its adverse effect. The exploration of the conjugation of small peptides with other NSAIDs such as (R)-flurbiprofen, racemic flurbiprofen, racemic ibuprofen and aspirin[290] confirmed that such NSAIDs were able to serve as the motif to promote aromatic-aromatic interactions for promoting self-assembly. The resulting supramolecular hydrogels contributed to the development of bioactive molecules that have dual or multiple roles as therapeutic agents. This approach has led to the design of hydrogelators containing both NSAID and antiHIV drugs with small peptides as self-assembling backbones.[291] The NSAID containing selfassembling molecules were able to preserve the efficacy of both NSAID and the anti-HIV drugs. Yang et al. reported the synthesis of a $\beta$-galactosidase-responsive molecular hydrogelator with a nitric oxide (NO) 
donor.[292] The hydrogelator, which self-assembled to form hydrogels for local delivery of NO, was synthesized by conjugating a $\beta$-galactosidase-responsive caged NO molecule with a self-assembling short peptide (Nap-FFGGG). By adjusting the concentrations of $\beta$-galactosidase (for removing the capping group, sugar) loaded into the hydrogels, they were able to control the rate of NO release. The same group also reported the preparation of injectable hybrid hydrogels by mixing the hexameric proteins of $2 \mathrm{~T}, 4 \mathrm{~T}$, and 6T with a peptide sequence NapGFFYGGGWRESAI.[293] The hexameric proteins of 2T, 4T, and 6T served as crosslinkers to interconnect the self-assembling nanofibers of NapGFFYGGGWRESAI, leading to the formation of hydrogels with tunable mechanical properties. Another drug delivery hydrogel, reported by Yang et al., is based on the conjugation of a peptide and two complementary anti-cancer drugs.[294] Upon the treatment of dithiothreitol (DTT), Dex-FFFK(Taxol/HCPT)E-ss-EE turned into Dex-FFFK(Taxol/HCPT)E, which self-assembled to form hydrogels for continuous co-delivery of anticancer drugs with enhanced retention time. Stupp et al. developed a peptide covalently containing hydrazide. This peptide self-assembled to form hydrogels for sustainable hydrazide release. Zhong and coworkers designed a synergistic dual-targeting hydrogel that was able to transport drugs for specifically targeting tumors.[295] Experimental results revealed the accumulation of hydrogel within the cancer cells in vitro as well as in breast tumor in vivo. They confirmed that the estrone and RGD peptide acted as the tumor-targeting moieties and contributed to the selective accumulation of the hydrogel in the breast tumor. The biocompatible and synergistic dual-targeting hydrogel efficiently assisted the release of the drug inside the cells.

\subsection{Cancer Therapy}

Although the understanding of cancer biology and the cancer therapies (e.g., traditional surgery, radiation and chemotherapy, hormone therapy, immunotherapy, stem cell transplant, and precision medicine) have progressed considerably in the last decade, cancer still remains one of the major challenges to public health.[296] Meanwhile, despite extensive efforts, pressing problems in the treatment of cancer are still emerging, such as drug resistance resulted from target mutations or redundant pathways. Thus, there is still an urgent need to develop innovative approaches for treating cancers. As discussed in 
the previous section, supramolecular hydrogels have already shown promises as possible cancer drug delivery systems.[277, 295, 297-300] In this section we discuss the recent development in the use of supramolecular hydrogelators themselves as innovative anticancer therapeutics.

The investigation of the unusual cytotoxic profile of a versatile self-assembling motif, a diphenylalanine derivative (Nap-FF),[179] has found that the nanofibers of Nap-FF, referred as prion-like nanofibrils of small molecules (PriSM), were able to selectively inhibit glioblastoma cancer cells over neuronal cell in cell culture and effectively inhibit xenograft tumor in animal models (Figure 9A).[129, 138, 139] Mechanistic investigation revealed that the PriSM selectively inhibited different types of cancer cells, while remained innocuous to normal cells like bone marrow stromal cells (i.e., HS-5) and neuronal cells (i.e., PC12) at the concentration above critical concentration for self-assembly. After accumulating inside cancer cells via macropinocytosis, the self-assembly of the dipeptide derivatives impeded the dynamics of cytoskeletal filaments (e.g., microtubules, actins), inducing cell apoptosis. The modification of Nap-FF at its C-terminal with an ester bond resulted in a novel precursor, which was able to enter cells and self-assemble to form nanofibers upon hydrolysis catalyzed by carboxylesterase (CES). The resulting nanofibers killed most of human cancer cells (i.e., HeLa) while being nontoxic to mouse fibroblast cells (i.e., NIH3T3) due to significantly higher esterase level in HeLa cell than NIH3T3 cell.[301] The unexpected selectivity and new mechanism of molecular nanofibers inside cell against cancer have led to the utilization of intracellular EISA of D-peptide for a combination therapy that used traditional anticancer drugs, such as cisplatin.[23, 302] As shown in Figure 16A, the designed small D-peptide precursors, as a substrate of carboxylesterase (CES), turned into hydrogelators that self-assembled in water to form nanofibers upon the cleavage of ester bond catalyzed by CES. At certain concentration, the precursors were innocuous to cells, but they dramatically boosted the activity of cisplatin against drugresistant ovarian cancer cells by 2 - to 3 -folds.[303]

Maruyama et al. also utilized enzymes to instruct the intracellular self-assembly of a peptide derivative to selectively inhibit cancer cells that express high level of metalloproteinase-7 (MMP-7) (Figure 16B).[304] The precursors developed by them became hydrogelators extracellularly in the 
presence of MMP-7, which self-assembled to form nanofibers after entering cells, inducing cell death. Notably, this small molecule exhibited remarkable cytotoxicity to several cancer cell lines while showed low cytotoxicity to normal cells due to the fact that cancer cells secrete excessive amount of MMP-7. Based on the report of the intracellular EISA of L-peptide derivative (Nap-FFK $\left.{ }_{p} Y\right),[119,305,306]$ Gao et al. reported the use of Nap-FFK $\mathrm{p}$ to co-assemble with indocyanine green (ICG) for in vivo cancer theranostics. The formation of ICG-doped nanofibers not only enhanced the tumor uptake of ICG (by 25fold compared with free ICG), but also largely extended the retention time of ICG in tumor site, resulting in complete and precise tumor elimination by laser ablation (Figure 16C).[307] 
B
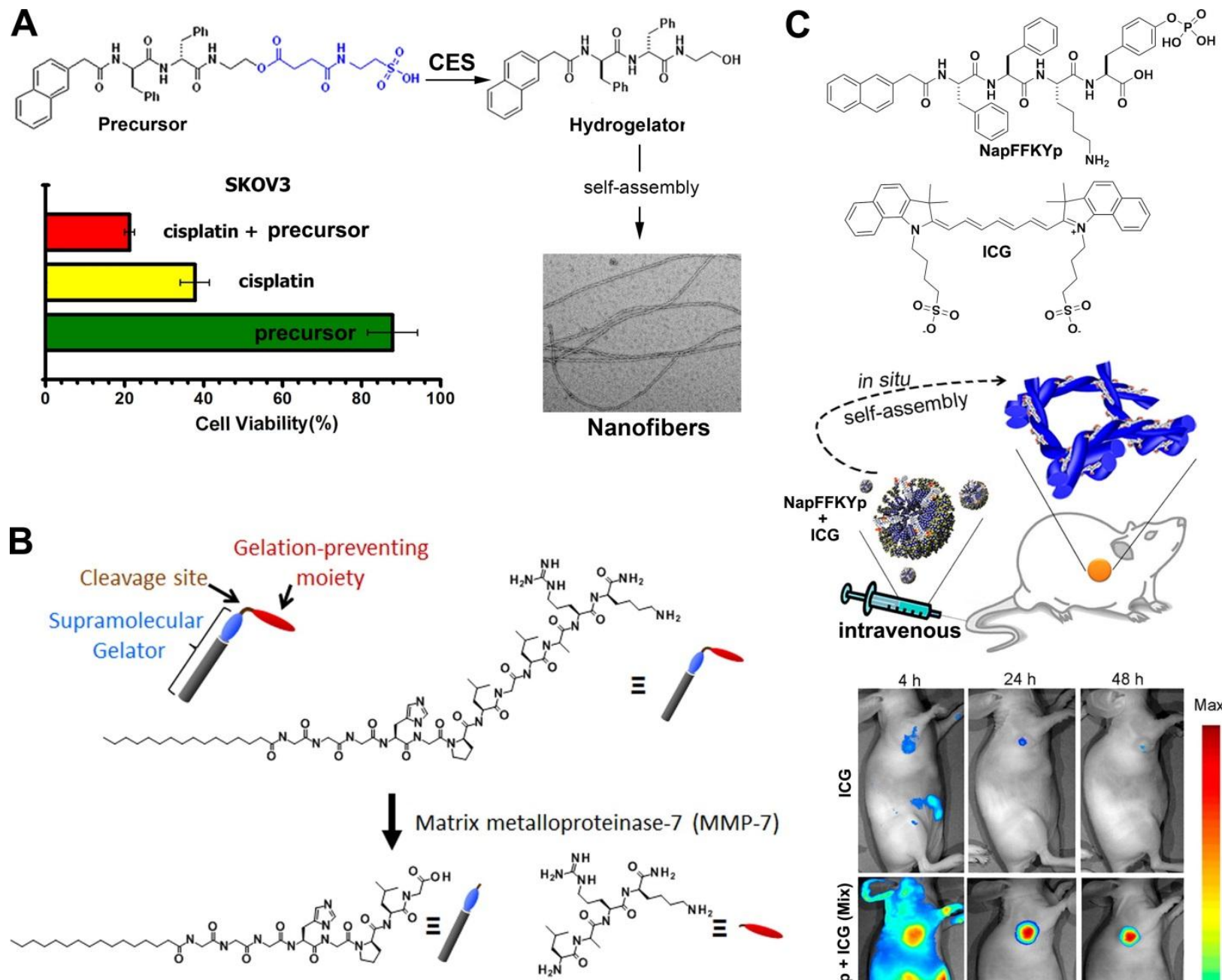

Intracellular self-assembly
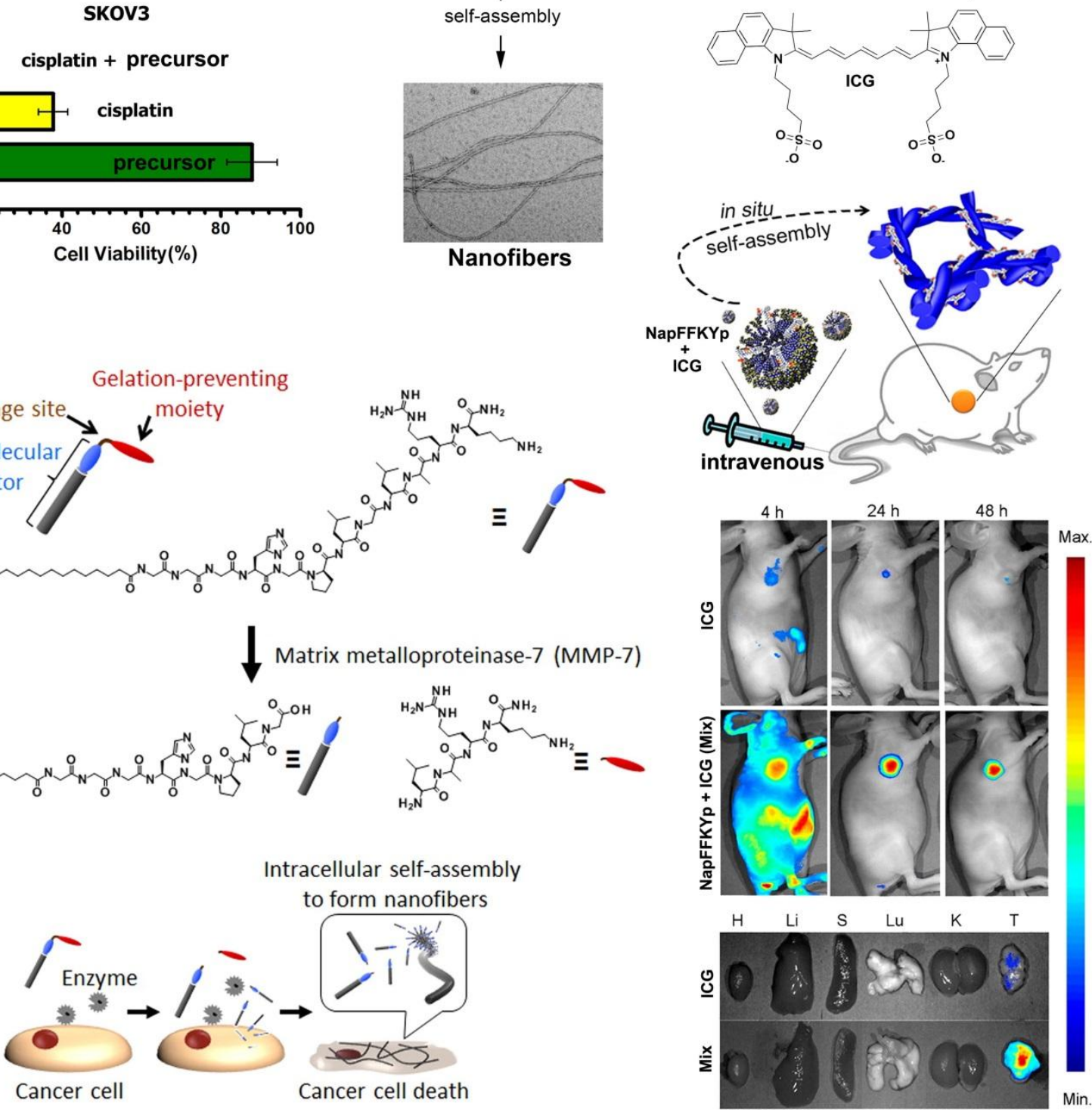

Figure 16. (A) Enzyme-instructed intracellular molecular self-assembly of a D-peptide derivative boosts activity of cisplatin against drug-resistant ovarian cancer cells (SKOV3). (B) MMP-7 mediated intracellular self-assembly of a peptide derivative selectively inhibits cancer cells. (C) An endogenous phosphatase-triggered co-assembly strategy to form tumor-specific indocyanine green (ICG)-doped nanofibers for cancer theranostics. (Adapted from (C) 2015 Wiley-VCH Verlag GmbH \& Co. KGaA, Weinheim, 2015 American Chemical Society with permission. [23, 304, 307]) 


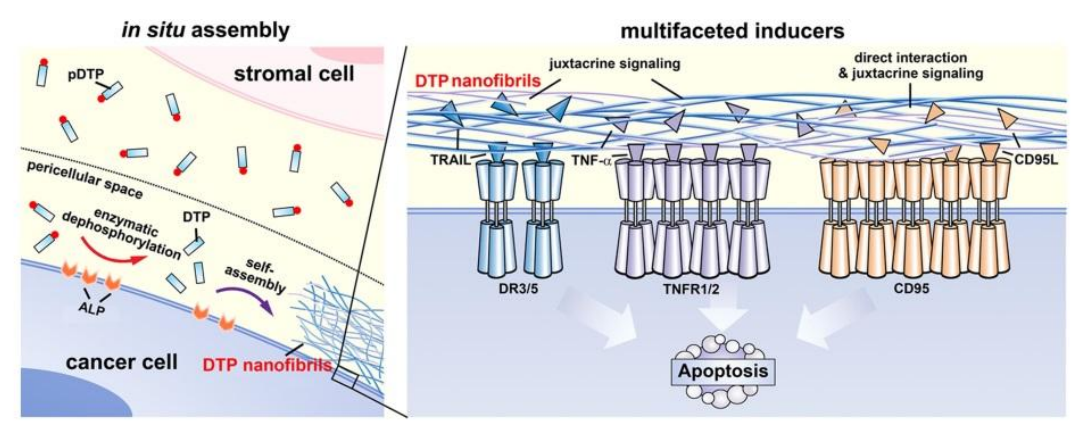

B
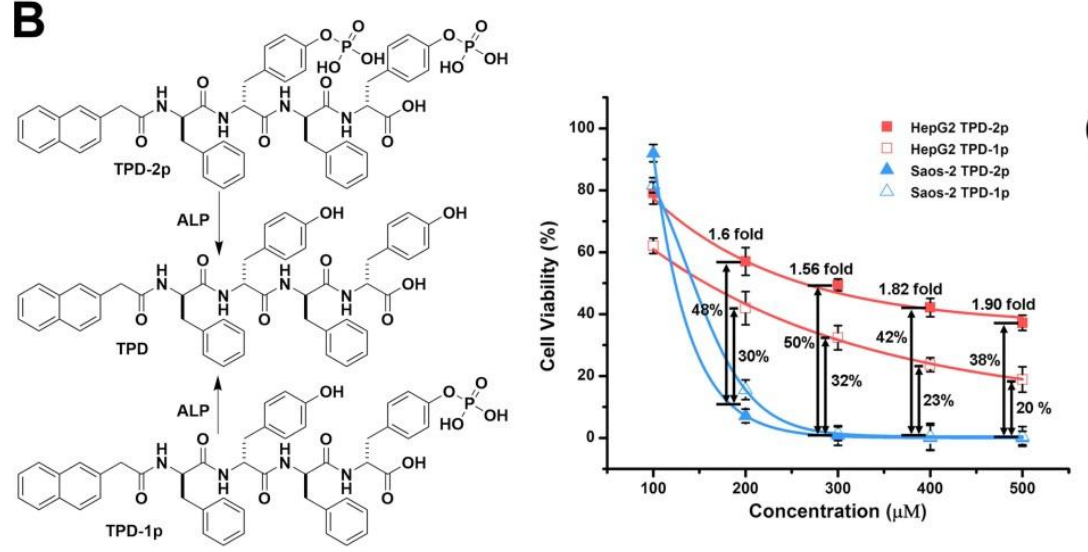

\section{C}
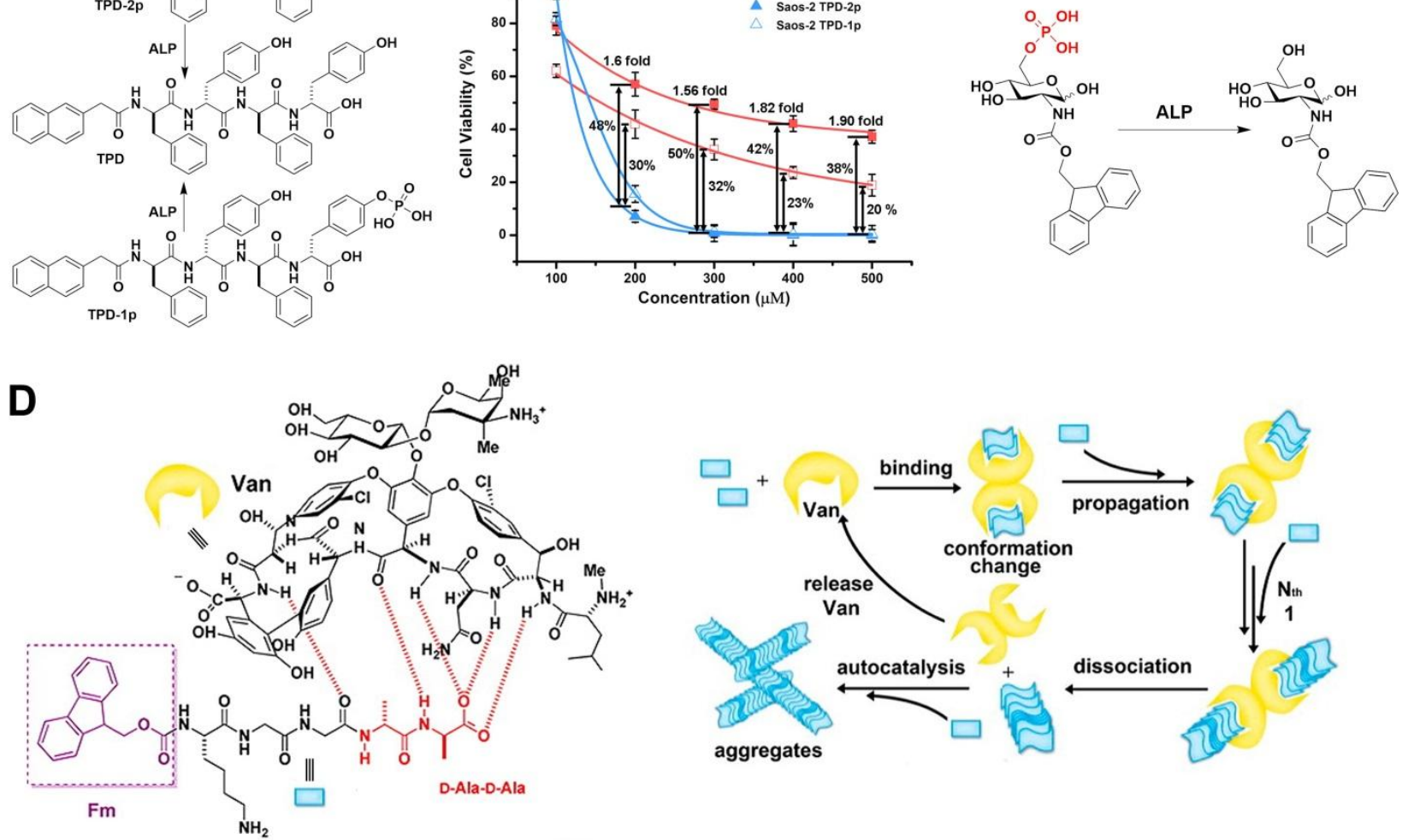

Figure 17. (A) Enzyme-instructed pericellular self-assembly of a small D-peptide derivative selectively inhibits cancer cells over normal cells. (B) Regulating the rate of molecular self-assembly for selectively targeting cancer cells by tailoring the number of enzymatic triggers on a single molecule. (C) Enzymed mediated self-assembly of an aromatic carbohydrate amphiphile selectively inhibits cancer cells. (D) Ligand-receptor interaction (i.e., vancomycin and D-Ala-D-Ala) to catalyze the aggregation of small molecules via an auto catalysis manner, which induce cell necroptosis. (Adapted from (C) 2014, 2016 

Chemical Society with permission. [20, 107, 308-310])

While the intracellular self-assembly of small molecules to form nanostructures for inhibiting cancer cells are having more instances, extracellular self-assembly of small molecule unexpectedly has shown the ability to form pericellular nanofibers for selective inhibiting cancer cells over normal ones (Figure 17A)[107]. This observation is the first example of using ectoenzyme to regulate the self-assembly of small molecules for controlling the fate of cells. Mechanism studies revealed that the selectivity came from that cancer cells overexpress certain phosphatase on their surface, as was confirmed by the fact that adding phosphatase inhibitor largely eliminated the cytotoxicity of the precursors. Notably, in the coculture of cancer cells (i.e., HeLa) and normal cell (i.e., HS-5), which largely mimicked the tumor microenvironment, the ectophosphatase-instructed hydrogelation of the designed D-peptide derivative mainly occurred in the pericellular space of cancer cells (HeLa), inducing cancer cell death, while the majority of the normal cells (HS-5) remained alive (Figure 17 A).[107, 311] Mechanistic investigation indicated that the nanofibers, selectively formed around the cancer cells overexpressing phosphatases, acted as multifaceted inducers of apoptosis by interacting with extrinsic cell death ligands and receptors (Figure 17A).[311] In a related study, the minimal C-terminal modification (only a $2 \%$ change of the molecular weight) of that D-peptide significant enhanced the anticancer potency, decreasing the $\mathrm{IC}_{90}$ against cancer cells (i.e., Saos-2) from $470 \mu \mathrm{M}$ to $36 \mu \mathrm{M}$.[308] In fact, the enhancement of efficacy is remarkable because the anticancer potency of the assemblies of the D-peptide derivative is even higher than that of a clinical used drug (e.g., carboplatin) against the same cells. These promising results motivated a comprehensive molecular and cellular validation of EISA as a multiple step process for selectively killing cancer cells that overexpressed alkaline phosphatase (ALPs). The use of a series of Dtetrapeptides containing zero, one or two enzymatic triggers[21] demonstrated that the peptides without phosphate (i.e., enzymatic trigger) were innocuous to all the cell lines, while both the mono- and diphosphorylated peptides selectively inhibited the cancer cells but sparing normal cells. The observation that the mono- and diphosphorylated peptides exhibited different cytotoxicity against different cancer cell 
lines, in fact, has led to the demonstration of selective inhibition of osteosarcoma cells over hepatocytes by regulating the rate of molecular self-assembly (Figure 17B).[20] Besides promising site selective drug delivery, this result opens a way to use the expression level (or activity) of enzymes to autonomously dose the drugs for selectively inhibiting cancer cells, which is certainly worth further exploration.

Another report on EISA is the conjugate of cholesterol and phosphotyrosine to selectively inhibit drug-resistant ovarian cancer cells by simultaneously activating extrinsic (e.g., DR4 and DR5) and intrinsic (caspase 3 and caspase 8) cell death signaling.[312] Notably, the $\mathrm{IC}_{50}$ of this conjugates is about five times lower than the $\mathrm{IC}_{50}$ of cisplatin (a clinical drug) against platinum-resistant ovarian cancer cells (A2780cis), promising to be an innovative anticancer drug. The feasibility to utilize extracellular EISA for pericellular hydrogelation that inhibited cancer cell selectively was also confirmed by Pires and Ulijn, who reported an aromatic, phosphorylated derivative of carbohydrate for pericellular EISA (Figure 17C).[309] Treating osteosarcoma Saos-2 cell and prechondrocytes ATDC5 cell (expressing 15-20 times lower ALP on the cell surface than on Saos-2 surface) with the designed carbohydrate amphiphile resulted in different consequences - the amphiphiles were more inhibitory to Saos-2 cells than to ATDC5 cell. This concept is also valid for other self-assembly entities, such as nanoparticles.[313, 314] For example, the D-phosphotyrosine decorated magnetic nanoparticles selectively captured and killed cancer cells upon the dephosphorylation by alkaline phosphatase overexpressed on cancer cell surfaces.[313, 314] Specifically, in-situ dephosphorylation on the surface of cancer cells resulted in the aggregates of the nanoparticles to adhere to the cell surface. With the assistance of a magnet, cancer cells can be captured or sorted. Changing the chirality of phosphotyrosine abolished the capturing ability and inhibitory effect of the nanoparticles, indicating a facile approach that used chirality to control the reaction-diffusion of nanoparticles for selectively targeting cancer cells.[315]

Besides EISA, ligand-receptor interaction (e.g., vancomycin binding D-Ala-D-Ala) also was able to catalyze the self-assembly of small molecules in an autocatalysis manner, which resulted in cell death because the resulting aggregates adhered to the cell surface to induce necroptosis.[316-318] Mechanism 
investigation revealed that the cytotoxicity largely depended on the ligand-receptor interaction and aromatic-aromatic interactions (Figure 17D).[310]

\subsection{Imaging}

Fluorescent imaging, now a popular and important method in biological research, can provide new perspective and precise details on the structural organizations of cells, the sophisticated cellular events, and the dynamics of biomolecular assemblies over wide timescales. Since small self-assembling molecules (e.g., hydrogelators) have found increased applications in biology and biomedicine, it is important and necessary to gain a comprehensive understanding of their self-assembly behavior in biological environment, their interactions with organelles, and their dynamics in cellular milieu. Therefore, considerable efforts have focused on combining fluorescent imaging and supramolecular chemistry (e.g., molecular recognition or molecular self-assembly) because fluorescent imaging is a straightforward yet revealing approach to distinguish, depict, and record the behavior of supramolecular assemblies in cellular environment. In general, synthetic fluorophores have a small size, exhibit many colors spanning the whole spectrum of visible light, are readily available for chemical modification, and have advantages of brightness, photostability, and photoswitchibility. Thus, they have the potential to substantially accelerate the broad applications of supramolecular biofunctional materials. The covalent incorporation of a suitable fluorophore to a self-assembling small molecule not only allows monitoring of the emergent properties of supramolecular assemblies, but also reveals the responses of biological systems (mainly cells) upon interaction of the supramolecular assemblies. In this section, we mainly focus on the applications of fluorescent hydrogelators for imaging in cellular milieu. 

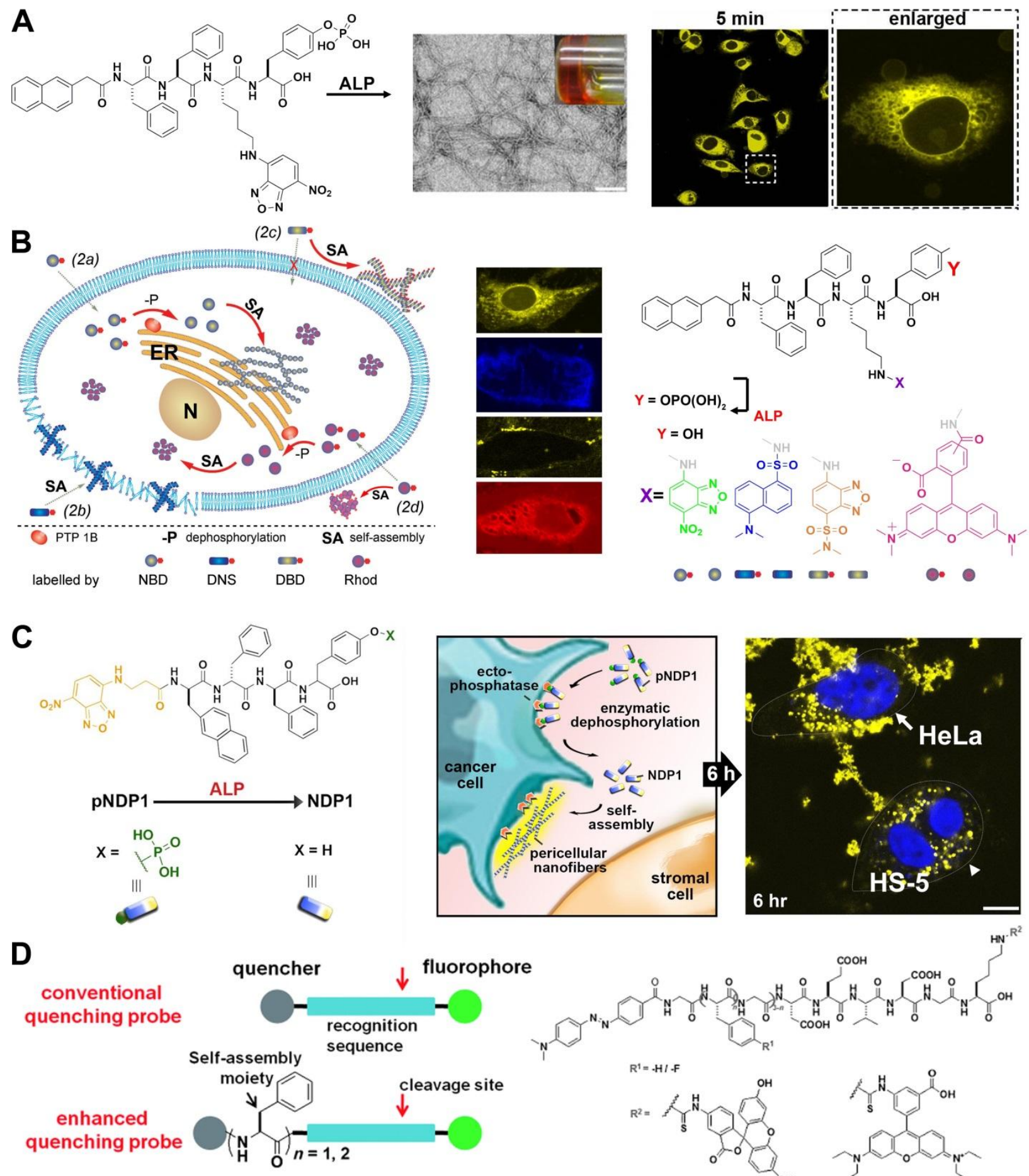

$6 \mathrm{hr}$

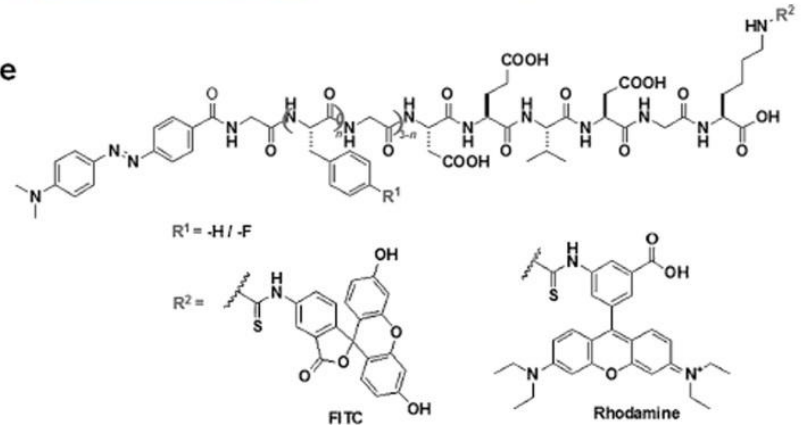

Figure 18. (A) Imaging enzyme-triggered supramolecular self-assembly of a small molecule inside cells.

(B) Imaging assembly-dependent spatial distribution of small molecules containing different fluorophores in a cellular environment. (C) EISA for spatiotemporal profiling of the activities of ALP on live cells. (D) The design of a probe with lower background lfuorescence compared to conventioal quenched probes by 
optimized molecular self-assembly. (Adapted from (C) 20122012 Macmillan Publishers Limited, part of Springer Nature, 2012 American Chemical Society, 2016 Elsevier Inc., 2015 Wiley-VCH Verlag GmbH \& Co. KGaA, Weinheim with permission.[119, 306, 319, 320])

Vancomycin (Van) is a powerful glycopeptide antibiotic against methicillin-resistant Gram-positive bacteria by specific binding to D-Ala-D-Ala sequence presented in bacteria cell wall. Utilizing this property and based on the self-assembly of vancomycin on bacteria surface,[201] Xing et al. developed a simple molecular strategy of divalent vancomycin-porphyrin for application in fluorescent imaging of vancomycin sensitive and resistant strains.[321] However, the imaging of self-assembly of small molecules inside cell requires more than just attaching a fluorophore, especially for the imaging of EISA in cellular milieu. The first report of the imaging of EISA of small molecules inside live cells was on the phosphatase-catalyzed self-assembly inside cells. The conjugate of a fluorophore to a self-assembling backbone with a phosphatase trigger (i.e., phosphotyrosine as a substrate of ALP) afforded a precursor $\left(\mathrm{Nap}-\mathrm{FFK}(\mathrm{NBD})_{\mathrm{p}} \mathrm{Y}\right)$ (Figure 18A) with good solubility so that the precursors dissolved well in physiological condition and diffused freely to make a homogeneous distribution of fluorophores. Upon the enzymatic dephosphorylation by ALP, the precursors turned into hydrogelators with decreased solubility to self-assemble to form nanofibers, which had fluorophores with much higher density thus to exhibit enhanced fluorescence. The principle for imaging molecular self-assembly inside live cells is that the resulting nanofibers are distinctly visible due to condensed and localized fluorophores after EISA (Figure 18A).[119] In another study about three fluorescent analogues consisting of the same L-peptide backbone, but with different fluorophores on the side chain of lysine, the fluorophores largely affected the EISA behavior of these molecules, thus further affecting the distribution of these small molecules in cellular environment (Figure 18B).[306] For example, the nanofibers of dansyl-bearing hydrogelators mainly adhered to the cell membrane and also exhibited significant cytotoxicity. The assemblies with DBD fluorophores were unable to enter cells and remained innocuous to cells. The molecules of rhodamine, being unable to self-assemble, showed homogenous fluorescence inside and outside of cells and barely affected the cells. These observations revealed that EISA could control the fate of cells via 
modulating the spatiotemporal distribution of the nanoscale assemblies of small molecules. To avoid the disadvantages of fluorescence labeling (e.g., alteration of intermolecular interactions, the need to confirm the innocence of the fluorophores, or the high cost of fluorophores), a doping method was used to assist the imaging of the self-assembly of small molecules without fluorescence inside mammalian cells. That was, the incorporation of tiny amount of dansyl-labeled hydrogelator into the self-assembly of the native molecules was able to determine the formation, localization, and progression of molecular assemblies generated from the non-fluorescent small molecular hydrogelators. The images taken with correlative light and electron microscopy (CLEM) confirmed the presence of ultra-structural assemblies of these precursors upon enzymatic catalysis in a cellular level.[305] The use of D-amino acids to replace the Lamino acids in the self-assembling molecule containing NBD fluorophore (mentioned above,[119] NapFFK(NBD) $)_{\mathrm{p}} \mathrm{Y}$ in Figure 18A) yielded the enantiomer of the fluorescent precursor. Unexpectedly, the resulting D-enantiomer is still an excellent substrate of ALP. It, in the presence of the phosphatase, turned into a self-assembling molecule to form nanofibers.[30] Thus this D-peptide based precursors, having greatly enhanced biostability, was also able to serve as an effective molecular probe for imaging intracellular molecular self-assembly instructed by phosphatases.

Because NBD exhibited enhanced fluorescence upon the formation of nanofibers and D-peptides ensured proteolytic stability in cellular environment, a precursor containing two parts-NBD and a phosphorylated, self-assembling D-peptide backbone-acted as a fluorescent probe to profile the activities of ectophosphatases on live cells by EISA to form localized, fluorescent, biocompatible and non-diffusive nanofibers (Figure 18C).[319] This precursor revealed different ALP levels on different cell surfaces and even worked in the co-culture of cancer and normal cells. Being a supplementary approach to the existing methods, this activity probe for ectophosphatase would contribute to our understanding of reversible phosphorylation-dephosphorylation in extracellular domains.

Utilizing the environment-sensitive property of NBD motif, Yang et al. designed a NBD-capped molecular probe (i.e., NBD-FFYEEGGH) consisting of three parts: the NBD (providing environmentsensitive fluorescent signal), the FFYEE sequence (rendering the molecule better self-assembly capacity 
and brighter fluorescence after self-assembly), and GGH motif (specifically binding to $\mathrm{Cu}^{2+}$, making it sensitive to the present of $\mathrm{Cu}^{2+}$ ). Based on that the specific binding to $\mathrm{Cu}^{2+}$ efficiently quenched the fluorescence of the formed nanofibers, Yang and co-workers confirmed the molecule as an excellent probe for the detection of $\mathrm{Cu}^{2+}$ in vitro and in cellular environment. Moreover, the incorporation of an enzyme cleavage site DEVD into this molecule afforded another probe NBD-FFFDEVDGGH, which not only was able to detect the presence of $\mathrm{Cu}^{2+}$, but also was used for the detection of caspase-3 in vitro and in cells.[322]

Yang et al. found that the supramolecular self-assembly containing 4-fluoro phenylalanine $\left({ }^{\mathrm{f}} \mathrm{F}\right)$ was able to greatly enhance the quenching effect of the quencher (i.e., dabcyl) in molecular probes by synergistic effects of FRET and ACQ. To optimize the quenching effect, they simply varied the number of ${ }^{\mathrm{f}} \mathrm{F}$ being incorporated into the molecular backbone. Briefly, they conjugated a quencher dabcyl and a fluorophore (rhodamine or FITC) to the N-terminal and side chain of a peptide backbone $\left(\mathrm{GF}_{\mathrm{n}} \mathrm{G}_{(3-}\right.$ ${ }_{n}$ DEVDGK) and also introduced aromatic ${ }^{\mathrm{f}} \mathrm{F}$ on phenylalanine. The self-assembly of the resulting molecule largely enhanced the quenching effect of dabcyl to FITC, and this molecules was able to rapidly respond to caspase-3 to recover its fluorescence due to the presence of enzyme cleavage site DEVD (Figure 18D).[320] Ding and Yang et al. developed a highly sensitive colloidal fluorophore, as a turn-on bioprobe (TPE-GFFYK(DVEDEEAc)), through facile incorporation of a self-assembling peptide sequence GFFY between a fluorophore TPE and a caspase-3 cleavage site. This probe fluoresced more in the presence of caspase-3 since the removal of DVEDEEAc segment by enzyme promoted the selfassembly of the remaining TPE-GFFYK fragment. In this case this probe could be used for imaging caspase-3.[323] Yang et al. also designed and synthesized a far-red/near-infrared (FR/NIR) fluorescence light-up probe (DBT-2EEGWRESAI) by conjugating two peptides with same sequences (EEGWRESAI, tax-interacting protein-1 (TIP-1) specific binding ligands) to both sides of a fluorophore 4,7-di(thiophen2-yl)-2,1,3-benzothiadiazole (DBT). DBT is an environment-sensitive dye-in aqueous solutions, the probe DBT-2EEGWRESAI is weakly fluorescent while it lighted up upon the specific binding with TIP-1 or polyprotein ULD-TIP-1 to form nanofiber network or spherical nano-complexes. The self-assembly- 
induced FR/NIR fluorescence turn-on made DBT-2EEGWRESAI an excellent probe for detecting and visualizing specific protein/polyprotein-peptide interactions in both cell-free solutions and in live bacteria.[324]

Besides supramolecular assemblies, molecular beacon[325] is another useful imaging tool based on nanoscale assemblies to reveal cellular and subcellular activities at molecular level by converting cellular events into optical signals. In 2013, Cui et al. reported a rational design of supramolecular spherical nanobeacons that served as a probe of cathepsin B.[326] Later in 2016, the same group developed another positively charged spherical nanobeacon for intracellular sensing of cathepsin B. They demonstrated that self-assembly of the well-designed molecules into filamentous nanobeacons significantly reduced their internalization by cancer cells, a useful property for probing extracellular protease activities.[327]

In addition to fluorescent imaging, magnetic resonance imaging (MRI) is another useful approach to report real-time molecule distribution because of its superior spatiotemporal resolution and soft tissue contrast. There have been several attempts to incorporate MRI modalities into supramolecular assemblies for real-time imaging applications. For example, chemical conjugation of a MRI modality into a selfassembling peptide derivative yielded a dynamic material that changed shape and size in response to slight $\mathrm{pH}$ changes in solutions that mimicked serum. This morphological change was rapid and reversible and occurred under thermodynamic equilibrium, which was ideal for in vivo MRI imaging.[328] To track the fate of bioactive supramolecular nanostructures, Stupp and Meade designed a series of PA molecules based on the well-established $\beta$-sheet peptide $\left(\mathrm{V}_{3} \mathrm{~A}_{3}\right)$ conjugated to macrocyclic Gd(III) labels for MRI imaging. They confirmed the feasibility of such strategy as an effective tracking method for PA materials in vivo over the timescale of days.[329] Using the Gd-based compounds and materials, Cui et al. also developed a supramolecular strategy to convert an FDA-approved anticancer drug, Pemetrexed, to a molecular hydrogelator with inherent chemical exchange saturation transfer (CEST) MRI signals.[330] The CEST MRI signal enabled noninvasive monitoring of the in vivo distribution and drug release profile of Pemetrexed.

\subsection{Immunology}


Immunology is an important branch of biological and medical sciences, where there has been recent interest in designing and developing novel therapies to modulate the immune system for treating cancers. Generally, supramolecular systems are able to modulate the responses of immune systems through either drug delivery or controlled presentation of immune signals (e.g., short peptide epitopes or antigens). Supramolecular hydrogels/assemblies, possessing artificial scaffolds that present multiple cell-interacting entities in spatially resolved network, are being explored as a new choice of adjuvant or delivery vehicles in immunotherapies.[18] Since we have discussed the supramolecular hydrogel for drug delivery in previous section, we will focus on presenting immunomodulating signals in this part. More specifically, the applications of supramolecular systems in immunology discussed here center on vaccine adjuvants and self-adjuvanting vaccines.

While safe and potent adjuvants are always in demand, supramolecular hydrogels made of peptide derivatives can serve as excellent candidates for adjuvants in immunotherapies and infectious diseases. For example, Collier et al. developed a self-assembling peptide OVA-Q11,[331] which contained three parts: the self-assembling transglutaminase substrate (Q-11), a spacer, and an epitope of OVA $323-339 \cdot[332]$ This peptide self-assembled to form long, unbranched nanofibers that displayed the epitope on their surfaces under physiological conditions and the resulting epitope-bearing nanofibers raised $\operatorname{IgG} 1, \operatorname{IgG} 2 \mathrm{a}$ and IgG3 in levels similar to epitope peptide delivered in complete Freund's adjuvant (CFA). Importantly, it promoted IgM production even greater than the epitope peptide itself. Experimental data revealed the correlation between the enhancement of the immune responses and the self-assembly behaviors of the peptides, which were not immunogenic by themselves (Figure 19A).[333] By investigating the molecular determinants and immunological mechanisms leading to the significant immunogenicity of this selfassembling peptide, Collier and coworkers found that these responses were T-cell dependent because deleting amino acid sequences in T-cell recognizing region diminished the immunogenicity. Another selfassembling peptide OVA-KFE8, baring the same epitope, also elicited strong antibody responses similar to OVA-Q11, indicating that the adjuvant action was not specific to certain self-assembling peptide sequences.[334] Besides varying the self-assembling peptides, Collier et al. developed another vaccine 
adjuvant $\left(\mathrm{NANP}_{3}\right)-\mathrm{Q} 11$ by incorporating another peptide epitope from plasmodium falciparum circumsporozoite protein into the self-assembling peptide. The resulting peptide raised long-lived T-celldependent antibody responses without frequent boosts. The co-assembling with a different epitopebearing peptides had little influence on the antibody responses to either epitopes, suggesting the promises of developing multi-epitope vaccines.[335] The incorporation of p-nitrophenyl phosphonate (pNP) into the same peptide sequences Q11 afforded another self-assembling self-adjuvanting vaccine. The resulting peptide self-assembled into nanofibers and subsequently reacted with cutinase fusion proteins to afford protein-laden nanofibers, which had a control over the amounts of protein antigen and acted as selfadjuvanting vaccines in mice.[336] Similarly, by combining two native sequences form a spider silk elastic segment and a human muscle calcium channel segment, Sun et al. designed a self-assembling peptide h9e (FLIVIGSIIGPGGDGPGGD), which self-assembled to form a hydrogel either in acidic condition or in the presence of $\mathrm{Ca}^{2+}$. The hydrogel made by the addition of $\mathrm{Ca}^{2+}$ was self-recovering and was able to serve as an H1N1 influenza vaccine adjuvant.[337] By evaluating the immunological response of h9e as an adjuvant for PRRSV modified live virus (MLV) vaccines, Sun and coworkers demonstrated that the h9e hydrogel, as an adjuvant, improved vaccination-induced host protection against RRRSV infection.[338] $\mathrm{Li}$ and coworkers designed, synthesized, and evaluated several synthetic glycopeptides, as self-adjuvanting vaccine candidates with self-assembly domains (Q11). Briefly, they facilely incorporated different vaccine candidates, $\mathrm{H} 1, \mathrm{H} 2, \mathrm{H} 3$ and $\mathrm{H} 4$ into the self-assembling sequences Q11 and prepared nanofibers over $200 \mathrm{~nm}$ in length with the resulting molecules. Immunological evaluations revealed that the synthetic glycopeptide with Tn glycosylation in the PDTRP domain elicited significant immune responses. The induced antibody was able to recognize human MUC1-expressing tumor cell.[339] In another recent work, Jiang and Yang et al. reported that the EISA of a small peptide to form nanofibers could efficiently condense DNA, resulting in strong immune responses against HIV by promoting DNA transfection and enhancing gene expression in vitro (Figure 19B).[19] The same group also developed a supramolecular hydrogel formed by a self-assembling D-tetra-peptide, which was able to serve as a promising vaccine adjuvant to evoke both humoral and cellular immune responses.[340] 

demonstrated that the in situ formation of peptidic nanofibers facilitated the induction of multiple crucial immunities against HIV DNA vaccine, including polyfunctional T cell response, broad IgG subclasses response, and V1/V2 loop-specific antibody response, all of which could hardly be triggered by HIV DNA vaccine alone.[341]

A

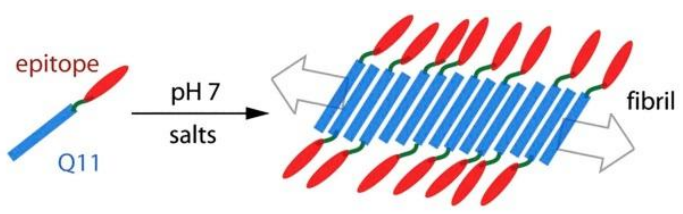

B
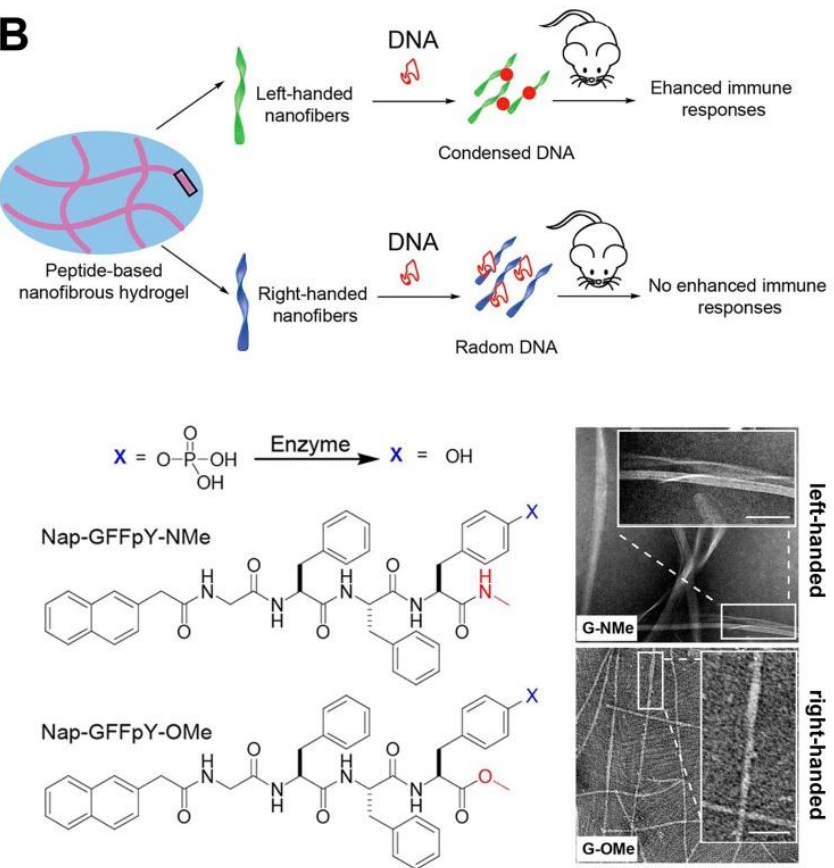

Nap-GFFpY-OH
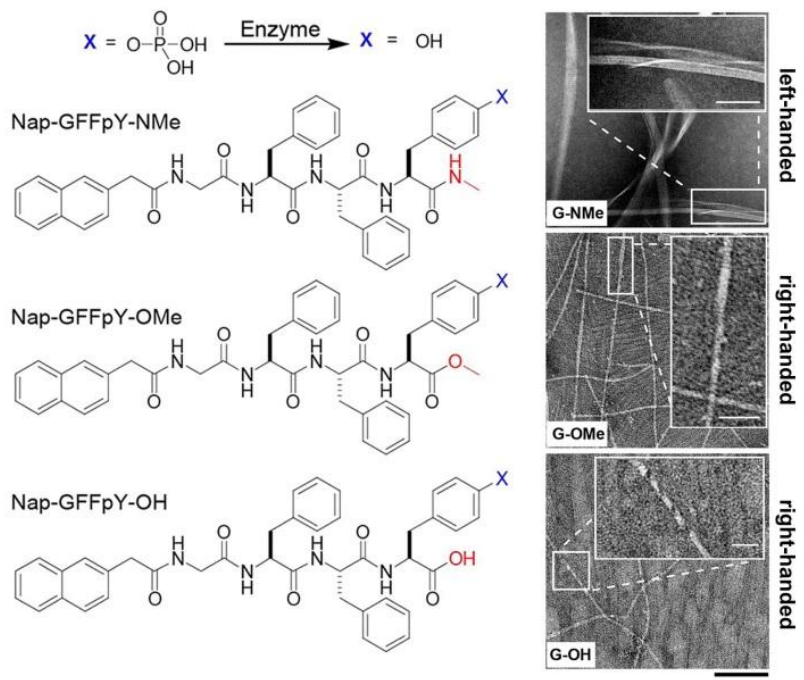

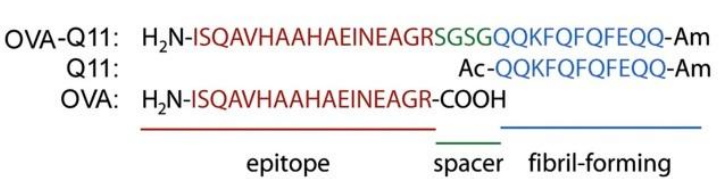

Q11:

epitope spacer fibril-forming

C
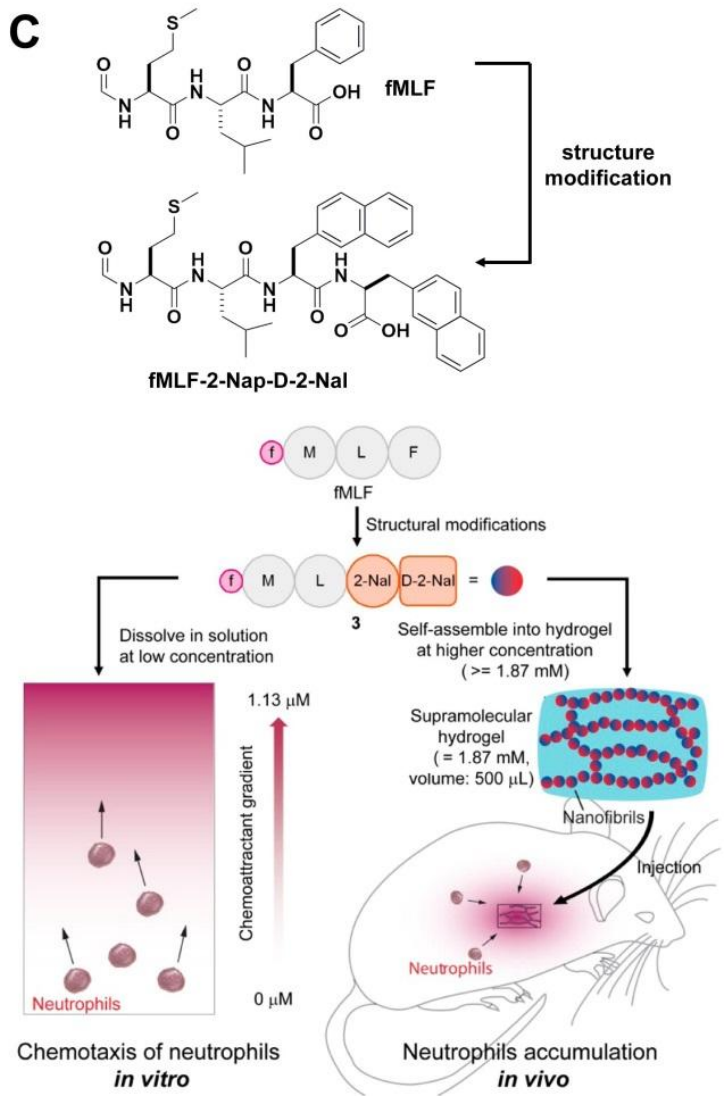

Figure 19. (A) A self-assembling peptide (OVA-Q11) acts as an immune adjuvant. (B) A peptide-based nanofibrous hydrogel of G-NMe as a promising DNA nanovector for optimizing the efficacy of HIV vaccine. (C) De Novo chemoattractants form supramolecular hydrogels for immunomodulating neutrophiles in vivo. (Adapted from @ 2010 National Academy of Sciences, 2014 American Chemical Society with permission.[19, 333, 342]) 
While molecular hydrogels or nanofibers are mostly used as self-adjuvanting vaccine or adjuvants, the incorporation of an unnatural amino acid into a well-established chemoattractant N-formyl-Lmethionyl-L-leucyl-L-phenylalanine, fMLF, afforded a supramolecular hydrogelator that self-assembled to form de novo multifunctional nanofibers or hydrogels. The resulting hydrogels acted as chemoattractants that exhibited not only preserved cross-species chemoattracting activity to human and murine neutrophils, but also protease resistance (Figure 19C).[342]

\section{Perspective and Outlook}

Rather than focusing on replicating the exact molecular structure of biomacromolecules or natural products through tedious synthesis, supramolecular biofunctional materials, being resulted from selfassembly of simple molecular entities via noncovalent interactions, aim to mimic sophisticated functions in biological systems. Without the constraints imposed by complex structures, the functional mimicking is always much more effective and simpler than replicating. One important future direction of supramolecular chemistry is to explore self-assembly of small molecules in biological systems; the development of supramolecular biofunctional materials is a core activity of that mission. For example, by exploiting innovative methods and approaches, the development of supramolecular biofunctional materials will improve the spatiotemporal precision of supramolecular nanostructures for better mimicking the functional aspects of extracellular matrix in nature so that supramolecular biofunctional materials will be able to modulate the behaviors of biological entities in well-defined or highly controllable manners.

By utilizing the biological building blocks for the construction of various biofunctional materials via self-assembly and noncovalent interactions, supramolecular chemistry represents the most molecular example of the bioinspired researches, which use phenomena in biology to guide and to stimulate the interdisciplinary sciences and technologies of chemistry, physics, biology, and engineering.[123] Nature has displayed many strategies for creatures to survive and thrive. These strategies, in essence, are molecular phenomena over a wide length scale (from nanometers to meter), which provide unlimited inspirations for solving problems in everyday life and in biomedicine. The development of 
supramolecular biofunctional materials now and in the future heavily relies and will keep relying on biological systems as a source of inspiration — both in problems and solutions. Thus, the advancement of our understanding of biology will fuel the development of supramolecular biofunctional materials to meet new challenges in developing innovative strategies for biomedicine. On the other hand, as a mimicry or simplified model of real systems in biology, the progresses of the supramolecular biofunctional materials will deepen and broaden our understanding of biological systems. That is the reason why supramolecular biofunctional materials will remain a frontier in biomaterials and chemistry. Over the past three decades, supramolecular chemistry has provided guiding principles to understand intermolecular interactions, as well as for designing medicines based on those principles (e.g., molecular recognition). As the fundamental science of intermolecular interactions, supramolecular chemistry, in the coming years, will become a key strategy for creating biofunctional materials that promise unlimited opportunities and applications in biomedical and clinical practice.

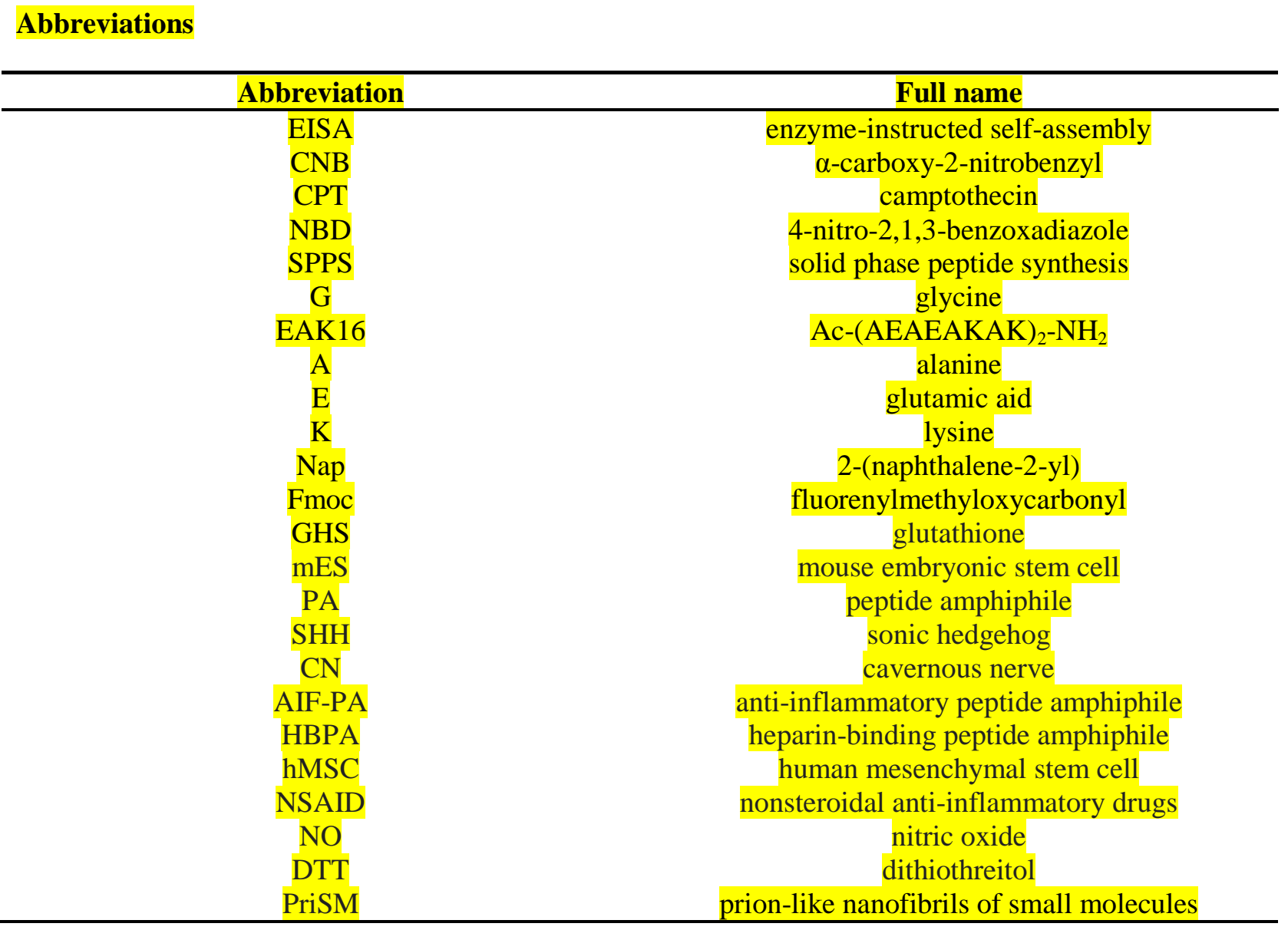




\section{Acknowledgement}

This work was partially supported by the National Institutes of Health (NIH) (Grant R01CA142746),

W.M. Keck Foundation, and National Science Foundation (NSF) (Grant DMR-1420382). J.Z. is a Howard Hughes Medical Institute (HHMI) International Research Fellow.

\section{Reference}

[1] X. Du, J. Zhou, J. Shi, B. Xu, Supramolecular Hydrogelators and Hydrogels: From Soft Matter to Molecular Biomaterials, Chem. Rev. 115(24) (2015) 13165-13307.

[2] J. Zhou, B. Xu, Enzyme-Instructed Self-Assembly: A Multistep Process for Potential Cancer Therapy, Bioconjugate Chem. 26(6) (2015) 987-999.

[3] J.D. Hartgerink, E. Beniash, S.I. Stupp, Self-assembly and mineralization of peptide-amphiphile nanofibers, Science 294(5547) (2001) 1684-1688.

[4] G.A. Silva, C. Czeisler, K.L. Niece, E. Beniash, D.A. Harrington, J.A. Kessler, S.I. Stupp, Selective differentiation of neural progenitor cells by high-epitope density nanofibers, Science 303(5662) (2004) $1352-1355$.

[5] S. Kiyonaka, K. Sada, I. Yoshimura, S. Shinkai, N. Kato, I. Hamachi, Semi-wet peptide/protein array using supramolecular hydrogel, Nat. Mater. 3(1) (2004) 58-64.

[6] M. Ikeda, T. Yoshii, T. Matsui, T. Tanida, H. Komatsu, I. Hamachi, Montmorillonite-Supramolecular Hydrogel Hybrid for Fluorocolorimetric Sensing of Polyamines, J. Am. Chem. Soc. 133(6) (2011) 16701673.

[7] Y. Kurishita, T. Kohira, A. Ojida, I. Hamachi, Rational Design of FRET-Based Ratiometric Chemosensors for in Vitro and in Cell Fluorescence Analyses of Nucleoside Polyphosphates, J. Am. Chem. Soc. 132(38) (2010) 13290-13299.

[8] A. Ojida, Y. Mito-oka, M. Inoue, I. Hamachi, First artificial receptors and chemosensors toward phosphorylated peptide in aqueous solution, J. Am. Chem. Soc. 124(22) (2002) 6256-6258. 
[9] A. Ojida, Y. Mito-oka, K. Sada, I. Hamachi, Molecular recognition and fluorescence sensing of monophosphorylated peptides in aqueous solution by bis(zinc(II)-dipicolylamine)-based artificial receptors, J. Am. Chem. Soc. 126(8) (2004) 2454-2463.

[10] I. Yoshimura, Y. Miyahara, N. Kasagi, H. Yamane, A. Ojida, I. Hamachi, Molecular recognition in a supramolecular hydrogel to afford a semi-wet sensor chip, J. Am. Chem. Soc. 126(39) (2004) 1220412205.

[11] S. Onogi, H. Shigemitsu, T. Yoshii, T. Tanida, M. Ikeda, R. Kubota, I. Hamachi, In situ real-time imaging of self-sorted supramolecular nanofibres, Nat. Chem. 8(8) (2016) 743-752.

[12] J. Boekhoven, W.E. Hendriksen, G.J.M. Koper, R. Eelkema, J.H. van Esch, Transient assembly of active materials fueled by a chemical reaction, Science 349(6252) (2015) 1075-1079.

[13] P.W.J.M. Frederix, G.G. Scott, Y.M. Abul-Haija, D. Kalafatovic, C.G. Pappas, N. Javid, N.T. Hunt, R.V. Ulijn, T. Tuttle, Exploring the sequence space for (tri-)peptide self-assembly to design and discover new hydrogels, Nat. Chem. 7(1) (2015) 30-37.

[14] A.G. Cheetham, P. Zhang, Y.-a. Lin, L.L. Lock, H. Cui, Supramolecular Nanostructures Formed by Anticancer Drug Assembly, J. Am. Chem. Soc. 135(8) (2013) 2907-2910.

[15] Z. Chen, P. Zhang, A.G. Cheetham, J.H. Moon, J.W. Moxley, Y.-a. Lin, H. Cui, Controlled release of free doxorubicin from peptide-drug conjugates by drug loading, J. Controlled Release 191 (2014) 123130.

[16] L.L. Lock, Z. Tang, D. Keith, C. Reyes, H. Cui, Enzyme-Specific Doxorubicin Drug Beacon as DrugResistant Theranostic Molecular Probes, ACS Macro Lett. 4(5) (2015) 552-555.

[17] P. Zhang, L.L. Lock, A.G. Cheetham, H. Cui, Enhanced Cellular Entry and Efficacy of Tat Conjugates by Rational Design of the Auxiliary Segment, Mol. Pharmaceutics 11(3) (2014) 964-973.

[18] H. Wang, Z. Luo, Y. Wang, T. He, C. Yang, C. Ren, L. Ma, C. Gong, X. Li, Z. Yang, Enzyme-Catalyzed Formation of Supramolecular Hydrogels as Promising Vaccine Adjuvants, Adv. Funct. Mater. 26(11) (2016) 1822-1829.

[19] Y. Tian, H. Wang, Y. Liu, L. Mao, W. Chen, Z. Zhu, W. Liu, W. Zheng, Y. Zhao, D. Kong, Z. Yang, W. Zhang, Y. Shao, X. Jiang, A Peptide-Based Nanofibrous Hydrogel as a Promising DNA Nanovector for Optimizing the Efficacy of HIV Vaccine, Nano Lett. 14(3) (2014) 1439-1445.

[20] J. Zhou, X. Du, B. Xu, Regulating the Rate of Molecular Self-Assembly for Targeting Cancer Cells, Angew. Chem. Int. Ed. 55(19) (2016) 5770-5775.

[21] J. Zhou, X.W. Du, N. Yamagata, B. Xu, Enzyme-Instructed Self-Assembly of Small D-Peptides as a Multiple-Step Process for Selectively Killing Cancer Cells, J. Am. Chem. Soc. 138(11) (2016) 3813-3823.

[22] R. Zhou, Y. Kuang, J. Zhou, X.W. Du, J. Li, J.F. Shi, R. Haburcak, B. Xu, Nanonets Collect Cancer Secretome from Pericellular Space, Plos One 11(4) (2016) e0154126.

[23] J. Li, Y. Kuang, J. Shi, J. Zhou, J. Medina, R. Zhou, D. Yuan, C. Yang, H. Wang, Z. Yang, J. Liu, D. Dinulescu, B. Xu, Enzyme-Instructed Intracellular Molecular Self-Assembly to Boost Activity of Cisplatin against Drug-Resistant Ovarian Cancer Cells, Angew. Chem. Int. Ed. 54(45) (2015) 13307-13311.

[24] J. Zhou, X.W. Du, B. Xu, Prion-like nanofibrils of small molecules (PriSM): A new frontier at the intersection of supramolecular chemistry and cell biology, Prion 9(2) (2015) 110-118.

[25] Z.M. Yang, P.L. Ho, G.L. Liang, K.H. Chow, Q.G. Wang, Y. Cao, Z.H. Guo, B. Xu, Using beta-lactamase to trigger supramolecular hydrogelation, J. Am. Chem. Soc. 129(2) (2007) 266-267.

[26] Y. Gao, Y. Kuang, Z.F. Guo, Z.H. Guo, I.J. Krauss, B. Xu, Enzyme-Instructed Molecular Self-assembly Confers Nanofibers and a Supramolecular Hydrogel of Taxol Derivative, J. Am. Chem. Soc. 131(38) (2009) 13576-13577.

[27] G. Liang, Z. Yang, R. Zhang, L. Li, Y. Fan, Y. Kuang, Y. Gao, T. Wang, W.W. Lu, B. Xu, Supramolecular Hydrogel of a D-Amino Acid Dipeptide for Controlled Drug Release in Vivo, Langmuir 25(15) (2009) 84198422. 

883-891.

[29] B. Xing, C.-W. Yu, K.-H. Chow, P.-L. Ho, D. Fu, B. Xu, Hydrophobic Interaction and Hydrogen Bonding Cooperatively Confer a Vancomycin Hydrogel: A Potential Candidate for Biomaterials, J. Am. Chem. Soc. 124(50) (2002) 14846-14847.

[30] J.Y. Li, Y. Gao, Y. Kuang, J.F. Shi, X.W. Du, J. Zhou, H.M. Wang, Z.M. Yang, B. Xu, Dephosphorylation of D-Peptide Derivatives to Form Biofunctional, Supramolecular Nanofibers/Hydrogels and Their Potential Applications for Intracellular Imaging and Intratumoral Chemotherapy, J. Am. Chem. Soc. 135(26) (2013) 9907-9914.

[31] J.Y. Li, Y. Kuang, Y. Gao, X.W. Du, J.F. Shi, B. Xu, D-Amino Acids Boost the Selectivity and Confer Supramolecular Hydrogels of a Nonsteroidal Anti-Inflammatory Drug (NSAID), J. Am. Chem. Soc. 135(2) (2013) 542-545.

[32] J. Shi, X. Du, D. Yuan, J. Zhou, N. Zhou, Y. Huang, B. Xu, D-Amino Acids Modulate the Cellular Response of Enzymatic-Instructed Supramolecular Nanofibers of Small Peptides, Biomacromolecules 15(10) (2014) 3559-3568.

[33] J. Zhou, X.W. Du, J. Li, N. Yamagata, B. Xu, Taurine Boosts Cellular Uptake of Small D-Peptides for Enzyme-Instructed Intracellular Molecular Self-Assembly, J. Am. Chem. Soc. 137(32) (2015) 10040-10043. [34] M.C. Branco, J.P. Schneider, Self-assembling materials for therapeutic delivery, Acta Biomater. 5(3) (2009) 817-831.

[35] M. Ikeda, R. Ochi, Y.-s. Kurita, D.J. Pochan, I. Hamachi, Heat-Induced Morphological Transformation of Supramolecular Nanostructures by Retro-Diels-Alder Reaction, Chem. - Eur. J. 18(41) (2012) 1309113096.

[36] M. Suzuki, K. Hanabusa, L-Lysine-based low-molecular-weight gelators, Chem. Soc. Rev. 38(4) (2009) 967-975.

[37] S.-i. Tamaru, I. Hamachi, Recent progress of phosphate derivatives recognition utilizing artificial small molecular receptors in aqueous media, in: R. Vilar (Ed.), Recognition of Anions2008, pp. 95-125.

[38] I. Tomatsu, K. Peng, A. Kros, Photoresponsive hydrogels for biomedical applications, Adv. Drug Delivery Rev. 63(14-15) (2011) 1257-1266.

[39] R.V. Ulijn, Enzyme-responsive materials: a new class of smart biomaterials, J Mater Chem 16(23) (2006) 2217-2225.

[40] Z.L. Wu, J.P. Gong, Hydrogels with self-assembling ordered structures and their functions, NPG Asia Mater. 3 (2011) 57-64.

[41] L.A. Estroff, A.D. Hamilton, Water gelation by small organic molecules, Chem. Rev. 104(3) (2004) 1201-1217.

[42] X.W. Du, J. Zhou, B. Xu, Supramolecular Hydrogels Made of Basic Biological Building Blocks, Chem. Asian J. 9(6) (2014) 1446-1472.

[43] Y. Pan, X.W. Du, F. Zhao, B. Xu, Magnetic nanoparticles for the manipulation of proteins and cells, Chem. Soc. Rev. 41(7) (2012) 2912-2942.

[44] M.J. Webber, E.A. Appel, E.W. Meijer, R. Langer, Supramolecular biomaterials, Nat. Mater. 15(1) (2016) 13-26.

[45] M.J. Webber, Engineering responsive supramolecular biomaterials: Toward smart therapeutics, Bioeng. Transl. Med. 1(3) (2016) 252-266.

[46] M.P. Lutolf, J.A. Hubbell, Synthetic biomaterials as instructive extracellular microenvironments for morphogenesis in tissue engineering, Nat. Biotechnol. 23(1) (2005) 47-55.

[47] E.A. Appel, J. del Barrio, X.J. Loh, O.A. Scherman, Supramolecular polymeric hydrogels, Chem. Soc. Rev. 41(18) (2012) 6195-6214.

[48] B. Rybtchinski, Adaptive Supramolecular Nanomaterials Based on Strong Noncovalent Interactions, ACS Nano 5(9) (2011) 6791-6818. 
[50] A. Pourjavadi, H. Ghasemzadeh, R. Soleyman, Synthesis, characterization, and swelling behavior of alginate-g-poly(sodium acrylate)/kaolin superabsorbent hydrogel composites, J. Appl. Polym. Sci. 105(5) (2007) 2631-2639.

[51] H.J. Chung, T.G. Park, Surface engineered and drug releasing pre-fabricated scaffolds for tissue engineering, Adv. Drug Delivery Rev. 59(4-5) (2007) 249-262.

[52] X. Shu, Y. Liu, F. Palumbo, Y. Lu, G. Prestwich, In situ crosslinkable hyaluronan hydrogels for tissue engineering, Biomaterials 25(7-8) (2004) 1339-1348.

[53] S. Ong, C. Zhang, Y. Toh, S. Kim, H. Foo, C. Tan, D. van Noort, S. Park, H. Yu, A gel-free 3D microfluidic cell culture system, Biomaterials 29(22) (2008) 3237-3244.

[54] J.F. Mano, Stimuli-responsive polymeric systems for biomedical applications, Adv. Eng. Mater. 10(6) (2008) 515-527.

[55] D. Seliktar, Designing Cell-Compatible Hydrogels for Biomedical Applications, Science 336(6085) (2012) 1124-1128.

[56] Z. Yang, G. Liang, M. Ma, A.S. Abbah, W.W. Lu, B. Xu, D-Glucosamine-based supramolecular hydrogels to improve wound healing, Chem. Commun. (8) (2007) 843-845.

[57] X. Du, J. Zhou, O. Guvench, F. Sangiorgi, X. Li, N. Zhou, B. Xu, Supramolecular Assemblies of a Conjugate of Nucleobase, Amino Acids, and Saccharide Act as Agonists for Proliferation of Embryonic Stem Cells and Development of Zygotes, Bioconjugate Chem. 25(6) (2014) 1031-1035.

[58] X.D. Yu, Q.A. Liu, J.C. Wu, M.M. Zhang, X.H. Cao, S. Zhang, Q. Wang, L.M. Chen, T. Yi, SonicationTriggered Instantaneous Gel-to-Gel Transformation, Chem. - Eur. J. 16(30) (2010) 9099-9106.

[59] S. Maity, P. Kumar, D. Haldar, Sonication-induced instant amyloid-like fibril formation and organogelation by a tripeptide, Soft Matter 7(11) (2011) 5239-5245.

[60] B. Roy, P. Bairi, A.K. Nandi, Metastability in a bi-component hydrogel of thymine and 6-methyl1,3,5-triazine-2,4-diamine: ultrasound induced vs. thermo gelation, Soft Matter 8(8) (2012) 2366-2369.

[61] M. He, J. Li, S. Tan, R. Wang, Y. Zhang, Photodegradable Supramolecular Hydrogels with Fluorescence Turn-On Reporter for Photomodulation of Cellular Microenvironments, J. Am. Chem. Soc. 135(50) (2013) 18718-18721.

[62] M. Wallace, A.Z. Cardoso, W.J. Frith, J.A. Iggo, D.J. Adams, Magnetically Aligned Supramolecular Hydrogels, Chem. - Eur. J. 20(50) (2014) 16484-16487.

[63] C. Tang, A.M. Smith, R.F. Collins, R.V. Ulijn, A. Saiani, Fmoc-Diphenylalanine Self-Assembly Mechanism Induces Apparent pK(a) Shifts, Langmuir 25(16) (2009) 9447-9453.

[64] G. Verma, V.K. Aswal, P. Hassan, pH-Responsive self-assembly in an aqueous mixture of surfactant and hydrophobic amino acid mimic, Soft Matter 5(15) (2009) 2919-2927.

[65] F. Zhao, Y. Gao, J. Shi, H.M. Browdy, B. Xu, Novel Anisotropic Supramolecular Hydrogel with High Stability over a Wide pH Range, Langmuir 27(4) (2011) 1510-1512.

[66] J.W. Steed, Coordination and organometallic compounds as anion receptors and sensors, Chem. Soc. Rev. 38(2) (2009) 506-519.

[67] J.W. Steed, A modular approach to anion binding podands: adaptability in design and synthesis leads to adaptability in properties, Chem. Commun. (25) (2006) 2637-2649.

[68] F. Mao, N. Mano, A. Heller, Long tethers binding redox centers to polymer backbones enhance electron transport in enzyme "Wiring" hydrogels, J. Am. Chem. Soc. 125(16) (2003) 4951-7.

[69] J.H. Rao, J. Lahiri, L. Isaacs, R.M. Weis, G.M. Whitesides, A trivalent system from vancomycin center dot D-Ala-D-Ala with higher affinity than avidin center dot biotin, Science 280(5364) (1998) 708-711.

[70] J. Lahiri, L. Isaacs, J. Tien, G. Whitesides, A strategy for the generation of surfaces presenting ligands for studies of binding based on an active ester as a common reactive intermediate: A surface plasmon resonance study, Anal. Chem. 71(4) (1999) 777-790. 
[71] B.G. Xing, M.F. Choi, B. Xu, Design of coordination polymer gels as stable catalytic systems, Chem. Eur. J. 8(21) (2002) 5028-5032.

[72] B.G. Xing, M.F. Choi, B. Xu, A stable metal coordination polymer gel based on a calix 4 arene and its 'uptake' of non-ionic organic molecules from the aqueous phase, Chem. Commun. (4) (2002) 362-363.

[73] S. Toledano, R.J. Williams, V. Jayawarna, R.V. Ulijn, Enzyme-triggered self-assembly of peptide hydrogels via reversed hydrolysis, J. Am. Chem. Soc. 128(4) (2006) 1070-1071.

[74] Z.M. Yang, G.L. Liang, M.L. Ma, Y. Gao, B. Xu, In vitro and in vivo enzymatic formation of supramolecular hydrogels based on self-assembled nanofibers of a beta-amino acid derivative, Small 3(4) (2007) 558-562.

[75] T.O. McDonald, H.L. Qu, B.R. Saunders, R.V. Ulijn, Branched peptide actuators for enzyme responsive hydrogel particles, Soft Matter 5(8) (2009) 1728-1734.

[76] Z. Yang, G. Liang, B. Xu, Enzymatic hydrogelation of small molecules, Acc. Chem. Res. 41(2) (2008) 315-326.

[77] Z.M. Yang, G.L. Liang, L. Wang, B. Xu, Using a kinase/phosphatase switch to regulate a supramolecular hydrogel and forming the supramoleclar hydrogel in vivo, J. Am. Chem. Soc. 128(9) (2006) 3038-3043.

[78] Q.G. Wang, Z.M. Yang, Y. Gao, W.W. Ge, L. Wang, B. Xu, Enzymatic hydrogelation to immobilize an enzyme for high activity and stability, Soft Matter 4(3) (2008) 550-553.

[79] A.A. Li, F. Shen, T. Zhang, P. Cirone, M. Potter, P.L. Chang, Enhancement of myoblast microencapsulation for gene therapy, J. Biomed. Mater. Res. B 77B(2) (2006) 296-306.

[80] J. Tauro, R. Gemeinhart, Matrix metalloprotease triggered delivery of cancer chemotherapeutics from hydrogel matrixes, Bioconjugate Chem. 16(5) (2005) 1133-1139.

[81] M. Malkoch, R. Vestberg, N. Gupta, L. Mespouille, P. Dubois, A.F. Mason, J.L. Hedrick, Q. Liao, C.W. Frank, K. Kingsbury, C.J. Hawker, Synthesis of well-defined hydrogel networks using Click chemistry, Chem. Commun. (26) (2006) 2774-2776.

[82] D.L. Elbert, A.B. Pratt, M.P. Lutolf, S. Halstenberg, J.A. Hubbell, Protein delivery from materials formed by self-selective conjugate addition reactions, J. Controlled Release 76(1-2) (2001) 11-25.

[83] M. Wathier, S. Johnson, T. Kim, M. Grinstaff, Hydrogels Formed by Multiple Peptide Ligation Reactions To Fasten Corneal Transplants, Bioconjugate Chem. 17(4) (2006) 873-876.

[84] Z. Yang, H. Gu, D. Fu, P. Gao, J. Lam, B. Xu, Enzymatic formation of supramolecular hydrogels, Adv. Mater. 16(16) (2004) 1440-1444.

[85] M. Zhou, J. Hu, M. Zheng, Q. Song, J. Li, Y. Zhang, Photo-click construction of a targetable and activatable two-photon probe imaging protease in apoptosis, Chem. Commun. 52(11) (2016) 2342-2345. [86] W. Wang, J. Hu, M. Zheng, L. Zheng, H. Wang, Y. Zhang, Multi-responsive supramolecular hydrogels based on merocyanine-peptide conjugates, Org. Biomol. Chem. 13(47) (2015) 11492-11498.

[87] L.A. Haines, K. Rajagopal, B. Ozbas, D.A. Salick, D.J. Pochan, J.P. Schneider, Light-Activated Hydrogel Formation via the Triggered Folding and Self-Assembly of a Designed Peptide, J. Am. Chem. Soc. 127(48) (2005) 17025-17029.

[88] X. Li, Y. Gao, Y. Kuang, B. Xu, Enzymatic formation of a photoresponsive supramolecular hydrogel, Chem. Commun. 46(29) (2010) 5364-5366.

[89] D. Loewik, I. Shklyarevskiy, L. Ruizendaal, P. Christianen, J. Maan, J. van Hest, A highly ordered material from magnetically aligned peptide amphiphile nanofiber assemblies, Adv. Mater. 19(9) (2007) 1191-1195.

[90] Z. Yang, H. Gu, J. Du, J. Gao, B. Zhang, X. Zhang, B. Xu, Self-assembled hybrid nanofibers confer a magnetorheological supramolecular hydrogel, Tetrahedron 63(31) (2007) 7349-7357.

[91] J. Shi, Y. Gao, Y. Zhang, Y. Pan, B. Xu, Calcium lons to Cross-Link Supramolecular Nanofibers to Tune the Elasticity of Hydrogels over Orders of Magnitude, Langmuir 27(23) (2011) 14425-14431. 
[92] L.-P. Ruan, H.-L. Luo, H.-Y. Zhang, X. Zhao, Investigation on structure and properties of a novel designed peptide with half-sequence ionic complement, Macromol. Res. 17(8) (2009) 597-602.

[93] B. Ozbas, J. Kretsinger, K. Rajagopal, J.P. Schneider, D.J. Pochan, Salt-Triggered Peptide Folding and Consequent Self-Assembly into Hydrogels with Tunable Modulus, Macromolecules 37(19) (2004) 73317337.

[94] Z. Huang, Q. Luo, S. Guan, J. Gao, Y. Wang, B. Zhang, L. Wang, J. Xu, Z. Dong, J. Liu, Redox control of GPx catalytic activity through mediating self-assembly of Fmoc-phenylalanine selenide into switchable supramolecular architectures, Soft Matter 10(48) (2014) 9695-9701.

[95] Y. Zhang, B. Zhang, Y. Kuang, Y. Gao, J.F. Shi, X.X. Zhang, B. Xu, A Redox Responsive, Fluorescent Supramolecular Metallohydrogel Consists of Nanofibers with Single-Molecule Width, J. Am. Chem. Soc. 135(13) (2013) 5008-5011.

[96] Y. Gao, F. Zhao, Q.-G. Wang, Y. Zhang, B. Xu, Small peptide nanofibers as the matrices of molecular hydrogels for mimicking enzymes and enhancing the activity of enzymes, Chem. Soc. Rev. 39(9) (2010) 3425-3433.

[97] Z.M. Yang, B. Xu, A simple visual assay based on small molecule hydrogels for detecting inhibitors of enzymes, Chem. Commun. (21) (2004) 2424-2425.

[98] Y. Takaoka, T. Sakamoto, S. Tsukiji, M. Narazaki, T. Matsuda, H. Tochio, M. Shirakawa, I. Hamachi, Self-assembling nanoprobes that display off/on $19 \mathrm{~F}$ nuclear magnetic resonance signals for protein detection and imaging, Nat. Chem. 1(7) (2009) 557-561.

[99] J. Gao, Y. Shi, Y.Z. Wang, Y.B. Cai, J. Shen, D.L. Kong, Z.M. Yang, Enzyme-controllable F-NMR turn on through disassembly of peptide-based nanospheres for enzyme detection, Org. Biomol. Chem. 12(9) (2014) 1383-1386.

[100] J.S. Park, S. Jeong, B. Ahn, M. Kim, W. Oh, J. Kim, Selective response of cyclodextrin-dye hydrogel to metal ions, J. Inclusion Phenom.Macrocyclic Chem. 71(1-2) (2011) 79-86.

[101] L. Haines-Butterick, K. Rajagopal, M. Branco, D. Salick, R. Rughani, M. Pilarz, M.S. Lamm, D.J. Pochan, J.P. Schneider, Controlling hydrogelation kinetics by peptide design for three-dimensional encapsulation and injectable delivery of cells, Proc. Natl. Acad. Sci. U. S. A. 104(19) (2007) 7791-7796.

[102] A. Baral, S. Roy, A. Dehsorkhi, I.W. Hamley, S. Mohapatra, S. Ghosh, A. Banerjee, Assembly of an Injectable Noncytotoxic Peptide-Based Hydrogelator for Sustained Release of Drugs, Langmuir 30(3) (2014) 929-936.

[103] A.S. Gomes, A.M.P. Timbo, INFLUENCE OF CROSSLINKING ON THE MODULI AND IMPACT STRENGTH OF METHACRYLATE POLYMERS, Polym. Eng. Sci. 21(12) (1981) 745-747.

[104] D. Ringe, G.A. Petsko, Biochemistry. How enzymes work, Science 320(5882) (2008) 1428-1429.

[105] Y. Zhang, Z. Yang, F. Yuan, H. Gu, P. Gao, B. Xu, Molecular Recognition Remolds the Self-Assembly of Hydrogelators and Increases the Elasticity of the Hydrogel by 106-Fold, J. Am. Chem. Soc. 126(46) (2004) 15028-15029.

[106] J. Zhou, X.W. Du, Y. Gao, J.F. Shi, B. Xu, Aromatic-Aromatic Interactions Enhance Interfiber Contacts for Enzymatic Formation of a Spontaneously Aligned Supramolecular Hydrogel, J. Am. Chem. Soc. 136(8) (2014) 2970-2973.

[107] Y. Kuang, J. Shi, J. Li, D. Yuan, K. Alberti, Q. Xu, B. Xu, Pericellular Hydrogel/Nanonets Inhibit Cancer Cells, Angew. Chem. Int. Ed. 53(31) (2014) 8104-8107.

[108] V. Jayawarna, M. Ali, T. Jowitt, A. Miller, A. Saiani, J. Gough, R. Ulijn, Nanostructured hydrogels for three-dimensional cell culture through self-assembly of fluorenylmethoxycarbonyldipeptides, Adv. Mater. 18(5) (2006) 611-614.

[109] M. Zhou, A. Smith, A. Das, N. Hodson, R. Collins, R. Ulijn, J. Gough, Self-assembled peptide-based hydrogels as scaffolds for anchorage-dependent cells, Biomaterials 30(13) (2009) 2523-2530. 
[110] B.F. Lin, K.A. Megley, N. Viswanathan, D.V. Krogstad, L.B. Drews, M.J. Kade, Y.C. Qian, M.V. Tirrell, $\mathrm{pH}$-responsive branched peptide amphiphile hydrogel designed for applications in regenerative medicine with potential as injectable tissue scaffolds, J Mater Chem 22(37) (2012) 19447-19454.

[111] H.M. Wang, Z.M. Yang, Short-peptide-based molecular hydrogels: novel gelation strategies and applications for tissue engineering and drug delivery, Nanoscale 4(17) (2012) 5259-5267.

[112] X.Q. Dou, P. Li, D. Zhang, C.L. Feng, RGD anchored C-2-benzene based PEG-like hydrogels as scaffolds for two and three dimensional cell cultures, J. Mater. Chem. B 1(29) (2013) 3562-3568.

[113] Enateri V. Alakpa, V. Jayawarna, A. Lampel, Karl V. Burgess, Christopher C. West, Sanne C.J. Bakker, S. Roy, N. Javid, S. Fleming, Dimitris A. Lamprou, J. Yang, A. Miller, Andrew J. Urquhart, Pim W.J.M. Frederix, Neil T. Hunt, B. Péault, Rein V. Ulijn, Matthew J. Dalby, Tunable Supramolecular Hydrogels for Selection of Lineage-Guiding Metabolites in Stem Cell Cultures, Chem 1(2) (2016) 298-319.

[114] L.S. Moreira Teixeira, J. Patterson, F.P. Luyten, Skeletal tissue regeneration: where can hydrogels play a role?, Int. Orthop. 38(9) (2014) 1861-1876.

[115] R. Ravichandran, M. Griffith, J. Phopase, Applications of self-assembling peptide scaffolds in regenerative medicine: the way to the clinic, J. Mater. Chem. B 2(48) (2014) 8466-8478.

[116] M. Ikeno, H. Hibi, K. Kinoshita, H. Hattori, M. Ueda, Effects of Self-Assembling Peptide Hydrogel Scaffold on Bone Regeneration with Recombinant Human Bone Morphogenetic Protein-2, Int. J. Oral Max. Impl. 28(5) (2013) E283-E289.

[117] F.W. Kotch, R.T. Raines, Self-assembly of synthetic collagen triple helices, Proc. Natl. Acad. Sci. U. S. A. 103(9) (2006) 3028-3033.

[118] V. Gauba, J.D. Hartgerink, Self-Assembled Heterotrimeric Collagen Triple Helices Directed through Electrostatic Interactions, J. Am. Chem. Soc. 129(9) (2007) 2683-2690.

[119] Y. Gao, J.F. Shi, D. Yuan, B. Xu, Imaging enzyme-triggered self-assembly of small molecules inside live cells, Nat. Commun. 3 (2012) 1033.

[120] C. Liang, R. Ni, J.E. Smith, W.S. Childers, A.K. Mehta, D.G. Lynn, Kinetic intermediates in amyloid assembly, J. Am. Chem. Soc. 136(43) (2014) 15146-15149.

[121] S. Li, A. Sidorov, A. Mehta, A. Bisignano, D. Das, W. Childers, E. Schuler, Z. Jiang, T. Orlando, K. Berland, D. Lynn, Neurofibrillar Tangle Surrogates: Histone H1 Binding to Patterned Phosphotyrosine Peptide Nanotubes, Biochemistry 53(26) (2014) 4225-4227.

[122] Y. Liang, D.G. Lynn, K.M. Berland, Direct Observation of Nucleation and Growth in Amyloid SelfAssembly, J. Am. Chem. Soc. 132(18) (2010) 6306-6308.

[123] G.M. Whitesides, Bioinspiration: something for everyone, Interface Focus 5(4) (2015) 20150031.

[124] D. Yuan, X. Du, J. Shi, N. Zhou, J. Zhou, B. Xu, Mixing Biomimetic Heterodimers of Nucleopeptides to Generate Biocompatible and Biostable Supramolecular Hydrogels, Angew. Chem. Int. Ed. 54(19) (2015) 5705-5708.

[125] J.D. Marth, A unified vision of the building blocks of life, Nat. Cell Biol. 10(9) (2008) 1015-1016.

[126] M. Reches, E. Gazit, Casting Metal Nanowires Within Discrete Self-Assembled Peptide Nanotubes, Science 300(5619) (2003) 625-627.

[127] N. Sanchez de Groot, T. Parella, F. Aviles, J. Vendrell, S. Ventura, Ile-Phe dipeptide self-assembly: clues to amyloid formation, Biophys. J. 92(5) (2007) 1732-1741.

[128] K. Thornton, A. Smith, C. Merry, R. Ulijn, Controlling stiffness in nanostructured hydrogels produced by enzymatic dephosphorylation, Biochem. Soc. Trans. 37 (2009) 660-664.

[129] Y. Kuang, M.J.C. Long, J. Zhou, J.F. Shi, Y. Gao, C. Xu, L. Hedstrom, B. Xu, Prion-like Nanofibrils of Small Molecules (PriSM) Selectively Inhibit Cancer Cells by Impeding Cytoskeleton Dynamics, J. Biol. Chem. 289(42) (2014) 29208-29218.

[130] A. Reddy M, A. Srivastava, Mechano-responsive gelation of water by a short alanine-derivative, Soft Matter 10(27) (2014) 4863-4868. 
[131] X. Chu, P. Xing, S. Li, M. Ma, J. Hao, A. Hao, Dual-tuning multidimensional superstructures based on a T-shaped molecule: vesicle, helix, membrane and nanofiber-constructed gel, RSC Adv. 5(3) (2015) 1969-1978.

[132] R.M. Amarendar, A. Srivastava, Mechano-responsive gelation of water by a short alaninederivative, Soft Matter 10(27) (2014) 4863-4868.

[133] R.B. Merrifield, Solid Phase Peptide Synthesis. I. The Synthesis of a Tetrapeptide, J. Am. Chem. Soc. 85(14) (1963) 2149-2154.

[134] V.R. Pattabiraman, J.W. Bode, Rethinking amide bond synthesis, Nature 480(7378) (2011) 471-479. [135] S. Kent, Bringing the Science of Proteins into the Realm of Organic Chemistry: Total Chemical Synthesis of SEP (Synthetic Erythropoiesis Protein), Angew. Chem. Int. Ed. 52(46) (2013) 11988-11996.

[136] X.M. Li, Y. Kuang, J.F. Shi, Y. Gao, H.C. Lin, B. Xu, Multifunctional, Biocompatible Supramolecular Hydrogelators Consist Only of Nucleobase, Amino Acid, and Glycoside, J. Am. Chem. Soc. 133(43) (2011) 17513-17518.

[137] X.M. Li, X.W. Du, Y. Gao, J.F. Shi, Y. Kuang, B. Xu, Supramolecular hydrogels formed by the conjugates of nucleobases, Arg-Gly-Asp (RGD) peptides, and glucosamine, Soft Matter 8(28) (2012) 7402-7407.

[138] Y. Kuang, B. Xu, Disruption of the Dynamics of Microtubules and Selective Inhibition of Glioblastoma Cells by Nanofibers of Small Hydrophobic Molecules, Angew. Chem. Int. Ed. 52(27) (2013) 6944-6948.

[139] Y. Kuang, X. Du, J. Zhou, B. Xu, Supramolecular Nanofibrils Inhibit Cancer Progression In Vitro and In Vivo, Adv. Healthcare Mater. 3(8) (2014) 1217-1221.

[140] D. Wade, A. Boman, B. Wahlin, C.M. Drain, D. Andreu, H.G. Boman, R.B. Merrifield, All-D amino acid-containing channel-forming antibiotic peptides, Proc. Natl. Acad. Sci. U. S. A. 87(12) (1990) 47614765.

[141] G. Guichard, N. Benkirane, G. Zeder-Lutz, M.H.V. Van Regenmortel, J.-P. Briand, S. Muller, Antigenic mimicry of natural L-peptides with retro-inversopeptidomimetics, Proc. Natl. Acad. Sci. U. S. A. 91(21) (1994) 9765-9769.

[142] D.J. Pochan, J.P. Schneider, J. Kretsinger, B. Ozbas, K. Rajagopal, L. Haines, Thermally reversible hydrogels via intramolecular folding and consequent self-assembly of a de Novo designed peptide, J. Am. Chem. Soc. 125(39) (2003) 11802-11803.

[143] K. Rajagopal, B. Ozbas, D.J. Pochan, J.P. Schneider, Probing the importance of lateral hydrophobic association in self-assembling peptide hydrogelators, Eur. Biophys. J. Biophy. 35(2) (2006) 162-169.

[144] R.A. Hule, R.P. Nagarkar, A. Altunbas, H.R. Ramay, M.C. Branco, J.P. Schneider, D.J. Pochan, Correlations between structure, material properties and bioproperties in self-assembled beta-hairpin peptide hydrogels, Faraday Discuss. 139 (2008) 251-264.

[145] J. Kretsinger, L. Haines, B. Ozbas, D. Pochan, J. Schneider, Cytocompatibility of self-assembled sshairpin peptide hydrogel surfaces, Biomaterials 26(25) (2005) 5177-5186.

[146] S. Zhang, T. Holmes, C. Lockshin, A. Rich, Spontaneous assembly of a self-complementary oligopeptide to form a stable macroscopic membrane, Proc. Natl. Acad. Sci. U. S. A. 90(8) (1993) 33343338.

[147] H. Yokoi, T. Kinoshita, S. Zhang, Dynamic reassembly of peptide RADA16 nanofiber scaffold, Proc. Natl. Acad. Sci. U. S. A. 102(24) (2005) 8414-8419.

[148] J. Li, X. Du, S. Hashim, A. Shy, B. Xu, Aromatic-Aromatic Interactions Enable $\alpha$-Helix to $\beta$-Sheet Transition of Peptides to Form Supramolecular Hydrogels, J. Am. Chem. Soc. 139(1) (2017) 71-74.

[149] E.F. Banwell, E.S. Abelardo, D.J. Adams, M.A. Birchall, A. Corrigan, A.M. Donald, M. Kirkland, L.C. Serpell, M.F. Butler, D.N. Woolfson, Rational design and application of responsive alpha-helical peptide hydrogels, Nat. Mater. 8(7) (2009) 596-600. 

Coquelle, J.-P. Colletier, The cytotoxic Staphylococcus aureus PSM $\alpha 3$ reveals a cross- $\alpha$ amyloid-like fibril, Science 355(6327) (2017) 831-833.

[151] P. Berndt, G.B. Fields, M. Tirrell, Synthetic lipidation of peptides and amino acids: monolayer structure and properties, J. Am. Chem. Soc. 117(37) (1995) 9515-22.

[152] J.D. Hartgerink, E. Beniash, S.I. Stupp, Peptide-amphiphile nanofibers: a versatile scaffold for the preparation of self-assembling materials, Proc. Natl. Acad. Sci. U. S. A. 99(8) (2002) 5133-5138.

[153] M.J. Webber, E.J. Berns, S.I. Stupp, Supramolecular Nanofibers of Peptide Amphiphiles for Medicine, Isr. J. Chem. 53(8) (2013) 530-554.

[154] Z. Yang, H. Gu, D. Fu, P. Gao, J.K. Lam, B. Xu, Enzymatic formation of supramolecular hydrogels, Adv. Mater. 16(16) (2004) 1440-1444.

[155] M. Ma, Y. Kuang, Y. Gao, Y. Zhang, P. Gao, B. Xu, Aromatic-aromatic interactions induce the selfassembly of pentapeptidic derivatives in water to form nanofibers and supramolecular hydrogels, J. Am. Chem. Soc. 132(8) (2010) 2719-2728.

[156] S. Fleming, R.V. Ulijn, Design of nanostructures based on aromatic peptide amphiphiles, Chem. Soc. Rev. 43(23) (2014) 8150-8177.

[157] Y. Yang, W. Feng, J. Hu, S. Zou, R. Gao, K. Yamato, M. Kline, Z. Cai, Y. Gao, Y. Wang, Y. Li, Y. Yang, L. Yuan, X.C. Zeng, B. Gong, Strong Aggregation and Directional Assembly of Aromatic Oligoamide Macrocycles, J. Am. Chem. Soc. 133(46) (2011) 18590-18593.

[158] P. Berndt, G.B. Fields, M. Tirrell, SYNTHETIC LIPIDATION OF PEPTIDES AND AMINO-ACIDS MONOLAYER STRUCTURE AND PROPERTIES, J. Am. Chem. Soc. 117(37) (1995) 9515-9522.

[159] Y.C. Yu, P. Berndt, M. Tirrell, G.B. Fields, Self-assembling amphiphiles for construction of protein molecular architecture, J. Am. Chem. Soc. 118(50) (1996) 12515-12520.

[160] T. Kunitake, Synthetic Bilayer Membranes: Molecular Design, Self-organization, and Application, Angew. Chem. Int. Ed. 31(6) (1992) 709-726.

[161] X. Cha, K. Ariga, T. Kunitake, Molecular recognition of aqueous dipeptides at multiple hydrogenbonding sites of mixed peptide monolayers, J. Am. Chem. Soc. 118(40) (1996) 9545-9551.

[162] X.A. Cha, K. Ariga, M. Onda, T. Kunitake, Molecular Recognition of Aqueous Dipeptides by Noncovalently Aligned Oligoglycine Units at the Airwater Interface, J. Am. Chem. Soc. 117(48) (1995) 11833-11838.

[163] J.C. Stendahl, M.S. Rao, M.O. Guler, S.I. Stupp, Intermolecular forces in the self-assembly of peptide amphiphile nanofibers, Adv. Funct. Mater. 16(4) (2006) 499-508.

[164] J.D. Tovar, R.C. Claussen, S.I. Stupp, Probing the interior of peptide amphiphile supramolecular aggregates, J. Am. Chem. Soc. 127(20) (2005) 7337-7345.

[165] S. Bai, C. Pappas, S. Debnath, P.W.J.M. Frederix, J. Leckie, S. Fleming, R.V. Ulijn, Stable Emulsions Formed by Self-Assembly of Interfacial Networks of Dipeptide Derivatives, ACS Nano 8(7) (2014) 70057013.

[166] T. Nakayama, T. Sakuraba, S. Tomita, A. Kaneko, E. Takai, K. Shiraki, K. Tashiro, N. Ishii, Y. Hasegawa, Y. Yamada, R. Kumai, Y. Yamamoto, Charge-Separated Fmoc-Peptide beta-Sheets: SequenceSecondary Structure Relationship for Arranging Charged Side Chains on Both Sides, Asian J. Org. Chem. 3(11) (2014) 1182-1188.

[167] L. Chen, T.O. McDonald, D.J. Adams, Salt-induced hydrogels from functionalised-dipeptides, RSC Adv. 3(23) (2013) 8714-8720.

[168] B.D. Wall, J.D. Tovar, Synthesis and characterization of pi-conjugated peptide-based supramolecular materials, Pure Appl. Chem. 84(4) (2012) 1039-1045.

[169] R. Li, C.C. Horgan, B. Long, A.L. Rodriguez, L. Mather, C.J. Barrow, D.R. Nisbet, R.J. Williams, Tuning the mechanical and morphological properties of self-assembled peptide hydrogels via control over the 
gelation mechanism through regulation of ionic strength and the rate of $\mathrm{pH}$ change, RSC Adv. 5(1) (2015) 301-307.

[170] Y. Shi, J. Wang, H. Wang, Y. Hu, X. Chen, Z. Yang, Glutathione-Triggered Formation of a FmocProtected Short Peptide-Based Supramolecular Hydrogel, Plos One 9(9) (2014) e106968.

[171] Y. Zou, K. Razmkhah, N.P. Chmel, I.W. Hamley, A. Rodger, Spectroscopic signatures of an Fmoctetrapeptide, Fmoc and fluorene, RSC Adv. 3(27) (2013) 10854-10858.

[172] J.F. Shi, X.W. Du, D. Yuan, R. Haburcak, D.D. Wu, N. Zhou, B. Xu, Enzyme transformation to modulate the ligand-receptor interactions between small molecules, Chem. Commun. 51(23) (2015) 4899-4901.

[173] J. Shi, X.W. Du, Yuan, R. Haburcak, N. Zhou, B. Xu, Supramolecular Detoxification of Neurotoxic Nanofibrils of Small Molecules via Morphological Switch, Bioconjugate Chem. 26(9) (2015) 1879-1883.

[174] R. Vegners, I. Shestakova, I. Kalvinsh, R.M. Ezzell, P.A. Janmey, Use of a gel-forming dipeptide derivative as a carrier for antigen presentation, J. Pept. Sci. 1(6) (1995) 371-8.

[175] Y. Zhang, H. Gu, Z. Yang, B. Xu, Supramolecular Hydrogels Respond to Ligand-Receptor Interaction, J. Am. Chem. Soc. 125(45) (2003) 13680-13681.

[176] A. Smith, R. Williams, C. Tang, P. Coppo, R. Collins, M. Turner, A. Saiani, R. Ulijn, FmocDiphenylalanine self assembles to a hydrogel via a novel architecture based on pi-pi interlocked betasheets, Adv. Mater. 20(1) (2008) 37-41.

[177] W. Helen, P. de Leonardis, R.V. Ulijn, J. Gough, N. Tirelli, Mechanosensitive peptide gelation: mode of agitation controls mechanical properties and nano-scale morphology, Soft Matter 7(5) (2011) 17321740.

[178] W. Truong, Y. Su, D. Gloria, F. Braet, P. Thordarson, Dissolution and degradation of Fmocdiphenylalanine self-assembled gels results in necrosis at high concentrations in vitro, Biomater. Sci. 3 (2015) 298-307.

[179] Y. Zhang, Y. Kuang, Y. Gao, B. Xu, Versatile Small-Molecule Motifs for Self-Assembly in Water and the Formation of Biofunctional Supramolecular Hydrogels, Langmuir 27(2) (2011) 529-537.

[180] J. Mei, X. Zhang, M. Zhu, J. Wang, L. Wang, L. Wang, Barium-triggered beta-sheet formation and hydrogelation of a short peptide derivative, RSC Adv. 4(3) (2014) 1193-1196.

[181] J. Zhang, C. Ou, Y. Shi, L. Wang, M. Chen, Z. Yang, Visualized detection of melamine in milk by supramolecular hydrogelations, Chem. Commun. 50(85) (2014) 12873-12876.

[182] Y. Kuang, Y. Gao, B. Xu, Supramolecular hydrogelators of N-terminated dipeptides selectively inhibit cancer cells, Chem. Commun. 47(47) (2011) 12625-12627.

[183] Y. Zhang, N. Zhou, N. Li, M.G. Sun, D. Kim, S. Fraden, I.R. Epstein, B. Xu, Giant Volume Change of Active Gels under Continuous Flow, J. Am. Chem. Soc. 136(20) (2014) 7341-7347.

[184] Y. Zhang, N. Zhou, J.F. Shi, S.S. Pochapsky, T.C. Pochapsky, B. Zhang, X.X. Zhang, B. Xu, Unfolding a molecular trefoil derived from a zwitterionic metallopeptide to form self-assembled nanostructures, Nat. Commun. 6 (2015) 6165.

[185] Y. Zhang, R. Zhou, J.F. Shi, N. Zhou, I.R. Epstein, B. Xu, Post-Self-Assembly Cross-Linking to Integrate Molecular Nanofibers with Copolymers in Oscillatory Hydrogels, J. Phys. Chem. B 117(21) (2013) 6566-6573.

[186] G. Roviello, S. Di Gaetano, D. Capasso, A. Cesarani, E. Bucci, C. Pedone, Synthesis, spectroscopic studies and biological activity of a novel nucleopeptide with Moloney murine leukemia virus reverse transcriptase inhibitory activity, Amino Acids 38(5) (2010) 1489-1496.

[187] G.N. Roviello, D. Musumeci, E.M. Bucci, C. Pedone, Evidences for supramolecular organization of nucleopeptides: synthesis, spectroscopic and biological studies of a novel dithymine L-serine tetrapeptide, Mol. Biosyst. 7(4) (2011) 1073-1080.

[188] G.N. Roviello, A. Ricci, E.M. Bucci, C. Pedone, Synthesis, biological evaluation and supramolecular assembly of novel analogues of peptidyl nucleosides, Mol. Biosyst. 7(5) (2011) 1773-1778. 
[189] O. Wong, P. Pradeepkumar, S. Silverman, DNA-Catalyzed Covalent Modification of Amino Acid Side Chains in Tethered and Free Peptide Substrates, Biochemistry 50(21) (2011) 4741-4749.

[190] K. Araki, I. Yoshikawa, Nucleobase-containing gelators, in: F. Fages (Ed.), Low Molecular Mass Gelators: Design, Self-Assembly, Function2005, pp. 133-165.

[191] D.D. Wu, X.W. Du, J.F. Shi, J. Zhou, N. Zhou, B. Xu, The first CD73-instructed supramolecular hydrogel, J. Colloid Interface Sci. 447 (2015) 269-272.

[192] X. Li, Y. Kuang, H. Lin, Y. Gao, J. Shi, B. Xu, Supramolecular Nanofibers and Hydrogels of Nucleopeptides, Angew. Chem. Int. Ed. 50(40) (2011) 9365-9369.

[193] D. Yuan, X. Du, J. Shi, N. Zhou, A. Baoum, B. Xu, Synthesis of novel conjugates of a saccharide, amino acids, nucleobase and the evaluation of their cell compatibility, Beilstein J. Org. Chem. 10 (2014) 2406-2413.

[194] X.W. Du, J.F. Li, Y. Gao, Y. Kuang, B. Xu, Catalytic dephosphorylation of adenosine monophosphate (AMP) to form supramolecular nanofibers/hydrogels, Chem. Commun. 48(15) (2012) 2098-2100.

[195] X.M. Li, X.W. Du, J.Y. Li, Y. Gao, Y. Pan, J.F. Shi, N. Zhou, B. Xu, Introducing D-Amino Acid or Simple Glycoside into Small Peptides to Enable Supramolecular Hydrogelators to Resist Proteolysis, Langmuir 28(37) (2012) 13512-13517.

[196] D. Yuan, R. Zhou, J.F. Shi, X.W. Du, X.M. Li, B. Xu, Enzyme-instructed self-assembly of hydrogelators consisting of nucleobases, amino acids, and saccharide, RSC Adv. 4(50) (2014) 26487-26490.

[197] F. Zhao, C.S. Weitzel, Y. Gao, H.M. Browdy, J.F. Shi, H.C. Lin, S.T. Lovett, B. Xu, beta-Galactosidaseinstructed formation of molecular nanofibers and a hydrogel, Nanoscale 3(7) (2011) 2859-2861.

[198] Y. Gao, M.J.C. Long, J. Shi, L. Hedstrom, B. Xu, Using supramolecular hydrogels to discover the interactions between proteins and molecular nanofibers of small molecules, Chem. Commun. 48(67) (2012) 8404-8406.

[199] Y. Kuang, D. Yuan, Y. Zhang, A. Kao, X. Du, B. Xu, Interactions between cellular proteins and morphologically different nanoscale aggregates of small molecules, RSC Adv. 3(21) (2013) 7704-7707.

[200] D. Yuan, J.F. Shi, X.W. Du, N. Zhou, B. Xu, Supramolecular Glycosylation Accelerates Proteolytic Degradation of Peptide Nanofibrils, J. Am. Chem. Soc. 137(32) (2015) 10092-10095.

[201] B. Xing, P.L. Ho, C.-W. Yu, K.-H. Chow, H. Gu, B. Xu, Self-assembled multivalent vancomycin on cell surfaces against vancomycin-resistant enterococci (VRE), Chem. Commun. (17) (2003) 2224-2225.

[202] F. Zhao, B.A. Heesters, I. Chiu, Y. Gao, J. Shi, N. Zhou, M.C. Carroll, B. Xu, L-Rhamnose-containing supramolecular nanofibrils as potential immunosuppressive materials, Org. Biomol. Chem. 12(35) (2014) 6816-6819.

[203] D. Yuan, X. Du, J. Shi, N. Zhou, A. Baoum, K. Al Footy, K. Badahdah, B. Xu, Synthesis and evaluation of the biostability and cell compatibility of novel conjugates of nucleobase, peptidic epitope, and saccharide, Beilstein J. Org. Chem. 11 (2015) 1352-1359.

[204] D.D. Wu, J. Zhou, J.F. Shi, X.W. Du, B. Xu, A naphthalene-containing amino acid enables hydrogelation of a conjugate of nucleobase-saccharide-amino acids, Chem. Commun. 50(16) (2014) 1992-1994.

[205] D.D. Wu, X.W. Du, J.F. Shi, J. Zhou, B. Xu, Supramolecular Nanofibers/Hydrogels of the Conjugates of Nucleobase, Saccharide, and Amino Acids, Chin. J. Chem. 32(4) (2014) 313-318.

[206] Y. Dong, Z. Yang, D. Liu, DNA Nanotechnology Based on i-Motif Structures, Acc. Chem. Res. 47(6) (2014) 1853-1860.

[207] N. Sreenivasachary, J.M. Lehn, Gelation-driven component selection in the generation of constitutional dynamic hydrogels based on guanine-quartet formation, Proc. Natl. Acad. Sci. U. S. A. 102(17) (2005) 5938-5943.

[208] S.M. Park, B.H. Kim, Ultrasound-triggered water gelation with a modified nucleoside, Soft Matter $4(10)(2008)$ 1995-1997. 
[209] G. Godeau, P. Barthelemy, Glycosyl-Nucleoside Lipids as Low-Molecular-Weight Gelators, Langmuir 25(15) (2009) 8447-8450.

[210] M.A. Ramin, J. Baillet, S. Benizri, L. Latxague, P. Barthelemy, Uracile based glycosyl-nucleosidelipids as low molecular weight organogelators, New J. Chem. 40(12) (2016) 9903-9906.

[211] J. Arigon, C.A.H. Prata, M.W. Grinstaff, P. Barthelemy, Nucleic acid complexing glycosyl nucleosidebased amphiphile, Bioconjugate Chem. 16(4) (2005) 864-872.

[212] G. Godeau, J. Bernard, C. Staedel, P. Barthelemy, Glycosyl-nucleoside-lipid based supramolecular assembly as a nanostructured material with nucleic acid delivery capabilities, Chem. Commun. (34) (2009) 5127-5129.

[213] S. Ziane, S. Schlaubitz, S. Miraux, A. Patwa, C. Lalande, I. Bilem, S. Lepreux, B. Rousseau, J.-F. Le Meins, L. Latxague, P. Barthelemy, O. Chassande, A thermosensitive low molecular weight hydrogel as scaffold for tissue engineering, Eur. Cells Mater. 23 (2012) 147-160.

[214] C. Dolain, A. Patwa, G. Godeau, P. Barthelemy, Nucleic Acid Based Fluorinated Derivatives: New Tools for Biomedical Applications, Applied Sci. Basel 2(2) (2012) 245-259.

[215] A. Patwa, A. Gissot, I. Bestel, P. Barthelemy, Hybrid lipid oligonucleotide conjugates: synthesis, self-assemblies and biomedical applications, Chem. Soc. Rev. 40(12) (2011) 5844-5854.

[216] A. Gissot, M. Camplo, M.W. Grinstaff, P. Barthelemy, Nucleoside, nucleotide and oligonucleotide based amphiphiles: a successful marriage of nucleic acids with lipids, Org. Biomol. Chem. 6(8) (2008) 1324-1333.

[217] K.Y. Lee, D.J. Mooney, Alginate: Properties and biomedical applications, Prog. Polym. Sci. 37(1) (2012) 106-126.

[218] G. Wang, S. Cheuk, K. Williams, V. Sharma, L. Dakessian, Z. Thorton, Synthesis and characterization of monosaccharide lipids as novel hydrogelators, Carbohydr. Res. 341(6) (2006) 705-716.

[219] N. Goyal, S. Cheuk, G. Wang, Synthesis and characterization of D-glucosamine-derived low molecular weight gelators, Tetrahedron 66(32) (2010) 5962-5971.

[220] M. Ikeda, R. Ochi, A. Wada, I. Hamachi, Supramolecular hydrogel capsule showing prostate specific antigen-responsive function for sensing and targeting prostate cancer cells, Chem. Sci. 1(4) (2010) 491498.

[221] Q. Chen, Y. Lv, D. Zhang, G. Zhang, C. Liu, D. Zhu, Cysteine and pH-Responsive Hydrogel Based on a Saccharide Derivative with an Aldehyde Group, Langmuir 26(5) (2010) 3165-3168.

[222] W. Wang, H. Wang, C. Ren, J. Wang, M. Tan, J. Shen, Z. Yang, P.G. Wang, L. Wang, A saccharidebased supramolecular hydrogel for cell culture, Carbohydr. Res. 346(8) (2011) 1013-1017.

[223] G. Liu, W. Ji, W. Wang, C. Feng, Multiresponsive Hydrogel Coassembled from Phenylalanine and Azobenzene Derivatives as 3D Scaffolds for Photoguiding Cell Adhesion and Release, ACS Appl. Mater. Interfaces 7(1) (2015) 301-307.

[224] P. Li, Z. Yin, X. Dou, G. Zhou, C. Feng, Convenient Three-Dimensional Cell Culture in Supermolecular Hydrogels, ACS Appl. Mater. Interfaces 6(10) (2014) 7948-7952.

[225] J.H. Collier, Y.F. Tian, J.M. Devgun, Fibrillized peptide microgels for cell encapsulation and 3D cell culture, Soft Matter 7(13) (2011) 6005-6011.

[226] C. Huang, S. Ravindran, Z. Yin, A. George, 3-D self-assembling leucine zipper hydrogel with tunable properties for tissue engineering, Biomaterials 35(20) (2014) 5316-5326.

[227] W. Wang, G. Li, W. Zhang, J. Gao, J. Zhang, C. Li, D. Ding, D. Kong, Reduction-triggered formation of EFK8 molecular hydrogel for 3D cell culture, RSC Adv. 4(57) (2014) 30168-30171.

[228] C. Soler-Botija, J. Bago, A. Llucia-Valldeperas, A. Valles-Lluch, C. Castells-Sala, C. Martinez-Ramos, T. Fernandez-Muinos, J. Chachques, M. Monleon Pradas, C. Semino, A. Bayes-Genis, Engineered 3D bioimplants using elastomeric scaffold, self-assembling peptide hydrogel, and adipose tissue-derived progenitor cells for cardiac regeneration, Am. J. Transl. Res. 6(3) (2014) 291-301. 
[229] H. Komatsu, S. Tsukiji, M. Ikeda, I. Hamachi, Stiff, Multistimuli-Responsive Supramolecular Hydrogels as Unique Molds for 2D/3D Microarchitectures of Live Cells, Chem. - Asian J. 6(9) (2011) 23682375.

[230] L. Lv, H. Liu, X. Chen, Z. Yang, Glutathione-triggered formation of molecular hydrogels for 3D cell culture, Colloid Surface B 108 (2013) 352-357.

[231] G. Liu, D. Zhang, C. Feng, Control of Three - Dimensional Cell Adhesion by the Chirality of Nanofibers in Hydrogels, Angew. Chem. Int. Ed. 53(30) (2014) 7789-7793.

[232] X.Q. Dou, D. Zhang, C.L. Feng, Wettability of Supramolecular Nanofibers for Controlled Cell Adhesion and Proliferation, Langmuir 29(49) (2013) 15359-15366.

[233] Z. Luo, Y. Yue, Y. Zhang, X. Yuan, J. Gong, L. Wang, B. He, Z. Liu, Y. Sun, J. Liu, M. Hu, J. Zheng, Designer D-form self-assembling peptide nanofiber scaffolds for 3-dimensional cell cultures, Biomaterials 34(21) (2013) 4902-4913.

[234] N. Stephanopoulos, R. Freeman, H.A. North, S. Sur, S.J. Jeong, F. Tantakitti, J.A. Kessler, S.I. Stupp, Bioactive DNA-Peptide Nanotubes Enhance the Differentiation of Neural Stem Cells Into Neurons, Nano Lett. 15(1) (2015) 603-609.

[235] L. Chronopoulou, A.R. Togna, G. Guarguaglini, G. Masci, F. Giammaruco, G.I. Togna, C. Palocci, Selfassembling peptide hydrogels promote microglial cells proliferation and NGF production, Soft Matter 8(21) (2012) 5784-5790.

[236] W.-N. Yin, F.-Y. Cao, K. Han, X. Zeng, R.-X. Zhuo, X.-Z. Zhang, The synergistic effect of a BMP-7 derived peptide and cyclic RGD in regulating differentiation behaviours of mesenchymal stem cells, $J$. Mater. Chem. B 2(47) (2014) 8434-8440.

[237] J.E. Kim, S.M. Lee, S.H. Kim, P. Tatman, A.O. Gee, D.-H. Kim, K.E. Lee, Y. Jung, S.J. Kim, Effect of selfassembled peptide-mesenchymal stem cell complex on the progression of osteoarthritis in a rat model, Int J Nanomed 9 (2014) 141-57.

[238] T.D. Sargeant, C. Aparicio, J.E. Goldberger, H.G. Cui, S.I. Stupp, Mineralization of peptide amphiphile nanofibers and its effect on the differentiation of human mesenchymal stem cells, Acta Biomater. 8(7) (2012) 2456-2465.

[239] M. Bury, N. Fuller, J. Meisner, M. Hofer, M. Webber, L. Chow, S. Prasad, H. Thaker, X. Yue, V. Menon, E. Diaz, S. Stupp, E. Cheng, A. Sharma, The promotion of functional urinary bladder regeneration using anti-inflammatory nanofibers, Biomaterials 35(34) (2014) 9311-9321.

[240] M.J. Webber, J. Tongers, C.J. Newcomb, K.T. Marquardt, J. Bauersachs, D.W. Losordo, S.I. Stupp, Supramolecular nanostructures that mimic VEGF as a strategy for ischemic tissue repair, Proc. Natl. Acad. Sci. U. S. A. 108(33) (2011) 13438-13443.

[241] Y.Q. Wang, Z.L. Zhang, L. Xu, X.Y. Li, H. Chen, Hydrogels of halogenated Fmoc-short peptides for potential application in tissue engineering, Colloid Surface B 104 (2013) 163-168.

[242] A.L. Rodriguez, T.Y. Wang, K.F. Bruggeman, C.C. Horgan, R. Li, R.J. Williams, C.L. Parish, D.R. Nisbet, In vivo assessment of grafted cortical neural progenitor cells and host response to functionalized selfassembling peptide hydrogels and the implications for tissue repair, J. Mater. Chem. B 2(44) (2014) 7771-7778.

[243] M.N. Rahaman, D.E. Day, B.S. Bal, Q. Fu, S.B. Jung, L.F. Bonewald, A.P. Tomsia, Bioactive glass in tissue engineering, Acta Biomater. 7(6) (2011) 2355-2373.

[244] F. Gelain, D. Silva, A. Caprini, F. Taraballi, A. Natalello, O. Villa, K.T. Nam, R.N. Zuckermann, S.M. Doglia, A. Vescovi, BMHP1-Derived Self-Assembling Peptides: Hierarchically Assembled Structures with Self-Healing Propensity and Potential for Tissue Engineering Applications, ACS Nano 5(3) (2011) 18451859.

[245] F. Gelain, D. Cigognini, A. Caprini, D. Silva, B. Colleoni, M. Donega, S. Antonini, B.E. Cohen, A. Vescovi, New bioactive motifs and their use in functionalized self-assembling peptides for NSC differentiation and neural tissue engineering, Nanoscale 4(9) (2012) 2946-2957. 
[246] A. Caprini, D. Silva, I. Zanoni, C. Cunha, C. Volonte, A. Vescovi, F. Gelain, A novel bioactive peptide: assessing its activity over murine neural stem cells and its potential for neural tissue engineering, New Biotechnol. 30(5) (2013) 552-562.

[247] L.E. Buerkle, H.A. von Recum, S.J. Rowan, Toward potential supramolecular tissue engineering scaffolds based on guanosine derivatives, Chem. Sci. 3(2) (2012) 564-572.

[248] E. Arslan, C. Garip, G. Gulseren, A. Tekinay, M. Guler, Bioactive Supramolecular Peptide Nanofibers for Regenerative Medicine, Adv. Healthcare Mater. 3(9) (2014) 1357-1376.

[249] N. Akiyama, T. Yamamoto-Fukuda, H. Takahashi, T. Koji, In situ tissue engineering with synthetic self-assembling peptide nanofiber scaffolds, PuraMatrix, for mucosal regeneration in the rat middle-ear, Int J Nanomed 8 (2013) 2629-2640.

[250] D.M. Ryan, B.L. Nilsson, Self-assembled amino acids and dipeptides as noncovalent hydrogels for tissue engineering, Polym. Chem. 3(1) (2012) 18-33.

[251] N. Angeloni, C. Bond, Y. Tang, D. Harrington, S. Zhang, S. Stupp, K. McKenna, C. Podlasek, Regeneration of the cavernous nerve by Sonic hedgehog using aligned peptide amphiphile nanofibers, Biomaterials 32(4) (2011) 1091-1101.

[252] L. Chow, R. Bitton, M. Webber, D. Carvajal, K. Shull, A. Sharma, S. Stupp, A bioactive selfassembled membrane to promote angiogenesis, Biomaterials 32(6) (2011) 1574-1582.

[253] S. Lee, B. Huang, S. Kaltz, S. Sur, C. Newcomb, S. Stock, R. Shah, S. Stupp, Bone regeneration with low dose BMP-2 amplified by biomimetic supramolecular nanofibers within collagen scaffolds, Biomaterials 34(2) (2013) 452-459.

[254] A. Li, A. Hokugo, A. Yalom, E. Berns, N. Stephanopoulos, M. McClendon, L. Segovia, I. Spigelman, S. Stupp, R. Jarrahy, A bioengineered peripheral nerve construct using aligned peptide amphiphile nanofibers, Biomaterials 35(31) (2014) 8780-8790.

[255] S. Sur, E. Pashuck, M. Guler, M. Ito, S. Stupp, T. Launey, A hybrid nanofiber matrix to control the survival and maturation of brain neurons, Biomaterials 33(2) (2012) 545-555.

[256] J. Tongers, M.J. Webber, E.E. Vaughan, E. Sleep, M.A. Renault, J.G. Roncalli, E. Klyachko, T. Thorne, Y. Yu, K.T. Marquardt, C.E. Kamide, A. Ito, S. Misener, M. Millay, T. Liu, K. Jujo, G.J. Qin, D.W. Losordo, S.I. Stupp, R. Kishore, Enhanced potency of cell-based therapy for ischemic tissue repair using an injectable bioactive epitope presenting nanofiber support matrix, J. Mol. Cell. Cardiol. 74 (2014) 231-239.

[257] S. Sur, C. Newcomb, M. Webber, S. Stupp, Tuning supramolecular mechanics to guide neuron development, Biomaterials 34(20) (2013) 4749-4757.

[258] Z. Huang, C. Newcomb, Y. Zhou, Y. Lei, P. Bringas, S. Stupp, M. Snead, The role of bioactive nanofibers in enamel regeneration mediated through integrin signals acting upon C/EBP alpha and c-Jun, Biomaterials 34(13) (2013) 3303-3314.

[259] T. Cheng, M. Chen, W. Chang, M. Huang, T. Wang, Neural stem cells encapsulated in a functionalized self-assembling peptide hydrogel for brain tissue engineering, Biomaterials 34(8) (2013) 2005-2016.

[260] T.Y. Cheng, H.C. Wu, M.Y. Huang, W.H. Chang, C.H. Lee, T.W. Wang, Self-assembling functionalized nanopeptides for immediate hemostasis and accelerative liver tissue regeneration, Nanoscale 5(7) (2013) 2734-2744.

[261] K.M. Galler, J.D. Hartgerink, A.C. Cavender, G. Schmalz, R.N. D'Souza, A Customized SelfAssembling Peptide Hydrogel for Dental Pulp Tissue Engineering, Tissue Eng. Part A $\quad 18(1-2)$ (2012) 176-184.

[262] W. Wu, H. Chen, F. Shan, J. Zhou, X. Sun, L. Zhang, T. Gong, A Novel Doxorubicin-Loaded in Situ Forming Gel Based High Concentration of Phospholipid for Intratumoral Drug Delivery, Mol. Pharmaceutics 11(10) (2014) 3378-3385. 
[263] R. Wieduwild, W. Lin, A. Boden, K. Kretschmer, Y. Zhang, A Repertoire of Peptide Tags for Controlled Drug Release from Injectable Noncovalent Hydrogel, Biomacromolecules 15(6) (2014) 20582066.

[264] Y. Tian, H. Wang, Y. Liu, L. Mao, W. Chen, Z. Zhu, W. Liu, W. Zheng, Y. Zhao, D. Kong, A peptidebased nanofibrous hydrogel as a promising DNA nanovector for optimizing the efficacy of HIV vaccine, Nano Lett. 14(3) (2014) 1439-1445.

[265] N. Ashwanikumar, N.A. Kumar, S.A. Nair, G.S.V. Kumar, Phenylalanine-containing self-assembling peptide nanofibrous hydrogel for the controlled release of 5-fluorouracil and leucovorin, RSC Adv. 4(55) (2014) 29157-29164.

[266] X.J. Zhao, M. Wu, Z.Y. Ye, Y.F. Liu, B. Liu, Release of hydrophobic anticancer drug from a newly designed self-assembling peptide, Mol. Biosyst. 7(6) (2011) 2040-2047.

[267] Y. Chen, C. Tang, J. Zhang, M. Gong, B. Su, F. Qiu, Self-assembling surfactant-like peptide A(6)K as potential delivery system for hydrophobic drugs, Int J Nanomed 10 (2015) 847-858.

[268] A. Nishimura, T. Hayakawa, Y. Yamamoto, M. Hamori, K. Tabata, K. Seto, N. Shibata, Controlled release of insulin from self-assembling nanofiber hydrogel, PuraMatrix (TM): Application for the subcutaneous injection in rats, Eur. J. Pharm. Sci. 45(1-2) (2012) 1-7.

[269] J. Nanda, A. Banerjee, beta-Amino acid containing proteolitically stable dipeptide based hydrogels: encapsulation and sustained release of some important biomolecules at physiological $\mathrm{pH}$ and temperature, Soft Matter 8(12) (2012) 3380-3386.

[270] F. Rodriguez-Llansola, J.F. Miravet, B. Escuder, Aldehyde responsive supramolecular hydrogels: towards biomarker-specific delivery systems, Chem. Commun. 47(16) (2011) 4706-4708.

[271] D. Roberts, C. Rochas, A. Saiani, A.F. Miller, Effect of Peptide and Guest Charge on the Structural, Mechanical and Release Properties of beta-Sheet Forming Peptides, Langmuir 28(46) (2012) 1619616206.

[272] P. Frederix, R. Kania, J.A. Wright, D.A. Lamprou, R.V. Ulijn, C.J. Pickett, N.T. Hunt, Encapsulating FeFe -hydrogenase model compounds in peptide hydrogels dramatically modifies stability and photochemistry, Dalton Trans. 41(42) (2012) 13112-13119.

[273] E. Moysan, Y. Gonzalez-Fernandez, N. Lautram, J. Bejaud, G. Bastiat, J.-P. Benoit, An innovative hydrogel of gemcitabine-loaded lipid nanocapsules: when the drug is a key player of the nanomedicine structure, Soft Matter 10(11) (2014) 1767-1777.

[274] S. Zarzhitsky, H. Rapaport, The interactions between doxorubicin and amphiphilic and acidic betasheet peptides towards drug delivery hydrogels, J. Colloid Interface Sci. 360(2) (2011) 525-531.

[275] D.G. Fatouros, D.A. Lamprou, A.J. Urquhart, S.N. Yannopoulos, I.S. Vizirianakis, S. Zhang, S. Koutsopoulos, Lipid-like Self-Assembling Peptide Nanovesicles for Drug Delivery, ACS Appl. Mater. Interfaces 6(11) (2014) 8184-8189.

[276] M. Casolaro, I. Casolaro, S. Bottari, B. Del Bello, E. Maellaro, K.D. Demadis, Long-term doxorubicin release from multiple stimuli-responsive hydrogels based on alpha-amino-acid residues, Eur. J. Pharm. Biopharm. 88(2) (2014) 424-433.

[277] J. Liu, J. Liu, L. Chu, Y. Zhang, H. Xu, D. Kong, Z. Yang, C. Yang, D. Ding, Self-Assembling Peptide of D-Amino Acids Boosts Selectivity and Antitumor Efficacy of 10-Hydroxycamptothecin, ACS Appl. Mater. Interfaces 6(8) (2014) 5558-5565.

[278] A.G. Cheetham, P. Zhang, Y.A. Lin, R. Lin, H. Cui, Synthesis and self-assembly of a mikto-arm star dual drug amphiphile containing both paclitaxel and camptothecin, J. Mater. Chem. B 2(42) (2014) 73167326.

[279] H. Wang, J. Wei, C. Yang, H. Zhao, D. Li, Z. Yin, Z. Yang, The inhibition of tumor growth and metastasis by self-assembled nanofibers of taxol, Biomaterials 33(24) (2012) 5848-5853.

[280] H.M. Wang, L.N. Lv, G.Y. Xu, C.B. Yang, J.T. Sun, Z.M. Yang, Molecular hydrogelators consist of Taxol and short peptides/amino acids, J Mater Chem 22(33) (2012) 16933-16938. 
[281] Z.M. Yang, H.M. Wang, C.H. Yang, L. Wang, D.L. Kong, Y.J. Zhang, Self-assembled nanospheres as a novel delivery system for taxol: a molecular hydrogel with nanosphere morphology, Chem. Commun. 47(15) (2011) 4439-4441.

[282] T. Su, Z. Tang, H. He, W. Li, X. Wang, C. Liao, Y. Sun, Q. Wang, Glucose oxidase triggers gelation of $\mathrm{N}$-hydroxyimide-heparin conjugates to form enzyme-responsive hydrogels for cell-specific drug delivery, Chem. Sci. 5(11) (2014) 4204-4209.

[283] G. Pu, C. Ren, D. Li, L. Wang, J. Sun, A supramolecular hydrogel for the delivery of bortezomib, RSC Adv. 4(91) (2014) 50145-50147.

[284] Y. Shi, Z. Wang, X. Zhang, T. Xu, S. Ji, D. Ding, Z. Yang, L. Wang, Multi-responsive supramolecular hydrogels for drug delivery, Chem. Commun. 51(83) (2015) 15265-15267.

[285] D. Kalafatovic, M. Nobis, N. Javid, P. Frederix, K. Anderson, B. Saunders, R. Ulijn, MMP-9 triggered micelle-to-fibre transitions for slow release of doxorubicin, Biomater. Sci. 3(2) (2015) 246-249.

[286] A. Altunbas, S. Lee, S. Rajasekaran, J. Schneider, D. Pochan, Encapsulation of curcumin in selfassembling peptide hydrogels as injectable drug delivery vehicles, Biomaterials 32(25) (2011) 5906-5914. [287] J. Li, R. Kooger, M. He, X. Xiao, L. Zheng, Y. Zhang, A supramolecular hydrogel as a carrier to deliver microRNA into the encapsulated cells, Chem. Commun. 50(28) (2014) 3722-3724.

[288] S.P. Patil, H.S. Jeong, B.H. Kim, A low-molecular-weight supramolecular hydrogel of riboflavin bolaamphiphile for VEGF-siRNA delivery, Chem. Commun. 48(71) (2012) 8901-8903.

[289] L. Qin, P.F. Duan, F. Xie, L. Zhang, M.H. Liu, A metal ion triggered shrinkable supramolecular hydrogel and controlled release by an amphiphilic peptide dendron, Chem. Commun. 49(92) (2013) 10823-10825.

[290] J. Li, Y. Kuang, J. Shi, Y. Gao, J. Zhou, B. Xu, The conjugation of nonsteroidal anti-inflammatory drugs (NSAID) to small peptides for generating multifunctional supramolecular nanofibers/hydrogels, Beilstein J. Org. Chem. 9 (2013) 908-917.

[291] J. Li, X. Li, Y. Kuang, Y. Gao, X. Du, J. Shi, B. Xu, Self-Delivery Multifunctional Anti-HIV Hydrogels for Sustained Release, Adv. Healthcare Mater. 2(12) (2013) 1586-1590.

[292] J. Gao, W. Zheng, J. Zhang, D. Guan, Z. Yang, D. Kong, Q. Zhao, Enzyme-controllable delivery of nitric oxide from a molecular hydrogel, Chem. Commun. 49(80) (2013) 9173-9175.

[293] X. Zhang, H. Zhou, Y. Xie, C. Ren, D. Ding, J. Long, Z. Yang, Rational Design of Multifunctional Hetero-Hexameric Proteins for Hydrogel Formation and Controlled Delivery of Bioactive Molecules, Adv. Healthcare Mater. 3(11) (2014) 1804-1811.

[294] L. Mao, H. Wang, M. Tan, L. Ou, D. Kong, Z. Yang, Conjugation of two complementary anti-cancer drugs confers molecular hydrogels as a co-delivery system, Chem. Commun. 48(3) (2012) 395-397.

[295] C. Shu, R. Li, Y. Yin, D. Yin, Y. Gu, L. Ding, W. Zhong, Synergistic dual-targeting hydrogel improves targeting and anticancer effect of Taxol in vitro and in vivo, Chem. Commun. 50(97) (2014) 15423-15426. [296] American Cancer Society. Cancer Facts \& Figures 2013, Atlanta: American Cancer Society, 2013.

[297] A. Huang, C. Ou, Y. Cai, Z. Wang, H. Li, Z. Yang, M. Chen, In situ enzymatic formation of supramolecular nanofibers for efficiently killing cancer cells, RSC Adv. 6(39) (2016) 32519-32522.

[298] D. Kalafatovic, M. Nobis, J. Son, K. Anderson, R. Ulijn, MMP-9 triggered self-assembly of doxorubicin nanofiber depots halts tumor growth, Biomaterials 98 (2016) 192-202.

[299] M.R. Reithofer, K.-H. Chan, A. Lakshmanan, D.H. Lam, A. Mishra, B. Gopalan, M. Joshi, S. Wang, C.A.E. Hauser, Ligation of anti-cancer drugs to self-assembling ultrashort peptides by click chemistry for localized therapy, Chem. Sci. 5(2) (2014) 625-630.

[300] S. Soukasene, D.J. Toft, T.J. Moyer, H.M. Lu, H.K. Lee, S.M. Standley, V.L. Cryns, S.I. Stupp, Antitumor Activity of Peptide Amphiphile Nanofiber-Encapsulated Camptothecin, ACS Nano 5(11) (2011) 9113-9121.

[301] Z. Yang, K. Xu, Z. Guo, Z. Guo, B. Xu, Intracellular enzymatic formation of nanofibers results in hydrogelation and regulated cell death, Adv. Mater. 19(20) (2007) 3152-3156. 
[302] J. Li, J. Shi, J.E. Medina, J. Zhou, X. Du, H. Wang, C. Yang, J. Liu, Z. Yang, D.M. Dinulescu, B. Xu, Selectively Inducing Cancer Cell Death by Intracellular Enzyme-Instructed Self-Assembly (EISA) of Dipeptide Derivatives, Adv. Healthcare Mater. (2017) Ahead of Print.

[303] D.J. Toft, T.J. Moyer, S.M. Standley, Y. Ruff, A. Ugolkov, S.I. Stupp, V.L. Cryns, Coassembled Cytotoxic and Pegylated Peptide Amphiphiles Form Filamentous Nanostructures with Potent Antitumor Activity in Models of Breast Cancer, ACS Nano 6(9) (2012) 7956-7965.

[304] A. Tanaka, Y. Fukuoka, Y. Morimoto, T. Honjo, D. Koda, M. Goto, T. Maruyama, Cancer Cell Death Induced by the Intracellular Self-Assembly of an Enzyme-Responsive Supramolecular Gelator, J. Am. Chem. Soc. 137(2) (2015) 770-775.

[305] Y. Gao, C. Berciu, Y. Kuang, J. Shi, D. Nicastro, B. Xu, Probing Nanoscale Self-Assembly of Nonfluorescent Small Molecules inside Live Mammalian Cells, ACS Nano 7(10) (2013) 9055-9063.

[306] Y. Gao, Y. Kuang, X.W. Du, J. Zhou, P. Chandran, F. Horkay, B. Xu, Imaging Self-Assembly Dependent Spatial Distribution of Small Molecules in a Cellular Environment, Langmuir 29(49) (2013) 15191-15200.

[307] P. Huang, Y. Gao, J. Lin, H. Hu, H. Liao, X. Yan, Y. Tang, A. Jin, J. Song, G. Niu, G. Zhang, F. Horkay, X. Chen, Tumor-Specific Formation of Enzyme-Instructed Supramolecular Self-Assemblies as Cancer Theranostics, ACS Nano 9(10) (2015) 9517-9527.

[308] Z.Q.Q. Feng, H.M. Wang, X.W. Du, J.F. Shi, J. Li, B. Xu, Minimal C-terminal modification boosts peptide self-assembling ability for necroptosis of cancer cells, Chem. Commun. 52(37) (2016) 6332-6335. [309] R.A. Pires, Y.M. Abul-Haija, D.S. Costa, R. Novoa-Carballal, R.L. Reis, R.V. Ulijn, I. Pashkuleva, Controlling Cancer Cell Fate Using Localized Biocatalytic Self-Assembly of an Aromatic Carbohydrate Amphiphile, J. Am. Chem. Soc. 137(2) (2015) 576-579.

[310] J. Shi, X. Du, Y. Huang, J. Zhou, D. Yuan, D. Wu, Y. Zhang, R. Haburcak, I.R. Epstein, B. Xu, LigandReceptor Interaction Catalyzes the Aggregation of Small Molecules To Induce Cell Necroptosis, J. Am. Chem. Soc. 137(1) (2015) 26-29.

[311] X. Du, J. Zhou, H. Wang, J. Shi, Y. Kuang, B. Xu, W. Zeng, Z. Yang, In situ generated D-peptidic nanofibrils as multifaceted apoptotic inducers to target cancer cells, Cell Death Differ. 8(2) (2017) e2614. [312] H. Wang, Z. Feng, D. Wu, K.J. Fritzsching, M. Rigney, J. Zhou, Y. Jiang, K. Schmidt-Rohr, B. Xu, Enzyme-Regulated Supramolecular Assemblies of Cholesterol Conjugates against Drug-Resistant Ovarian Cancer Cells, J. Am. Chem. Soc. 138(34) (2016) 10758-10761.

[313] X. Du, J. Zhou, L. Wu, S. Sun, B. Xu, Enzymatic Transformation of Phosphate Decorated Magnetic Nanoparticles for Selectively Sorting and Inhibiting Cancer Cells, Bioconjugate Chem. 25(12) (2014) 2129-2133.

[314] X.W. Du, J. Zhou, B. Xu, Ectoenzyme switches the surface of magnetic nanoparticles for selective binding of cancer cells, J. Colloid Interface Sci. 447 (2015) 273-277.

[315] X. Du, J. Zhou, J. Wang, R. Zhou, B. Xu, Chirality Controls Reaction-Diffusion of Nanoparticles for Inhibiting Cancer Cells, ChemNanoMat (2016) n/a-n/a.

[316] P. Vandenabeele, L. Galluzzi, T. Vanden Berghe, G. Kroemer, Molecular mechanisms of necroptosis: an ordered cellular explosion, Nat. Rev. Mol. Cell Biol. 11(10) (2010) 700-714.

[317] G. Kroemer, L. Galluzzi, P. Vandenabeele, J. Abrams, E. Alnemri, E. Baehrecke, M. Blagosklonny, W. El-Deiry, P. Golstein, D. Green, M. Hengartner, R. Knight, S. Kumar, S. Lipton, W. Malorni, G. Nunez, M. Peter, J. Tschopp, J. Yuan, M. Piacentini, B. Zhivotovsky, G. Melino, Classification of cell death: recommendations of the Nomenclature Committee on Cell Death 2009, Cell Death Differ. 16(1) (2009) 311.

[318] L. Galluzzi, I. Vitale, J. Abrams, E. Alnemri, E. Baehrecke, M. Blagosklonny, T. Dawson, V. Dawson, W. El-Deiry, S. Fulda, E. Gottlieb, D. Green, M. Hengartner, O. Kepp, R. Knight, S. Kumar, S. Lipton, X. Lu, F. Madeo, W. Malorni, P. Mehlen, G. Nunez, M. Peter, M. Piacentini, D. Rubinsztein, Y. Shi, H. Simon, P. Vandenabeele, E. White, J. Yuan, B. Zhivotovsky, G. Melino, G. Kroemer, Molecular definitions of cell 
death subroutines: recommendations of the Nomenclature Committee on Cell Death, Cell Death Differ. 19(1) (2012) 107-120.

[319] J. Zhou, X. Du, C. Berciu, H. He, J. Shi, D. Nicastro, B. Xu, Enzyme-Instructed Self-Assembly for Spatiotemporal Profiling of the Activities of Alkaline Phosphatases on Live Cells, Chem 1(2) (2016) 246263.

[320] C. Ren, H. Wang, D. Mao, X. Zhang, Q. Fengzhao, Y. Shi, D. Ding, D. Kong, L. Wang, Z. Yang, When Molecular Probes Meet Self-Assembly: An Enhanced Quenching Effect, Angew. Chem. Int. Ed. 54(16) (2015) 4823-4827.

[321] B.G. Xing, T.T. Jiang, W.G. Bi, Y.M. Yang, L.H. Li, M.L. Ma, C.K. Chang, B. Xu, E.K.L. Yeow, Multifunctional divalent vancomycin: the fluorescent imaging and photodynamic antimicrobial properties for drug resistant bacteria, Chem. Commun. 47(5) (2011) 1601-1603.

[322] Y. Cai, Y. Shi, H. Wang, J. Wang, D. Ding, L. Wang, Z. Yang, Environment-Sensitive Fluorescent Supramolecular Nanofibers for Imaging Applications, Anal. Chem. 86(4) (2014) 2193-2199.

[323] A. Han, H. Wang, R. Kwok, S. Ji, J. Li, D. Kong, B. Tang, B. Liu, Z. Yang, D. Ding, Peptide-Induced AlEgen Self-Assembly: A New Strategy to Realize Highly Sensitive Fluorescent Light-Up Probes, Anal. Chem. 88(7) (2016) 3872-3878.

[324] H. Wang, J. Liu, A. Han, N. Xiao, Z. Xue, G. Wang, J. Long, D. Kong, B. Liu, Z. Yang, D. Ding, SelfAssembly-Induced Far-Red/Near-Infrared Fluorescence Light-Up for Detecting and Visualizing Specific Protein-Peptide Interactions, ACS Nano 8(2) (2014) 1475-1484.

[325] J.F. Lovell, T.W.B. Liu, J. Chen, G. Zheng, Activatable Photosensitizers for Imaging and Therapy, Chem. Rev. 110(5) (2010) 2839-2857.

[326] L.L. Lock, A.G. Cheetham, P. Zhang, H. Cui, Design and Construction of Supramolecular Nanobeacons for Enzyme Detection, ACS Nano 7(6) (2013) 4924-4932.

[327] L.L. Lock, C.D. Reyes, P. Zhang, H. Cui, Tuning Cellular Uptake of Molecular Probes by Rational Design of Their Assembly into Supramolecular Nanoprobes, J. Am. Chem. Soc. 138(10) (2016) 3533-3540. [328] A. Ghosh, M. Haverick, K. Stump, X. Yang, M.F. Tweedle, J.E. Goldberger, Fine-tuning the pH trigger of self-assembly, J. Am. Chem. Soc. 134(8) (2012) 3647-50.

[329] A.T. Preslar, G. Parigi, M.T. McClendon, S.S. Sefick, T.J. Moyer, C.R. Haney, E.A. Waters, K.W. MacRenaris, C. Luchinat, S.I. Stupp, T.J. Meade, Gd(III)-Labeled Peptide Nanofibers for Reporting on Biomaterial Localization in Vivo, ACS Nano 8(7) (2014) 7325-7332.

[330] L.L. Lock, Y. Li, X. Mao, H. Chen, V. Staedtke, R. Bai, W. Ma, R. Lin, Y. Li, G. Liu, H. Cui, OneComponent Supramolecular Filament Hydrogels as Theranostic Label-Free Magnetic Resonance Imaging Agents, ACS Nano 11(1) (2017) 797-805.

[331] C.B. Chesson, E.J. Huelsmann, A.T. Lacek, F.J. Kohlhapp, M.F. Webb, A. Nabatiyan, A. Zloza, J.S. Rudra, Antigenic peptide nanofibers elicit adjuvant-free CD8+ T cell responses, Vaccine 32(10) (2014) 1174-1180.

[332] J. Chen, R. Pompano, F. Santiago, L. Maillat, R. Sciammas, T. Sun, H. Han, D. Topham, A. Chong, J. Collier, The use of self-adjuvanting nanofiber vaccines to elicit high-affinity $B$ cell responses to peptide antigens without inflammation, Biomaterials 34(34) (2013) 8776-8785.

[333] J.S. Rudra, Y.F. Tian, J.P. Jung, J.H. Collier, A self-assembling peptide acting as an immune adjuvant, Proc. Natl. Acad. Sci. U. S. A. 107(2) (2010) 622-627.

[334] J.S. Rudra, T. Sun, K.C. Bird, M.D. Daniels, J.Z. Gasiorowski, A.S. Chong, J.H. Collier, Modulating Adaptive Immune Responses to Peptide Self-Assemblies, ACS Nano 6(2) (2012) 1557-1564.

[335] J. Rudra, S. Mishra, A. Chong, R. Mitchell, E. Nardin, V. Nussenzweig, J. Collier, Self-assembled peptide nanofibers raising durable antibody responses against a malaria epitope, Biomaterials $33(27)$ (2012) 6476-6484. 
[336] G. Hudalla, J. Modica, Y. Tian, J. Rudra, A. Chong, T. Sun, M. Mrksich, J. Collier, A Self-Adjuvanting Supramolecular Vaccine Carrying a Folded Protein Antigen, Adv. Healthcare Mater. 2(8) (2013) 11141119.

[337] H. Huang, J. Shi, J. Laskin, Z. Liu, D.S. McVey, X.S. Sun, Design of a shear-thinning recoverable peptide hydrogel from native sequences and application for influenza H1N1 vaccine adjuvant, Soft Matter 7(19) (2011) 8905-8912.

[338] X.D. Li, A. Galliher-Beckley, H.Z. Huang, X.Z. Sun, J.S. Shi, Peptide nanofiber hydrogel adjuvanted live virus vaccine enhances cross-protective immunity to porcine reproductive and respiratory syndrome virus, Vaccine 31(41) (2013) 4508-4515.

[339] Z.-H. Huang, L. Shi, J.-W. Ma, Z.-Y. Sun, H. Cai, Y.-X. Chen, Y.-F. Zhao, Y.-M. Li, a Totally Synthetic, Self-Assembling, Adjuvant-Free MUC1 Glycopeptide Vaccine for Cancer Therapy, J. Am. Chem. Soc. 134(21) (2012) 8730-8733.

[340] Y. Liu, H. Wang, D. Li, Y. Tian, W. Liu, L. Zhang, W. Zheng, Y. Hao, J. Liu, Z. Yang, Y. Shao, X. Jiang, In situ formation of peptidic nanofibers can fundamentally optimize the quality of immune responses against HIV vaccine, Nanoscale Horiz. 1(2) (2016) 135-143.

[341] Z. Luo, Q. Wu, C. Yang, H. Wang, T. He, Y. Wang, Z. Wang, H. Chen, X. Li, C. Gong, Z. Yang, A powerful CD8+ T-cell stimulating D-tetra-peptide hydrogel as a very promising vaccine adjuvant, Adv. Mater. 29(5) (2017) n/a.

[342] F. Zhao, J. Li, N. Zhou, J. Sakai, Y. Gao, J. Shi, B. Goldman, H. Browdy, H. Luo, B. Xu, De Novo Chemoattractants Form Supramolecular Hydrogels for Immunomodulating Neutrophils In Vivo, Bioconjugate Chem. 25(12) (2014) 2116-2122. 